\title{
AN URBAN PLANNING APPROACH TO DIGITAL INEQUALITY: PROPOSED METHODS AND LESSONS FROM A CASE STUDY OF TORONTO
}

\author{
by \\ Teresa J. Liu \\ B.Sc. (Hons.), Queen's University, 2015 \\ A Major Research Paper \\ presented to Ryerson University \\ in partial fulfillment of the requirements for the degree of \\ Master of Planning \\ in \\ Urban Development
}

Toronto, Ontario, Canada, 2017

(c) Teresa J. Liu, 2017 


\section{Author's Declaration for Electronic Submission of a MRP}

I hereby declare that I am the sole author of this MRP. This is a true copy of the MRP, including any required final revisions.

I authorize Ryerson University to lend this MRP to other institutions or individuals for the purpose of scholarly research.

I further authorize Ryerson University to reproduce this MRP by photocopying or by other means, in total or in part, at the request of other institutions or individuals for the purpose of scholarly research.

I understand that my MRP may be made electronically available to the public. 


\title{
An Urban Planning Approach to Digital Inequality: Proposed Methods and Lessons from a Case Study of Toronto
}

\author{
(c) Teresa J. Liu, 2017 \\ Master of Planning \\ in \\ Urban Development \\ Ryerson University
}

\begin{abstract}
Disparities in the access of digital resources and opportunities have been a concern since the early days of the internet, yet most jurisdictions do not currently have comprehensive and detailed datasets to support planning and policy. This study seeks to develop a practical approach for exploring intra-community digital inequalities from an urban planning perspective, in particular through the lenses of digital engagement and governance, and the redistribution of resources. Lessons from a scan of issues, existing frameworks, and examples in academic and grey literature show the importance of local context in understanding digital inequality, contribute to the development of a toolbox of possible practices, and reveal suggestions for data collection and sharing. These findings are applied to a case study of Toronto, which finds both concerns regarding digitally excluded groups as well as opportunities for more equitable engagement practices through digital platforms.
\end{abstract}

Key Words: internet, digital inequality, digital policy, public engagement, e-government 


\section{Acknowledgements}

First and foremost, I would like to thank my supervisor, Dr. Pamela Robinson. Your ideas and insights have been invaluable to this project. I appreciate your support in keeping me on track and inspired over the past few months.

Thank you, also, to Sameer Vasta for taking time out of your busy schedule to be my second reader.

Finally, I want to thank my family for supporting (and feeding) me as I chipped away at this

paper, as well as my friends both within and outside of the program for letting me complain and keeping me sane. 


\section{Table of Contents}

List of Figures vii

List of Tables $\quad$ ix

1.0 Introduction 1

2.0 Context 4

2.1 What is Digital Inequality?

2.2 Connectivity $\quad 5$

$\begin{array}{ll}\text { 2.2.1 Type of Connection } & 7\end{array}$

2.2.2 Locations of Use $\quad 8$

$\begin{array}{ll}2.2 .3 \text { Affordability } & 9\end{array}$

2.3 Usage Activities $\quad 9$

2.4 Digital Literacy 11

$\begin{array}{ll}2.5 \text { Attitudes } & 12\end{array}$

2.6 Outcomes of Digital Inclusion 13

$\begin{array}{ll}\text { 2.6.1 Digital Citizenship } & 13\end{array}$

2.6.2 Educational \& Economic Opportunity 14

$\begin{array}{ll}3.0 \text { Methods } & 16\end{array}$

3.1 Environmental Scan 16

3.2 Case Study of Toronto 16

4.0 Environmental Scan: Developing a Practical Approach for Planners 20

4.1 Aggregated Frameworks and Indices $\quad 20$

4.2 Municipal Approaches $\quad 24$

4.2.1 Intra-City Population Data 25

4.2.2 Program-Based Data 26

4.3 Digital Engagement and Governance $\quad 27$

5.0 Case Study: A Profile of Digital Inclusion in Toronto 29

$\begin{array}{ll}5.1 \text { Context } & 29\end{array}$

5.1.1 Background $\quad 29$

5.1.2 Digital Policy $\quad 31$

5.2 Connectivity 32

5.2.1 Quality of Access 35

5.2.2 Location of Access $\quad 41$

$\begin{array}{ll}\text { 5.2.3 Affordability } & 43\end{array}$ 
5.3 Usage Activities $\quad 48$

5.4 Attitudes $\quad 53$

5.5 Programs: Toronto Public Library 55

5.6 Limitations and Gaps $\quad 59$

6.0 Discussion and Conclusion $\quad 61$

6.1 An Urban Planning Approach to Digital Inequality 64

6.1.1 The Importance of Context 64

6.1.2 Data Collection Across the Dimensions of Digital Inequality 65

6.1.3 Data Access for Better Planning 66

6.2 Findings from Toronto $\quad 67$

6.2.1 Digital Tools for Greater Inclusivity $\quad 67$

6.2.2 Understanding Digitally Excluded Groups 67

$\begin{array}{ll}6.3 \text { Moving Forward } & 68\end{array}$

Appendices $\quad 69$

$\begin{array}{ll}7.1 \text { Summary of Jurisdictional Scan } & 70\end{array}$

7.2 2012 Canadian Internet Use Survey Household Component - Summary of Selected Questions in Toronto CMA $\quad 71$

7.3 2012 Canadian Internet Use Survey Individual Component - Summary of Selected Questions in Toronto CMA $\quad 72$

7.4 Toronto Public Library Branch, Workstation, and Workstation Users Summary 75

$\begin{array}{ll}\text { References } & 77\end{array}$

Glossary of Terms $\quad 84$ 


\section{List of Figures}

Figure 2.1- 1. The dimensions of digital inequality guiding the structure of the literature review.

Figure 2.2-1. Internet access rates in Canada across demographic groups (Haight et al., 2014).

Figure 3.2-1. The Toronto Census Metropolitan Area as defined by Statistics Canada (Statistics Canada, 2011).

Figure 4.1-2. Indicators, reference values and weights used in the calculation of the ICT Development Index (ITU, 2017).

Figure 4.1-3. A conceptual model of interrelationships between components of digital inequality (Barzilai-Nahon, 2006).

Figure 4.3-1. Use of the Digital Inclusion Scale in the development of targeted, accessible government online services for caregivers (United Kingdom, 2014).

Figure 5.1.1-1. Neighbourhood Improvement Areas (NIAs) in the City of Toronto.

Figure 5.1.1-2. Estimated median annual household income in 2016.

Figure 5.2-1. Number of Internet and Cell Phone Connections per 100,000 Population in the City of Toronto (WCCD, 2015).

Figure 5.2-2. Home internet access in Toronto CMA households in 2012 by demographic characteristics.

Figure 5.2-3. Personal use of the internet by individuals in Toronto CMA in 2012 by demographic characteristics.

Figure 5.2.1-1. Internet service coverage areas in Toronto.

Figure 5.2.1-2. Average monthly household spending on internet access services by dissemination area, 2016.

Figure 5.2.1-3. OpenSignal crowdsourced data for mobile network coverage in Toronto.

Figure 5.2.1-4. Average monthly household spending on cellphone services by dissemination area, 2016.

Figure 5.2.1-5. Devices used by Toronto households to access home internet in 2012.

Figure 5.2.2-1. Locations of internet access for internet users in Toronto CMA in 2012.

Figure 5.2.2-2. Internet access at public libraries across demographic groups in Toronto CMA, 2012.

Figure 5.2.3-1. Toronto's fixed broadband prices in comparison to Canadian and international cities in 2016. 
Figure 5.2.3-2. Toronto's mobile broadband prices in comparison to Canadian and international cities in 2016.

Figure 5.2.3-3. Average household spending on cellphone and internet access services over time in Toronto and Canada.

Figure 5.2.3-4. Spending on cellphone and internet services relative to income in Toronto, 2016.

Figure 5.3-1. Level of online activity by demographic groups in Toronto CMA, 2012.

Figure 5.3-2. Use of the internet to search for employment across demographic groups in Toronto CMA, 2012.

Figure 5.3-3. Use of government websites across demographic groups in Toronto CMA, 2012.

Figure 5.3-4. Use of social networking sites across demographic groups in Toronto CMA, 2012.

Figure 5.3-5. Use of the internet to research community events across demographic groups in Toronto CMA, 2012.

Figure 5.4-1. Reasons for not having home internet access in Toronto CMA, 2012.

Figure 5.4-2. Reasons for not accessing the internet for personal use in Toronto CMA, 2012.

Figure 5.5-1. Toronto Public Library branches by digital services available.

Figure 5.5-2. Wireless sessions and workstation users (by session) in Toronto Public Library branches over time.

Figure 5.5-3. Change in workstation users in Toronto Public Library by branch, 2010-2015. 57

Figure 5.5-4. Toronto Public Library branches by workstation users per workstation, 2015. 


\section{List of Tables}

Table 4.1-1. The composition of common indices to measure digital inequality.

Table 4.21-1. Definition of User Profiles in Barcelona's Digital Divide Report (Mobile World Capital, 2016).

Table 5.5-5. Toronto Public Library branches with five highest number of workstation users per workstation, 2015.

Table 6.0-1. Best practices of methodologies for collecting and analyzing digital inequality data. 


\subsection{Introduction}

The past few decades have seen feat after astounding feat in the Digital Revolution. The invention of the internet in the 1980s and its subsequent popularization have allowed people to gain unprecedented access to immense stores of information during their everyday lives. It has provided a platform for quick and immediate communication across the globe. The use of digital tools for record-keeping, research and content creation have created changes in many workplaces. Social networking websites have established new ways of connecting with other people, and applications like Google Maps have changed the way we see and navigate the world.

Policymakers and researchers have long noted, however, that these impacts have not taken form at a uniform rate for all citizens. In 1995, the United States National Telecommunications and Information Administration (NTIA) identified groups that were "falling through the net." As early as 1994, Canadian policymakers envisioned the creation of an affordable, connected network, recognizing the internet's potential in helping Canadians achieve economic, social, and cultural objectives (Industry Canada, 1994; 1996). Today, universal, affordable access continues to be a key component of Canada's telecommunications policy, with the Telecommunications Act (S.C. 1993, c. 38) mandating "services of high quality accessible to Canadians in both urban and rural areas in all regions of Canada".

Issues regarding this unequal access to digital opportunities have largely been absent in urban planning discourse, however, despite its many implications on the work of planners to advance the public interest. The redistributive function of planning aims to achieve equality in resources and opportunities (Davidoff, 1980). In the digital context, this translates into two broad categories of concerns: the interaction of social and digital inequalities to produce offline disparities, and implications for digital engagement and governance initiatives. For planners, recognizing the importance of digital technology in people's lives and the subsequent impacts of its exclusion leads to better understanding of the range of the services required by communities to be successful and equitable in the modern age. Appreciation of digital issues can also result in changes in the ways in which planners conduct their practice, particularly through the use of different platforms to reach various groups during public engagement. With growing interest from many governments to leverage these opportunities, the implications of digital inequality on participation in these processes become an issue of concern. 
Over the past few decades, governments in Canada have developed many initiatives to close digital inequalities and minimize their offline impacts. In particular, the federal government has made efforts to address inequality between communities, with programs to achieve connectivity in rural and remote communities including Indigenous communities. This began with the Community Access Program in 1996 and continues with the current Connecting Canadians program (Industry Canada, 1996; Innovation, Science and Economic Development Canada, 2016a). In December 2016, the Canadian Radio-television and Telecommunications Commission's (CRTC) review of telecommunication services reaffirmed this commitment with the establishment of additional CRTC funds for underinvested communities. In this decision, it declared high-speed fixed and mobile broadband access as a basic telecommunication service for Canadians, citing its growing importance in households and its role as a "catalyst for so much change" in government, business, and civic society (CRTC, 2016).

On the intra-community scale, collaboration between the federal, provincial and territorial governments as well as private and not-for-profit sector partners have provided digital access and skills development in schools and other community spaces, such as through the internationally-acclaimed SchoolNet program (Mappin, 1995). Significant investments have also been made related to content creation, in recognition of the role of culturally relevant content in inhibiting internet use. In particular, federal programs have sought to promote the production of Indigenous and Francophone content (Howard, Busch and Sheets, 2010).

Meanwhile, although government digitization initiatives have been a part of policy discourse since the early days of the internet, the past few years have seen heightened momentum. The greater accessibility of government services and opportunities to engage have been one of the driving forces of many digital strategies developed in Canada (City of Calgary, 2014; City of Vancouver, 2013; Ville de Montréal, 2014). In the example of Ontario, the Province has recently committed to becoming "Canada's most open, transparent and digitally connected government" with its first Minister Responsible for Digital Government and the hiring of a Chief Digital Officer (Government of Ontario, 2016). The aim is to digitize government as an organization to provide better services, and to advance digital inclusivity for citizens particularly through the development of digital skills (Government of Ontario, 2017a). Specifically, there are several proposed and ongoing projects across different ministries that could have implications on digital inequality in the province. These actions include exploring opportunities for online access of 
health information, creating a digital literacy strategy, and using digital tools for public engagement as part of open government initiatives (Government of Ontario, 2016).

In an urban planning context, the City of Toronto's TOCore study for its downtown draws extensively on digital forms of engagement. In its second phase, the City's online survey was a major part of its engagement strategy, soliciting over 1400 responses (City of Toronto, 2016). It also received numerous responses through Twitter, text messages and email in addition to more traditional forms of outreach like stakeholder workshops and public open houses.

While these advancements in digital engagement and service delivery may help to create a more effective or efficient process that bridges current gaps, they also create concerns that some populations may be left behind. Currently, however, most municipalities and provinces do not have comprehensive and detailed datasets of who these populations may be within their jurisdiction, in contrast to the data sources available regarding social and economic inequalities such as income, employment, and housing. Forty years ago, Davidoff (1980) called for greater understanding of the conditions faced by minority groups as a basis for reducing these disparities. Similarly, the role of planners in transforming digital inequality into digital inclusion begins with grasping the needs, challenges and opportunities of citizens in the Information Age. The core objective of this study is to develop a foundation for this kind of understanding by examining existing theories, frameworks and data. 


\subsection{Context}

\subsection{What is Digital Inequality?}

The issue of the "digital divide" has been in academic and policy discourse since the 1990s in Canada and the United States (Industry Canada, 1994; NTIA, 1995). As governmental and business functions began to migrate to the internet, concerns were raised as studies reported on disparities between different demographic groups (Katz and Aspden, 1997). These early discussions were mostly concerned with issues of technical access to the internet. By the early 2000s, researchers began to question the concept of the "digital divide" as a binary between "haves" and "have-nots" (DiMaggio and Hargittai, 2001; van Dijk, 2003). Since then, a number of more nuanced conceptualizations have been proposed from academic and policy sources.

DiMaggio and Hargittai (2001) argue that as penetration levels of the internet increase, attention should become focused on the quality of use. They identified five broad dimensions of inequality: technical means (hardware and connectivity), autonomy (including location of access and associated variables of flexibility, privacy and ease of access), skill, social support (technical assistance and emotional reinforcement), and purpose of use. For van Dijk (2006), digital access is represented by a cumulative model consisting of motivational, material, skills and usage access. Meanwhile, Mossberger, Tolbert, and Stansbury (2003) distinguish between four divides: an access divide, a skills divide, an economic opportunity divide, and a democratic divide.

Based on these various conceptualizations of digital inequality, broad dimensions of the issue have been identified for the purposes of this study. Figure 2.1-1 summarizes these dimensions and provides an outline for the organization of the remainder of Section 2, with acknowledgement that the dimensions are interconnected and discussions will sometimes overlap. The four broad categories of connectivity, usage, digital literacy and attitudes are examined through the lens of sociodemographic variables such as income, education, gender and ethnicity. The literature review ends with a discussion of the outcomes of these digital inequalities on civic participation and socioeconomic well-being. 


\section{Connectivity}

- Technology and equipment

- Type and quality of connection

- Location of access

- Affordability

Usage Activities

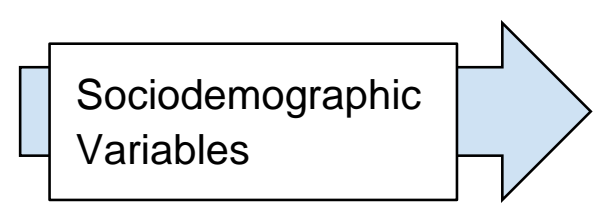

Civic Participation

Outcomes

Socioeconomic

Outcomes

Digital Literacy

Attitudes

Figure 2.1- 1. The dimensions of digital inequality guiding the structure of the literature review.

\subsection{Connectivity}

Digital connectivity has significantly increased since the early years of research, with an estimated 86.6\% of Canadian households having internet access in 2016 (ITU, 2016). Studies from across the Global North, however, still report differentials in physical access to personal computers and the internet based on a number of demographic and geographic factors, often corresponding to existing socioeconomic inequalities (Haight, Quan-Qaase, and Corbett, 2014; Hargittai, 2010).

Researchers have consistently found unequal internet access based on education, income, and age. Across Canada (Haight et al., 2014), the United States (Pew Research, 2015) and Europe (Eurostat, 2016), home internet access increases with greater education and income, and decreases with age. For example, this is shown through the results of Haight et al.'s analysis (2014) of the 2010 Canadian Internet Use Survey (CIUS) in Figure 2.2-1 below. 


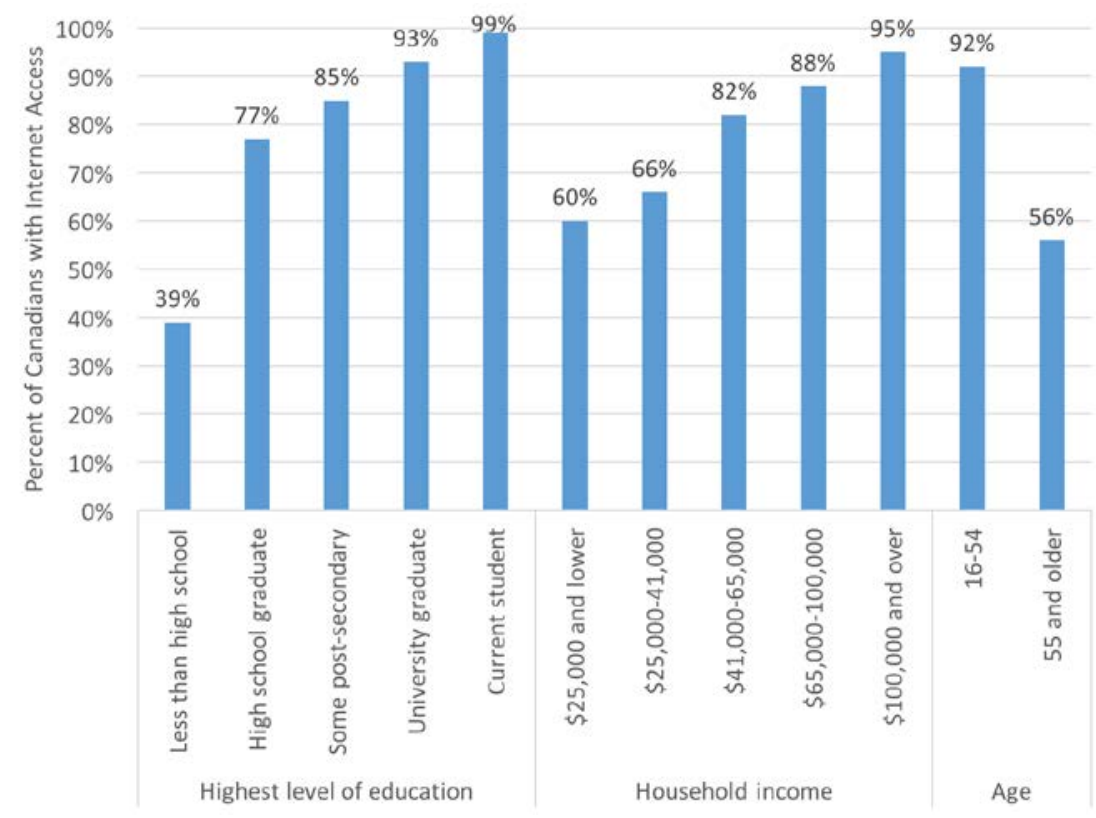

Figure 2.2-1. Internet access rates in Canada across demographic groups (Haight et al., 2014).

Researchers have found less consistent results with regards to gender. For example, Bimber (2000) found that a significant difference existed with $60 \%$ of men and $50 \%$ of women having access to the internet, but that these results were based on socioeconomic rather than genderspecific factors. Other studies have not found significant differences in access based on gender, including in Haight et al.'s (2014) analysis.

Studies of internet access of ethnic minorities have typically found lower levels of access compared to majority groups, often persisting after controlling for socioeconomic variables (Robinson et al., 2015; Mesch and Talmud, 2011; Campos-Castillo, 2015; Talukdar and Gauri, 2011; Kim, Jung, and Ball-Rokeach, 2007). In American contexts, these differences often have a geographical element with disparities in inner city neighbourhoods. For example, Mossberger et al. (2012) found that Latinos in Chicago living in enclaves face a "double burden" with even lower rates of access, possibly due to lack of knowledge about the technology from a limited social circle. Conversely, "geo-ethnic" characteristics may also contribute to internet access by offering unique services such as special telecommunications providers or internet cafes (Kim et al., 2007).

In Canada, Howard, Busch and Sheets (2010) find that there are generally less access disparities within urban contexts based on population-level research and the outcomes of policy 
initiatives. Geographic differences are primarily found along rural and urban lines, with urban Canadians being 51\% more likely to have internet access in 2010 (Haight et al., 2014). In terms of the access to physical infrastructure, CRTC (2016) finds that broadband services of speeds of at least $5 \mathrm{Mbps}$ is only available in $93 \%$ of rural households in comparison to $100 \%$ of urban households. Some researchers have also explored internet access Indigenous communities and the impacts of government programs to bring connectivity to these communities, particularly in remote and northern areas (Fiser, 2010; McMahon, 2014).

Immigration status also appears to have some effect on internet and computer access. Haight et al. (2014) finds that Canadian-born residents or earlier immigrants are $68 \%$ more likely to have internet access than recent immigrants. Explanations for this discrepancy may relate to the alignment of immigration and socioeconomic status, as well as English language ability and the lack of online services and relevant content in the native language (Ono and Zavodny, 2008).

Finally, while most digital divide literature addresses each of these variables separately, some researchers have argued the importance of investigating intersections between these characteristics (Campos-Castillo, 2015). This type of analysis may reveal trends that are masked in a more general analysis, and the effects of membership in multiple groups is not always simply additive.

While the summary above provides a general outline of internet connections across various social, economic and spatial groups, there are many other nuances within the data. Not all connections are created equal, and become pronounced in the digital experience as general connection rates increase, particularly in urban areas. Different types of connections, performance levels and locations of access will create varying online experiences. Affordability also plays into this discussion in determining the quality of connections that can be accessed.

\subsubsection{Type of Connection}

Much of digital access research defines internet access generally, and does not take into account the type of network, bandwidth, or speed. Hilbert (2016) argues that the traditional method of measuring access by subscription to internet service yields the false conclusion of closing access gaps between the Global North and South, and finds "a second, more mature, and also more persistent stage of the digital divide" by modelling bandwidth. Within a major 
metropolitan area like Toronto, digital infrastructure to offer a wide range of services may be present but actual service levels and digital experiences may vary.

Service levels are partly determined by the type of internet connection, which also impacts speed. Internet service may be accessed through a variety of technologies. Dial-up connections provide the lowest download speeds of 64 Kilobits per second (Kbps) (CRTC, 2016). Broadband internet service is defined as connections with download speeds of $1.5 \mathrm{Mbps}$ or higher, and may be provided through digital subscriber line (DSL), cable or optic fibre. CRTC (2016) currently defines high-speed internet as having speeds of 50 Megabits per second (Mbps) for downloads and 10 Mbps for uploads, with over $80 \%$ of Canadian households having access to this level of service.

Increasingly, mobile broadband through smartphones have also become a major means of connecting to the internet. CRTC (2016) finds that in 2014, $85.6 \%$ of Canadians owned a cellphone, and Canadians in the lowest income quintile are more likely to own a cellphone than a computer. With regards to internet access, $74 \%$ of mobile wireless subscribers had a data plan (CRTC). While there is no Canadian data specifically regarding the experience of "smartphone-dependent" internet users, Pew Research (2015) has noted the greater vulnerability of these individuals to data caps and service suspensions in the United States. Evidence from the U.S. also suggests that low-income, rural, and some racial and ethnic minority groups rely more heavily on mobile broadband compared to home broadband (Pew Research, 2015; Prieger, 2015). The primary reason cited is related to cost, as the price of a mobile device is often subsidized by the service provider whereas a personal computer requires a greater financial investment (Prieger, 2015).

\subsubsection{Locations of Use}

While there are limited studies examining locations of internet access, some researchers propose that it should be considered as an indicator of autonomy of use (DiMaggio and Hargittai, 2001; Hassani, 2006). Home internet connection is often used by researchers as a metric of access because it allows for flexibility, privacy, and the time and frequency required for effective skill acquisition and a broad range of activities (Mossberger et al., 2012). 
Some research regarding public libraries suggest that public computers and internet connections serve as important points of access for individuals with limited personal access (Liu et al., 2006). These locations often also have the advantage of offering training, technical support, and assistance with social services. Interviewees, however, expressed that public access is often their least preferred option, citing issues of inconvenience (Dixon et al., 2014). In addition, there appears to be "divides within the divide" as usage of public internet varies between groups (Dixon et al., 2014). Men appear to consistently outnumber women in utilizing public computer access (Liu et al., 2006; Dixon et al., 2014). Ethnic minority groups in the United States appear to have higher rates of public access internet use, although there may be variations between minority groups (Gant et al, 2010; Mossberger et al., 2003).

\subsubsection{Affordability}

The use of the internet incurs costs related to hardware, software, and connection services, with Mossberger et al. (2012) noting that the monthly payments for access may be especially taxing. CRTC (2016) finds that lower-income households spend a significantly higher proportion of their income on communications services at $6.6 \%$ compared to $2.4 \%$ for the national average. Based on the Consumer Price Index (CPI), it also finds that internet services price index rose at a higher rate than inflation from 2014 to 2015 (CRTC, 2016).

ACORN (Association of Community Organizations for Reform Now) Canada (2015) conducted a survey of low- and moderate-income families to understand their perceptions on the affordability of internet. In the survey, $58.9 \%$ of respondents state that they have had to take money away from budget items like food, rent and recreation to afford home internet.

These findings highlight the importance of the role of affordability in the discussion of digital inequality, and the disproportionate burden of internet access on low-income groups. Even in urban areas where individuals may be able to access free public terminals, their experience and benefits differ and play into the other issues of connection quality discussed above.

\subsection{Usage Activities}

It has been noted that in contrast to traditional media forms, the internet is significantly less uniform and straightforward. It requires users to navigate through large amounts of information 
compared to the relatively small range of choices of television and newspapers, therefore having the potential to result in far greater variations in online activities (van Deursen and van Dijk, 2014). In 2010, Canadian families with high income and education levels, as well as current students, performed more activities on the internet (Haight et al., 2014). Men engaged in more activities than women, and recent immigrants who used the internet participated in more activities even though they have lower rates of access (Haight et al., 2014).

Many models have been created to classify types of internet activity. It has been noted that the majority of online activities are passive and consumptive such as reading or watching a video, rather than active and contributing new content in the form of discussions or creative materials (van Dijk, 2006). Van Deursen and van Dijk (2014) identify seven clusters of activities: personal development, leisure, commercial transaction, social interaction, information, news, and gaming. Other researchers have investigated usage based on motivations and gratifications, such as problem solving, persuading others, relationship maintenance, status seeking and gaining insight (Flanagin and Metzger, 2001).

A key assumption in studies regarding the digital usage divide is that some activities are more beneficial than others in advancing one's career, education, and social status (van Deursen and van Dijk, 2014). Activities that may be categorized as "more beneficial" include searching for jobs, political participation, and accessing online government services. Generally, it appears that gaps in this type of use are based on familiar social and demographic lines. Studies show that individuals with higher income and education are more likely to use the internet in ways that improve their social and economic outcomes, as well as for information seeking purposes (Hargittai and Hinnant, 2008; Helsper and Galacz, 2009; van Deursen and van Dijk, 2014). In a study in the Netherlands, van Deursen and van Dijk (2014) found that this is true even though people with low levels of education actually use the internet for more hours in a day.

Some recent research have attributed positive outcomes to the use of social media through the creation of social capital, which can lead to greater access to information and opportunities, closer relationships, and social organization (Ellison, Steinfield, and Lampe, 2007). While some argue that the internet detracts from face-to-face time in personal relationships, studies have found that online communities lead to greater community involvement and social capital (Hampton and Wellman, 2003; Kavanaugh et al., 2005). Some researchers propose that the ability of social media and other online communication platforms to allow for loose but more far- 
reaching social ties is especially beneficial for people from disadvantaged groups who have less access to opportunities in their traditional offline networks (Mossberger et al., 2003). Haight et al. (2014) found that in 2010, income had no effect on Canadians' use of social media networks. People with higher education levels and current students were more likely to use social media, with the exception that individuals who had not graduated high school more likely used social media than those with only a high school diploma. Younger Canadians and women were also more likely to use social media (Haight et al., 2014). As governments are beginning to make use of social networking sites to engage with their citizens (Lee and Kwak, 2012), it is crucial for planners to understand who is reached through these channels and the biases that may be associated with consultation data collected in this matter. This is especially important as some online platforms make it difficult to obtain demographic information related to the participants.

\subsection{Digital Literacy}

"Digital skills" are not a definitive collection of skills, as the ability to function effectively in a digital environment requires many skills beyond the basic knowledge of operating the hardware and software of a device. Van Deursen and van Dijk (2010) identify the need for skills to navigate the structure of the internet, to search for information, and to utilize technology for selfadvancement. Greene, Yu, and Copeland (2014) argue that digital literacy is composed of selfregulated learning skills and epistemic cognition, the latter of which contains a range of skills related to comprehending, evaluating and reconciling the large amount of complex, sometimes contradictory information from multiple sources. Meanwhile, Eshet-Alkalai (2004) proposes a broader set of skills encompassing motor, sociological and emotional skills in addition to cognitive skills.

Large-scale population-wide surveys mostly rely on self-assessments of ability. Some surveys, such as the Digital Economy and Society Index (DESI), question respondents on their past activities as a proxy for skill assessment (European Commission, 2016). This methodology has been found by researchers to be unreliable as accurate measurements of skill (Hargittai, 2005). For example, there is a tendency for underestimation or overestimation amongst some social groups compared to others (Hargittai and Shaw, 2015), potentially leading to false reports of the presence or magnitude of digital literacy gaps. Some newer research techniques measure participant skill levels as they perform tasks, but these usually focus on a relatively narrow range of tasks indicating a subset of skills and require high levels of resources for data 
collection (van Deursen and van Dijk, 2010; Greene et al., 2014). As the integration of a broad range of skills is required for success in a digital environment, it is difficult to comprehensively assess digital literacy levels.

Taking into account these limitations to digital literacy research, it is possible to gauge broad trends in skill levels. Generally, it has been found that the skills divide follow the demographic lines that define access divides such as education, age, race and income, and is more persistent and growing (van Deursen and van Dijk, 2010). With regards to gender, there is disagreement in the literature regarding potential inequalities. Various studies show advantages for either men or women while still others find no difference, with the variations possibly differing based on type of skill, location and age (Hargittai, 2010; Ünlüsoy et al., 2010; Cheung, Mak, and Sit, 2013; van Deursen and van Dijk, 2010). Additionally, a population of interest for researchers is youth, who are generally considered to be "digital natives" and universally adept at using technology. In-depth research, however, has shown variation in skill levels corresponding to traditional lines of inequality as they relate to students and their family backgrounds (Hargittai, 2010).

\subsection{Attitudes}

In addition to cost- and skills-related barriers to internet use, non-adopters of digital technology may also cite a lack of interest or fear. Disinterest in digital access may stem from a lack of awareness of potential benefits and applications, or a perceived lack of relevance (Selwyn, Gorard, and Furlong, 2005). Other individuals may avoid the internet because of fear such as security and privacy concerns (Mossberger et al., 2012). Still others may choose not to use the internet based on ideological reasons such as resistance to mainstream culture or change and innovation (Selwyn, 2003).

The likelihood of individuals citing these attitudinal barriers to internet use varies based on personal and demographic characteristics. Fears of technology may be more prevalent in individuals with less experience with the technology, as well as people with social circles that are less educated or have less internet use (Horrigan, 2010; Warschauer, 2003). From a Chicago survey, Mossberger et al. (2012) finds that amongst individuals who do not use the internet, high-income, elderly, and non-Hispanic White individuals are more likely to cite lack of interest as a limiting factor. 


\subsection{Outcomes of Digital Inclusion}

Digital inequality is both a reflection of and a contributor to social inequality. A review of the various components of digital inequality reveals long-standing divides based on income, education, race, ethnicity, and possibly gender in addition to new divides such as age. As a result of the increasing digitization of broad aspects of society, however, digital exclusion also becomes a causal agent in producing inequality.

\subsubsection{Digital Citizenship}

Since the introduction of the internet, proponents have suggested that it could be a great democratizing agent, providing a highly accessible platform for information, communication and social organization. For example, Hanzl (2007) suggests that planners can use digital technologies to better present planning information to the public through visualizations, utilize games as educational and participatory tools, and adopt collaborative software such as wikis. There is some evidence to support this optimism, with studies finding that internet use is associated with greater exposure to political discussion, voter turnout, and other forms of participation, a trend that holds after controlling for socioeconomic variables (Tolbert and McNeal, 2003; Kenski and Stroud, 2006; Buente, 2015).

There are, however, causes for concern. As part of their study of online geospatial participatory tools, Sieber et al. (2016) find evidence of inequalities in engagement based on age, urban-rural divides and socioeconomic status. A comparison of internet users by age group shows that individuals under 30 have lower rates of online political participation even though they are more likely to use the internet in general (Schlozman, Verba, and Brady, 2010). Regarding digital participation more generally, Hargittai and Walejko (2008) find that contribution and sharing of content is not uniform but based on socioeconomic status. Evidently, online participation is not evenly distributed throughout the population but biased along the same socioeconomic and demographic lines as traditional offline participation, compounded with new divides based on age.

Looking at digitization at the level of governments and other institutions, many researchers, policy think tanks, and technology enthusiasts have recognized the potential of digital 
technology and the internet to provide more convenient, efficient, and personalized public service delivery (Kleinman, 2016). Governments at all levels are beginning to take steps in this direction, including the Ontario (2016) and Canadian (2016) governments as well as municipal governments. A field that has received recent attention in the literature is eHealth, the currently most realized application of which is to provide health information but also has the potential to provide more personalized care, patient autonomy, and better communication between healthcare professionals and patients (Robinson et al., 2015; Murray, 2014; Kaminski, 2016). The danger of these new forms of service delivery is in the possibility that they may lead to traditional forms of delivery being neglected, so that individuals who are not active digitally are placed at a disadvantage.

\subsubsection{Educational \& Economic Opportunity}

In today's increasingly digital world, the effects of digital access begin to impact an individual's socioeconomic outcome beginning in childhood and adolescence. Lack of or insufficient digital access deprives youth of informational resources, digital skill development, and independence in decision-making outside of parental influence, all of which may impact their future career outlook (Robinson, 2011; 2012). Conversely, youth who have unlimited access to the internet may see decreased academic performance (Robinson et al., 2015). Educational institutions and learning opportunities have progressively become more digitized, especially in higher education, raising concerns about inequalities of access, use and skill in students (Selwyn, 2010).

The use of digital skills is becoming increasingly important in the workplace. The OECD (2014) identifies four ways in which digital technology has impacted employment: the creation of new jobs, transforming existing jobs, global outsourcing of jobs, and the loss of jobs to technological replacements. These trends result in the growing demand for digital skills both in information and communications technology (ICT) sector jobs as well as in jobs in all sectors that require the use of digital technology. The advantage provided by digital skills is borne out in research showing that workers who use the internet enjoy higher earnings (DiMaggio and Bonikowski, 2008). Researchers also suggest that individuals who use the internet have greater access to job information including through social media platforms such as Linkedln (DiMaggio and Bonikowski, 2008; Robinson et al., 2015). For people who are self-employed, digital skills are important for business administration, raising social and financial capital, and other entrepreneurial functions (Robinson et al., 2015). 
While the full impacts of digitization on society is uncertain, the extension of functions into the digital realm suggests that digital exclusion represents a barrier to full participation in society. Having the means and the ability to navigate online systems gives individuals the choice to access additional resources to advance their status and wellbeing. Evidently, it is important that the effects of the lack of digital participation be addressed in the pursuit of an equitable, prosperous and healthy society. In order for this to take place, however, the extent of digital inequality in its many forms need to be understood so that initiatives can be thoughtful and targeted, and be evaluated for effectiveness. 


\subsection{Methods}

This study uses mixed methods to uncover the issue of digital inequality through a planning lens. It consists of two major components. Firstly, an environmental scan is used to establish a methodology for analyzing digital inequality. This framework is then applied to the case study of Toronto to construct a profile of digital inequality in the city.

\subsection{Environmental Scan}

Similar to previous studies on digital inequality frameworks (Barzilai-Nahon, 2006; Bruno, Esposito, and Genovese, 2010), a review of grey and academic literature is conducted to understand current methods for measuring digital inequality, issues of interest, and critiques. In particular, the environmental scan examines approaches taken by international organizations, governments and non-governmental organizations. Based on the research questions of this study, this scan will focus on methodology and conceptual frameworks rather than trends or solutions to digital inequality.

From the perspective of applying these frameworks to Toronto, a jurisdictional scan of other urban areas form a significant portion of this analysis. This is similar to policy research practices that have been used in the development of digital initiatives in other cities (e.g. City of Vancouver, 2013; Ville de Montréal, 2014). Cities were selected based on two criteria: best practice cases across the Global North to provide insight on methods to approach digital inequality, or other major urban areas in Canada for comparison in a closer political and social context. The municipalities examined in this study included the following: Barcelona, Calgary, Chicago, London (United Kingdom), Montréal, New York City, San Francisco, and Vancouver.

\subsection{Case Study of Toronto}

Using the findings from the environmental scan as a basis, a case study is conducted to analyze digital inequalities in Toronto and their implications for planners. Currently, there is a lack of comprehensive and up-to-date publicly-available data on the subject, and time constraints make it difficult to obtain master files that is not available to the public. Therefore, this study aggregates secondary data from a number of different sources but primarily draws from three major datasets. 
Canadian Internet Use Survey (CIUS)

Survey results from respondents living in the Toronto Census Metropolitan Area (CMA) from the 2012 Canadian Internet Use Survey (CIUS) are used in this section to illustrate digital inequalities within the population. The Toronto CMA also includes many surrounding municipalities as seen in Figure 3.2-1, but this population is used to approximate the Toronto population in the analysis as it is the finest geographic scale available. Caution should be used when interpreting these results.

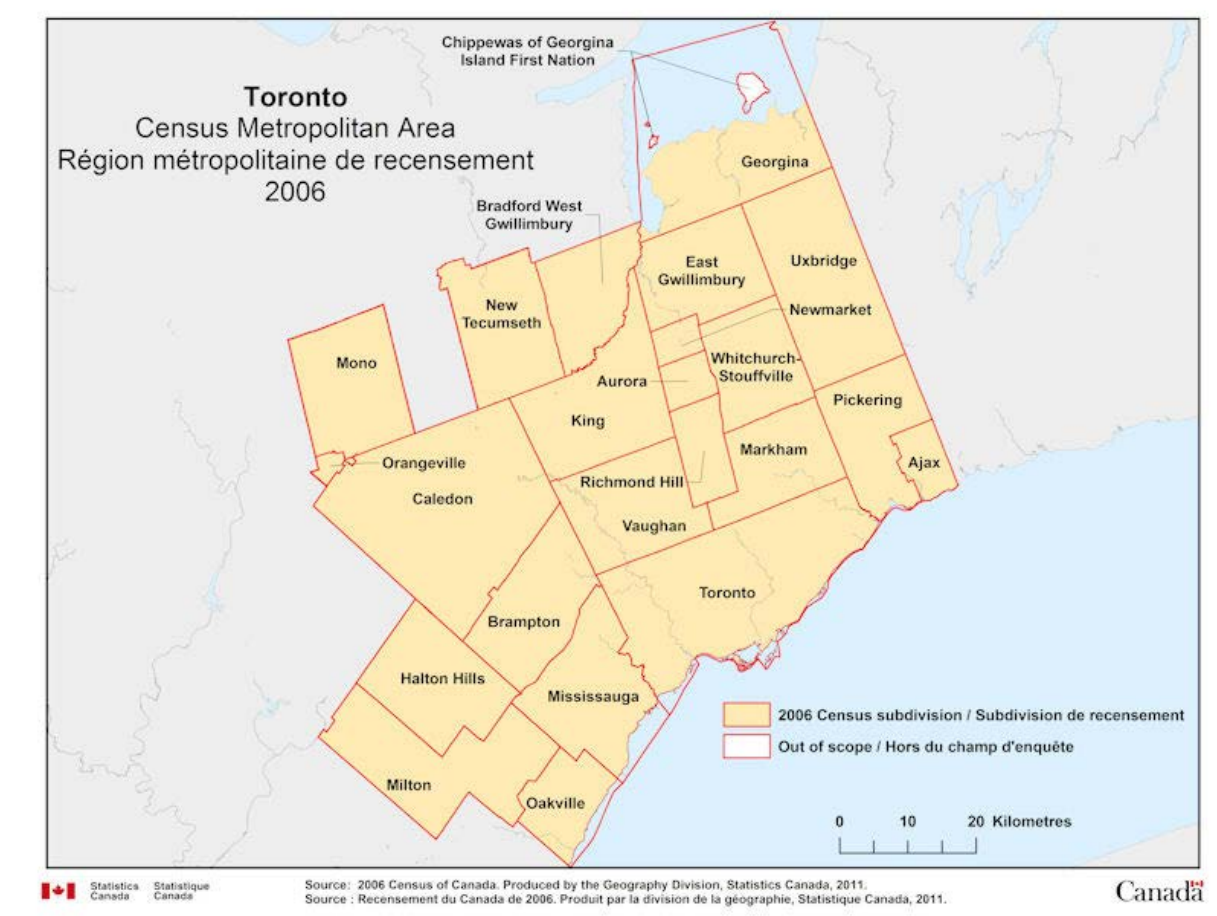

Figure 3.2-1. The Toronto Census Metropolitan Area as defined by Statistics Canada (Statistics Canada, 2011).

The CIUS consists of the Household and Individual components, both of which are included in this report. This subset of the CIUS includes 1065 respondents representing 2,105,056 households for the Household component and 872 respondents representing a population of $4,870,708$ for the Individual component. This study uses the Household component in analyses related to home access, and the Individual component in analysis of usage patterns. These 
results serve as a best estimate of the current condition as the CIUS was last conducted in 2012 and there have been no subsequent surveys of similar scale or scope.

Analysis was conducted on the Public Use Microdata File (PUMF) available through Statistics Canada's Data Liberation Initiative (DLI). As only estimates of the coefficients of variance (CV) were available for the PUMF, the quality and significance of findings based on complex statistical tests cannot be verified. Therefore, only simple comparisons were made across variables. In some cases, t-tests were performed using the CV estimates table and methods released in the CIUS User Guide (Statistics Canada, 2013). The CIUS User Guide classifies the quality of estimates based on sample size and CV estimates as acceptable, marginal or unacceptable. Estimates of marginal and unacceptable quality have been identified in this report. Concerns regarding quality of estimates also limit analysis on segments of the population within the Toronto CMA dataset due to small sample sizes.

The results of this analysis is considered in comparison with the findings of Haight et al.'s (2014) analysis of the 2010 CIUS, although the present study necessarily has a lower level of statistical rigour. Also drawing from the Haight et al. (2014) study, current students in the dataset form a group of analysis separate from the other education levels, so that young students still in the process of obtaining education are not sorted into lower education groups.

\section{Environics Analytics Household Expenditure Potential (HEP)}

As the dataset for the Survey of Household Spending (SHS) is not publicly-available for the years after 2009, the Environics Analytics HEP was used. The HEP estimates current household expenditures in different categories based on the results of the SHS (which are typically released about 2 years after they are conducted) and demographic data (SimplyMap, 2017). The HEP estimate for the variables of interest were obtained from SimplyMap for dissemination areas in the City of Toronto.

Demographic estimates for 2016 were also obtained from Environics via SimplyMap to reflect current conditions. Population counts and household income estimates were obtained from the Demographic Estimates and Projections (DemoStats) database. 
The role of the Toronto Public Library (TPL) in providing internet and computer access is explored through the combination of several datasets from its open data website including the following: Branch Geolocations, Branch Catchment Population, Neighbourhood Improvement Area Branches, Workstations, and Workstation Users. Additional data points and information about services and programs are collected from the other parts of the TPL website.

The most up-to-date data for workstations and workstation users is from 2015, as 2016 data has not yet been released. Catchment populations were calculated by the TPL based on 2011 census data and catchment areas of $1.6 \mathrm{~km}$ for neighbourhood-tier branches and $2.5 \mathrm{~km}$ for district-tier branches (TPL, 2010).

Other Data Sources

Additional datasets are also presented in the case study to supplement the three major data sources. These data sources and relevant methodological notes are shared in the case study section of this report where they occur. 


\subsection{Environmental Scan: Developing a Practical Approach for Planners}

\subsection{Aggregated Frameworks and Indices}

In addition to measurements of individual components of digital inequality by researchers and governments, there have been many efforts to create frameworks to aggregate these multiple dimensions. In particular, several well-known indices have been developed by international organizations to allow for comparisons and tracking over time. Table 4.1-1 shows the major components of some of the these indices.

Table 4.1-1. The composition of common indices to measure digital inequality.

\begin{tabular}{|c|c|c|}
\hline Framework & Categories & $\begin{array}{l}\text { Number of } \\
\text { Indicators }\end{array}$ \\
\hline $\begin{array}{l}\text { ICT Development Index } \\
(\text { ITU, 2017) }\end{array}$ & $\begin{array}{l}\text { ICT Access } \\
\text { ICT Use } \\
\text { ICT Skills }\end{array}$ & 11 \\
\hline $\begin{array}{l}\text { Network Readiness Index } \\
\text { (Baller, Dutta, and Lanvin, } \\
2016 \text { ) }\end{array}$ & $\begin{array}{l}\text { Environment } \\
\text { - Political and Regulatory Environment } \\
\text { - Business and Innovation Environment } \\
\text { Readiness } \\
\text { - Infrastructure } \\
\text { - Affordability } \\
\text { - Skills } \\
\text { Usage } \\
\text { - Individual } \\
\text { - Business } \\
\text { - Government } \\
\text { Impact } \\
\text { - Economic } \\
\text { - Social }\end{array}$ & 53 \\
\hline
\end{tabular}




\begin{tabular}{|c|c|c|}
\hline $\begin{array}{l}\text { Digital Economy and Society } \\
\text { Index } \\
\text { (European Commission, } \\
2017 \text { ) }\end{array}$ & $\begin{array}{l}\text { 1. Connectivity } \\
\text { a. Fixed Broadband } \\
\text { b. Mobile Broadband } \\
\text { c. Speed } \\
\text { d. Affordability } \\
\text { 2. Human Capital/Digital Skills } \\
\text { a. Basic Skills and Usage } \\
\text { b. Advanced Skills and } \\
\text { 3. Development } \\
\text { a. Content } \\
\text { b. Communication } \\
\text { c. Transactions } \\
\text { 4. Integration of Digital Technology by } \\
\text { Businesses } \\
\text { a. Business Digitisation } \\
\text { b. eCommerce } \\
\text { 5. Digital Public Services } \\
\text { a. eGovernment }\end{array}$ & 24 \\
\hline
\end{tabular}

As seen in Figure 4.1-1 above, each of these integrative frameworks consist of categories and subcategories relating to various components of digital inclusion, similar to the issues identified in Section 2 of this paper. Specific indicators are used to characterize each of the categories, which have defined weights in the calculation of the overall index. As an example, Figure 4.1-2 shows the detailed makeup of the ICT Development Index. 


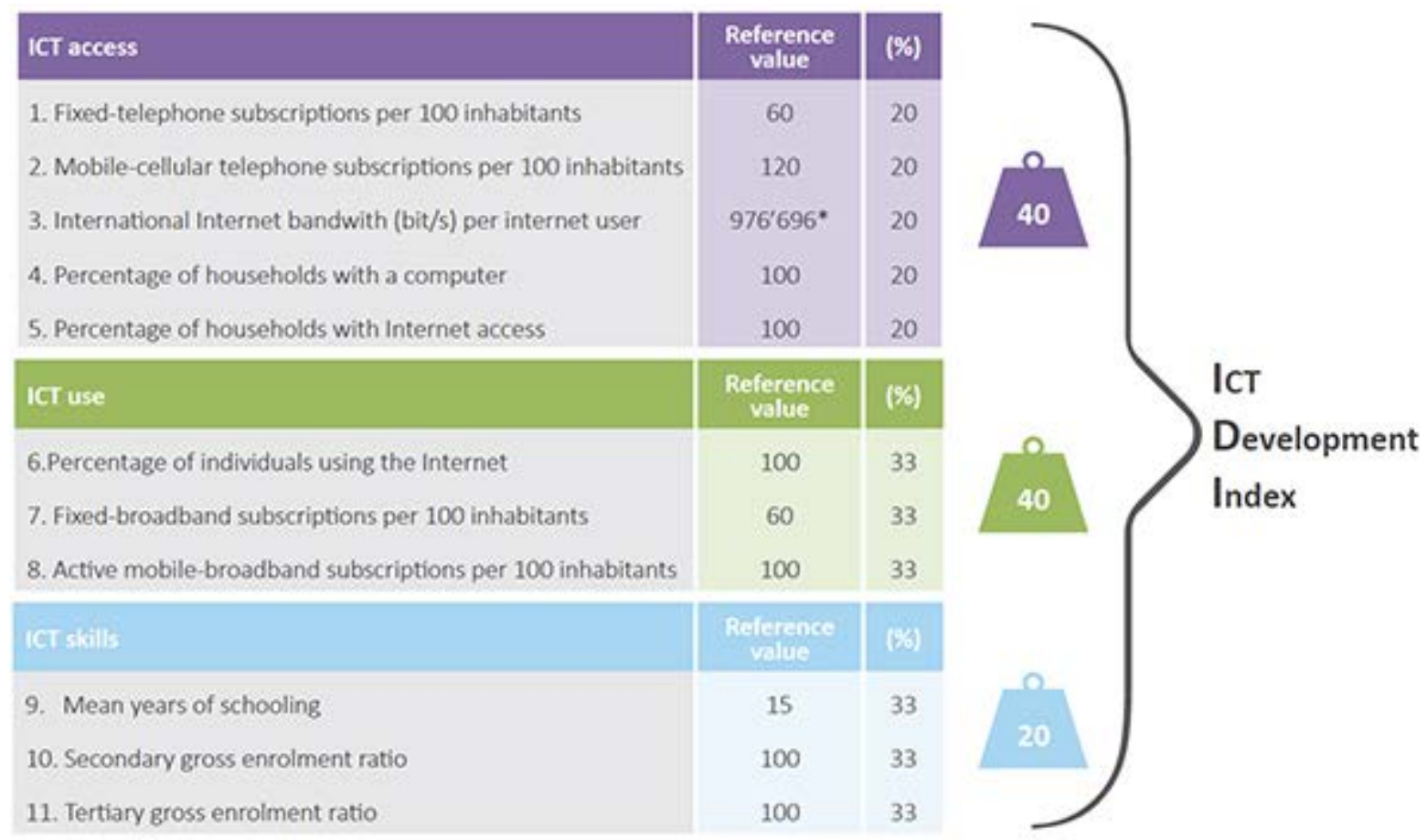

Figure 4.1-2. Indicators, reference values and weights used in the calculation of the ICT Development Index (ITU, 2017).

These indices can provide a useful summary to assess the general state of digital inclusion in a region, and allows for comparisons between different areas and over time. They also present a more comprehensive and nuanced view than statistics for single indicators. Although these existing frameworks provide important suggestions for planners regarding appropriate indicators that are feasible to measure, their broad geographical scope and one-size-fits-all approach make them impractical for direct application in planning. These indices are primarily developed for observation and comparisons at large units of study such as countries and international regions. They would need to be adapted to provide granular, community-level results. For instance, in Huesing and Selhofer (2002)'s Digital Divide Index (DDIX) for the research and consultancy firm Empirica, three units of observation are defined to provide a finer-grained perspective: citizens (individuals and households), businesses and organizations, and regions.

A related approach is to identify risk groups within the general population to provide areas of focus and comparison over time. The DDIX identifies four such groups: women, seniors, individuals with low education, and individuals with low income. A similar approach is used in South Korea's Digital Divide Index (DDI) and the United Kingdom's Government Digital Inclusion Strategy (Park and Kim, 2014; United Kingdom, 2014). Comparison of these three 
applications show the context-specific nature of group definition. In Canadian contexts, examples of groups for consideration may include Indigenous persons, immigrants and refugees in addition to other disadvantaged groups typically referenced in literature like elderly, low-income, or low-education individuals. There are issues of concern when using this approach, however, with researchers pointing out that group membership is not mutually exclusive and additional disadvantaged groups may be left out (Huesing and Selhofer, 2002; Park and Kim, 2014).

Researchers have also pointed out concerns that existing indices measuring digital inclusion may oversimplify the issue and ignore the causes underlying digital inequality (Bruno, Esposito, and Genovese, 2011). In the existing, most widely-used frameworks, the weighting of indicators is rigid despite drastically different social, economic and political circumstances in the jurisdictions measured. A simple example is that of physical access, whereby areas already well-connected by physical infrastructure will require greater consideration to be placed on factors such as affordability.

This lack of flexibility diminishes the utility of the framework for planners, who need to understand the interplay between these contexts and digital inequality to address unequal distribution and to ensure inclusive opportunities to participate in planning processes. A more useful approach for planners may be to base the framework on a solid understanding of the interrelationships of various factors on digital inequalities, such as in the model proposed by Barzilai-Nahon's (2006) shown in Figure 4.1-3. This basis, along with context-specific knowledge of existing socioeconomic disparities and other cultural, political and psychological contexts, allows for deeper understanding of the reasons behind digital inequalities and the barriers to inclusion. 


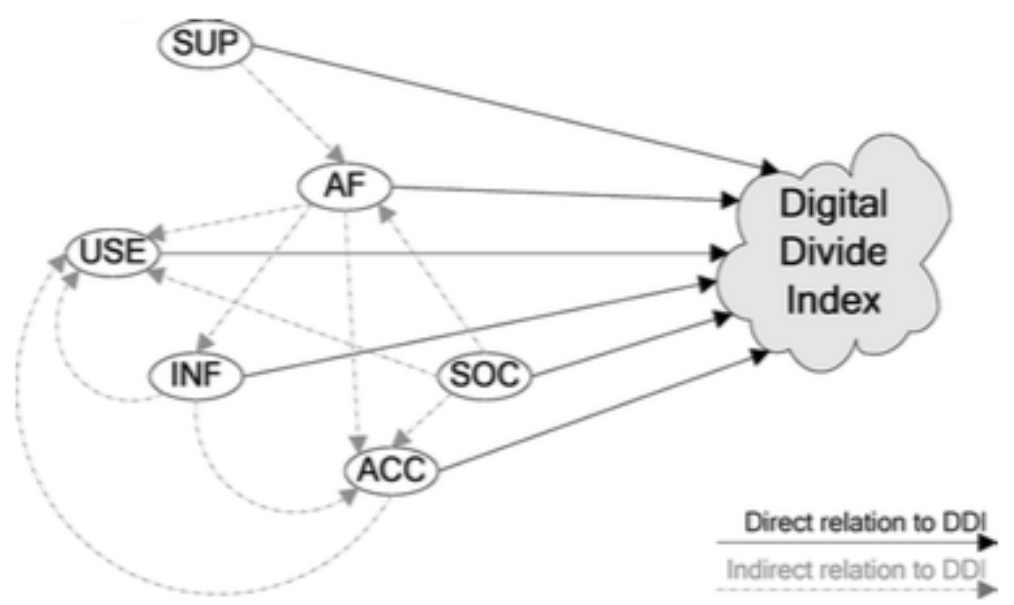

Figure 4.1-3. A conceptual model of interrelationships between components of digital inequality (Barzilai-Nahon, 2006).

SUP = social and government constraints/support; $A F=$ affordability; USE = use; INF = infrastructure access; $A C C=$ accessibility (related to populations with disabilities and special needs); SOC = sociodemographic factors.

\subsection{Municipal Approaches}

As digital technologies play an increasing role in people's lives and businesses, cities across the Global North have begun to consider and plan for their impacts on government functions. A jurisdictional scan of municipal perspectives on digital inequality provides further suggestions for a practical approach for planners to understand the issue in their communities.

While many cities have made efforts to digitize government and promote their digital economy, they vary in their levels of consideration for digital inequalities. For municipalities that do incorporate significant elements of digital inequality into their policies, their conceptualizations of the issue and methods of measurement range in scope and complexity. Appendix 8.1 summarizes the main findings from a jurisdictional scan of best practices from North America and Europe, as well as comparable cities in Canada. It was found that cities generally collect two broad types of data to supplement their understanding of digital inequality: intra-city population data, and program-based data. 


\subsubsection{Intra-City Population Data}

Data regarding the level of digital inclusion in populations within cities was available for Barcelona, Chicago, London and San Francisco. All four of these cities have access to selfreported survey responses collected within the past five years.

The Cities of Barcelona and Chicago both commissioned studies specifically for the purpose of measuring digital inequality and have detailed data regarding digital access, devices used and online activities (Mobile World Capital, 2016; Mossberger, Tolbert and Feeney, 2014). These studies have allowed the cities to develop a comprehensive understanding of various elements of the digital divide amongst different segments of their population along demographic and spatial dimensions. In particular, Chicago has longitudinal data from surveys conducted in 2008, 2011, and 2013, allowing for evaluation over time of their Smart Communities initiative that promotes broadband access and skills training in targeted neighbourhoods (Mossberger et al., 2014).

In addition to analyzing digital inequalities based on demographic and geographic characteristics, the data collected from Barcelona's survey was also used to sort respondents into five user profiles as defined in Table 4.21-1. This approach allows for the presentation of a simple, impactful snapshot of the city's usage patterns for policymakers and public education, but no clear rationale or methodology was given for the definition of these profiles.

Table 4.21-1. Definition of User Profiles in Barcelona's Digital Divide Report (Mobile World Capital, 2016).

\begin{tabular}{|l|l|l|l|}
\hline User Type & Last Internet Use & Number of Devices Used & Activities Done \\
\hline Advanced & Last three months & Minimum 3 & Minimum 6 \\
\hline Intermediate & Last three months & Minimum 2 & Minimum 4 \\
\hline Basic & Last three months & Minimum 1 & Minimum 2 \\
\hline Sporadic & Last three months & Minimum 1 & or 1 \\
\hline Non-user & Does not use internet & & \\
\hline
\end{tabular}


While Chicago and Barcelona conducted purpose-built surveys to examine digital inequality, the Cities of London and San Francisco obtained their data as part of broader surveys. London's Digital Inclusion Strategy draws from analysis conducted on the national Labour Force Survey (Greater London Authority, 2015), while San Francisco included questions regarding internet access and online government service use in their biennial City Survey (City and County of San Francisco, n.d.). Leveraging existing data and processes provided some insights on the state of digital inequality in these cities, although the results contained less details including geographic information.

An additional point of interest from the cities examined is the use of inclusive techniques to broaden the pool of respondents, particularly with regards to crossing multilingual barriers in highly diverse cities. Chicago's surveys were conducted in both English and Spanish, and San Francisco residents had the option to request Spanish or Chinese versions of the City Survey.

\subsubsection{Program-Based Data}

Most of the cities examined as part of the jurisdictional scan reported some level of data regarding the performance of their digital inclusion programs. Examples of these statistics include the number of initiatives implemented and the numbers of people connected or trained. These statistics provide important measures regarding the success and reach of programs. They are, however, usually presented out of context from the individuals and communities that are impacted as well as those who are left behind. For instance, a common report of progress is the number of public computers or wifi hotspots installed (Ville de Montréal, 2017; City of Vancouver, 2017). These statistics do not give a sense of the number or kinds of people who benefit from the initiative or the overall impact to the city's digital landscape. New York City (2013) reports the number of people receiving digital access and training through initiatives for low-income residents which provides more social context, but it is difficult to understand the scale of these impacts without linkages to comprehensive surveys of digital inclusion for the city's population.

Some cities have taken measures to fill this gap. In their evaluation of the Smart Communities program, in addition to city-wide surveys, Chicago used follow-up questionnaires from program participants to gauge any effects on internet access, self-reported skills, online activities, and attitudes (Mossberger et al., 2014). Interviews were also conducted with partner organizations 
to understand impacts on technological organizational capacity throughout the program as well as attitudes towards the initiative including opportunities and challenges (Mossberger et al., 2014).

\subsection{Digital Engagement and Governance}

The development of a framework for a digitally inclusive society requires input and validation from its stakeholders in addition to theoretical understanding of the concepts and practices. The American Institute of Museum and Library Services (2012) suggests that communities need to develop a common understanding of its digital goals and needs through a shared learning experience of data collection and analysis. The inclusion of the public, private and non-profit sectors in addition to citizens in this process provides perspectives from the broad realms impacting and impacted by digital inequality such as education, social housing, economic development and civic engagement (Institute of Museum and Library Services, 2012).

In terms of service delivery, the British Government Digital Inclusion Strategy (2014) takes an approach which integrates digital inequality into e-government initiatives. It has developed a digital inclusion scale to visualize the digital capabilities of individuals ranging from 1 (Never have, never will) to 9 (Expert) (United Kingdom, 2014). In addition to providing a snapshot of the UK population through detailed data collection, a main application of the scale is for the development of digital government services. Figure 4.3-1 below provides an example where the target users of a digital service have been mapped on the digital inclusion scale, allowing government and non-profit sector staff to develop tools that align with the users' capabilities and needs. 


\section{Claim Carer's Allowance}

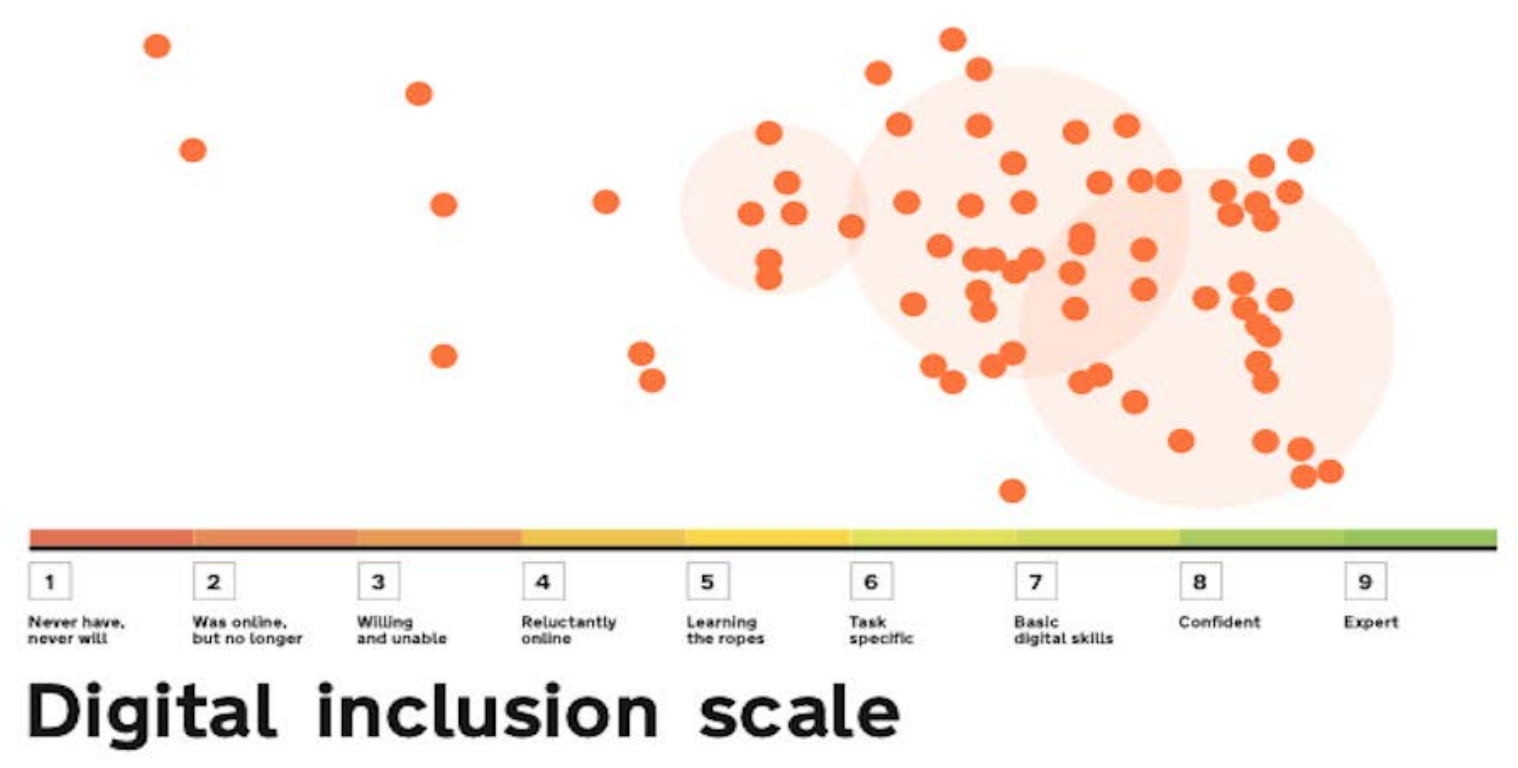

Figure 4.3-1. Use of the Digital Inclusion Scale in the development of targeted, accessible government online services for caregivers (United Kingdom, 2014). 


\subsection{Case Study: A Profile of Digital Inclusion in Toronto}

This case study of Toronto will provide a profile of digital inequality in the city based on available information. The structure of this section is guided by the main dimensions of digital inequality identified in the literature review and the key findings from the environmental scan, but is limited by the data sources available. The case study begins by setting the social and policy contexts within which discussions of digital inequality take place in the city. Next, it presents data impacting connectivity in the city and the usage activities of its residents. Digital literacy is not separately addressed because of the lack of data, although inferences can be made from online activity trends. The attitudes section examines the barriers to internet access and use, as well as security concerns expressed by Toronto residents. Program-based data includes information relating to Toronto Public Library's digital inclusion initiatives, while acknowledging that there are other programs by public, non-profit, and private sector organizations meriting future study. Finally, gaps in data identified through the process of assembling this case study is outlined and strategies for data collection are presented.

\subsection{Context}

\subsubsection{Background}

As Canada's largest city, Toronto has a population of 2.7 million (Statistics Canada, 2017). It has often been cited as one of the most diverse cities in the world, with $47 \%$ of the population in 2011 identifying as being part of a visible minority ${ }^{1}$ and $48 \%$ being born outside of Canada (Statistics Canada, 2016b). As of 2006, more than 140 different languages were spoken in Toronto, with half of the population having a mother tongue other than English or French and $5 \%$ of residents with no knowledge of either official language (City of Toronto, 2017). This diversity of peoples is an important consideration for planners both in identifying potential inequalities and for engagement practices.

In 1998, the six previous municipalities of East York, Etobicoke, North York, Scarborough, Toronto, and York were amalgamated into the present City of Toronto. Today, these boroughs continue to define community planning boundaries in the City and influence political processes.

\footnotetext{
${ }^{1}$ Statistics Canada (2015) defines visible minorities as "persons who are non-Caucasian in race or nonwhite in colour and who do not report being Aboriginal."
} 
The City of Toronto is further divided into 140 neighbourhoods to aid in local planning by the government and community agencies (City of Toronto, 2017b). 31 of these neighbourhoods have been identified as Neighbourhood Improvement Areas (NIAs) for policy and investment based on inequities related to economic opportunity, social development, healthy living, civic participation and physical surroundings (City of Toronto, 2014). Based on the connections between social and digital inequalities established in Section 2, these neighbourhoods represent potential areas of focus for understanding and addressing digital inequality. A map of NIAs is shown in Figure 5.1.1-1. A more detailed comparison of existing equities in various parts of the city is shown in Figure 4.11-2 through the mapping of median household income by dissemination area. This figure uses Environics estimates for 2016 to approximate current conditions.

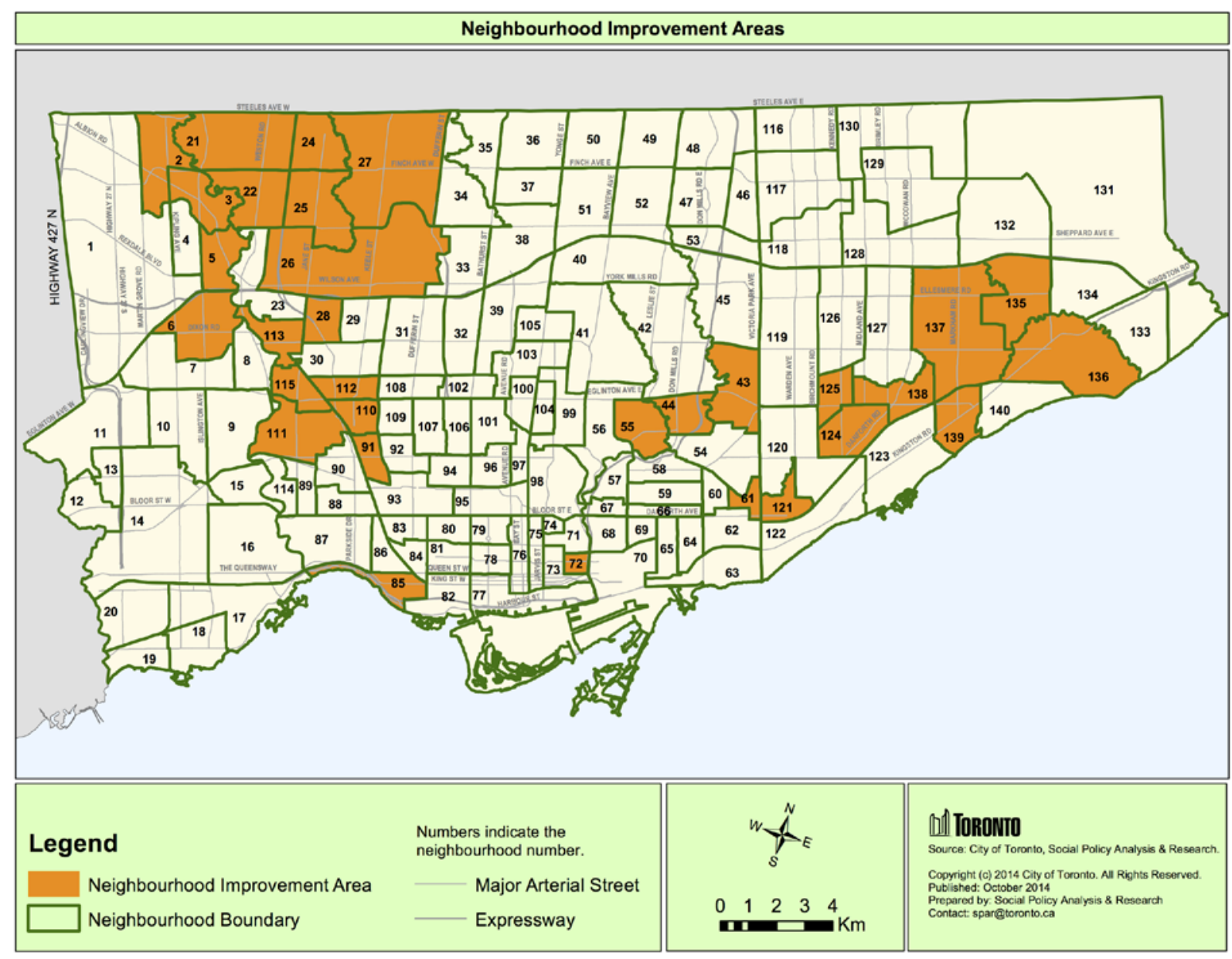

Figure 5.1.1-1. Neighbourhood Improvement Areas (NIAs) in the City of Toronto. 


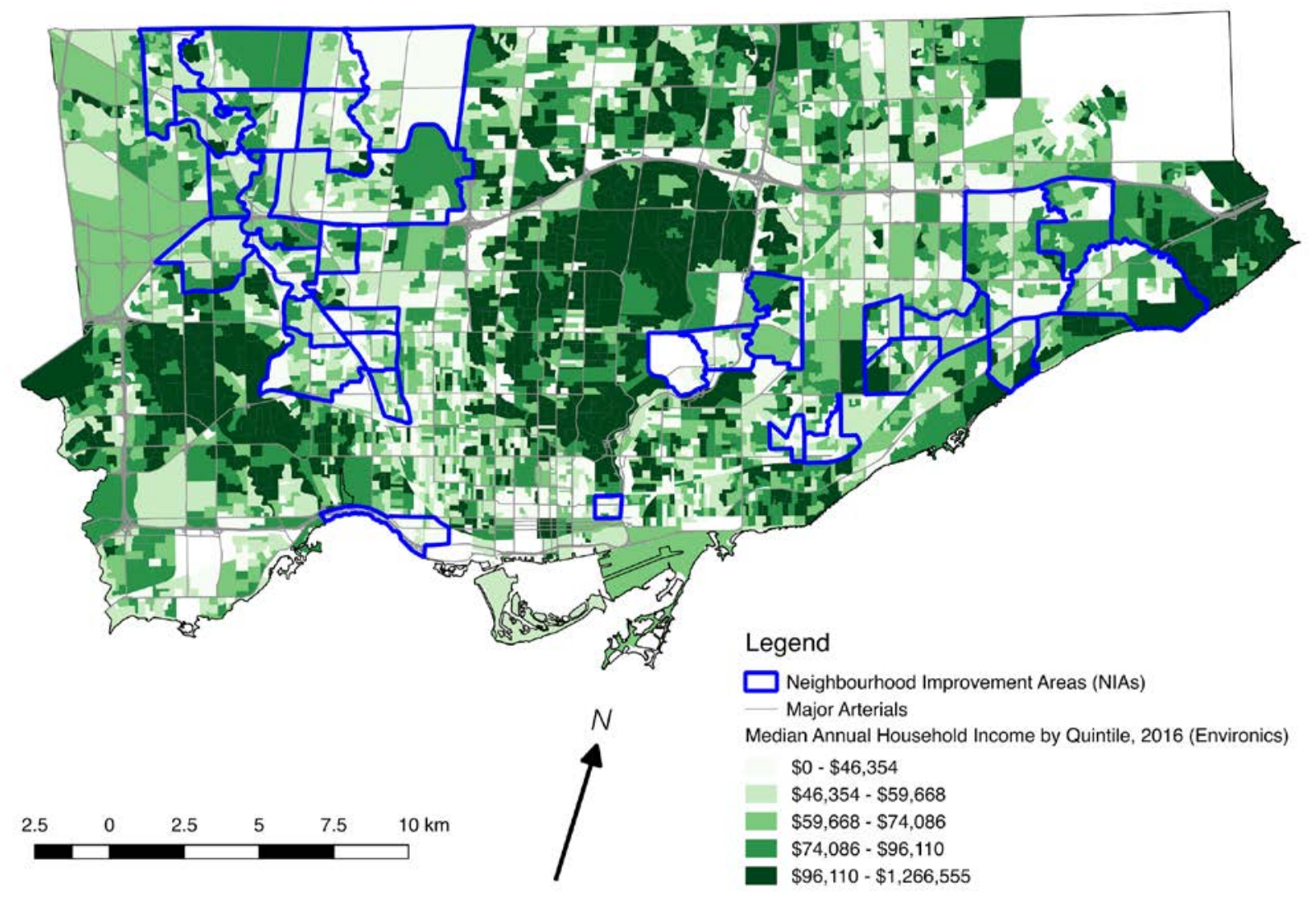

Figure 5.1.1-2. Estimated median annual household income in 2016.

\subsubsection{Digital Policy}

The City of Toronto currently has no framework in place to address digital inequality nor a comprehensive digital strategy, although internal processes are taking place to move in this direction. From September 2015 to June 2016, City Council and the Economic Development Committee requested staff reports regarding a number of digital issues in the city. In October 2016, staff presented the outline of an internet connectivity report including the elements of physical digital infrastructure, subscription rates, public wifi, specialized networks, and smart city initiatives (City of Toronto, 2016b). While the discussions of connectivity, subscription rates and public wifi zones contains references to addressing digital inequality, its importance within the final report remains to be seen. In comparison to the first two Member Motions' emphasis on "bridging the digital divide", concerns regarding "smart" technology and its economic potential appear to have taken the forefront in the latest update (City of Toronto, 2015a; City of Toronto, 
2015b; City of Toronto, 2016b). The outline also makes no references to dimensions of digital inequality other than connectivity (City of Toronto, 2016b).

Outside of this process, the City has taken several initiatives over the past few years to increase digital engagement. This includes the use of email and social networking sites for outreach, online surveys contributing to planning and policymaking processes, and the open data initiative (City of Toronto, 2017a). As the City's engagement practices progressively expands into the online realm, digital inequalities in the city need to be explicitly considered as part of government initiatives to ensure inclusivity.

\section{Toronto Public Library}

The Toronto Public Library (TPL) has made access to digital technology and skills training a key part of its goals and operations, recognizing the persistence of the digital divide and that "internet access has become essential to full participation in society" (TPL, 2015). With 100 branches throughout the city, the TPL potentially has significant impacts on digital inclusivity goals.

The TPL's Strategic Plan 2016-2019 highlights the need for access to a broad range of technologies including emerging technologies such as 3D printing, alongside with technical support and training. It provides computer workstations, internet access and basic software at all of its branches, as well as 17 Computer Learning Centres for digital training and three Digital Innovation Hubs with specialized software (TPL, 2017). In addition to providing these services at its branches, TPL is making efforts to expand its reach outside of its physical locations with a wifi hotspot lending program, distance learning, and a new Bookmobile with wifi, computers and tablets to visit communities without easy access to a permanent branch (TPL, 2015; Naccarato, 2017).

\subsection{Connectivity}

The latest publicly-available data for Toronto shows that in 2014, there were 89,923 internet connections and 80,996 cell phone connections per 100,000 population (WCCD, 2015). The numbers of connections have grown since 2013, as shown in Figure 5.2-1. More recent numbers can be derived from other sources such as the Survey of Household Spending (SHS), 
which could also provide details such as the number of digital devices owned and the amount of telecommunications spending. This data is not accessible to the public, however, and is further discussed in the gap analysis in Section 5.6.

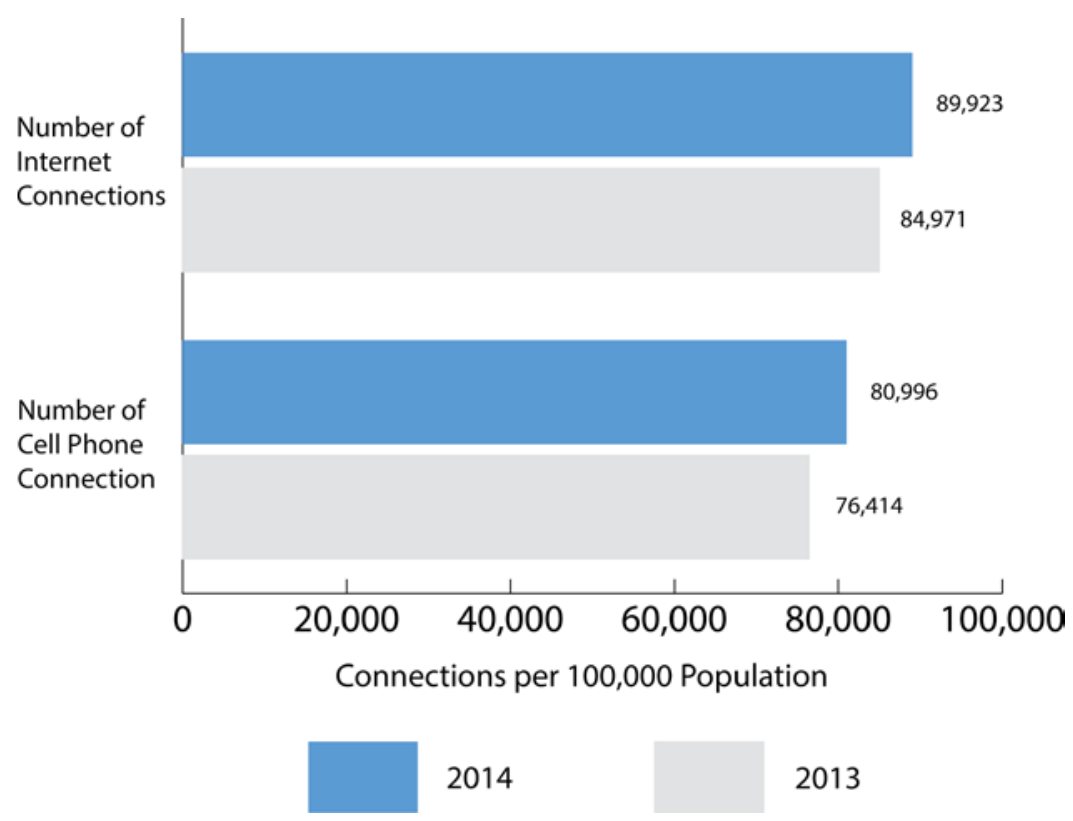

Figure 5.2-1. Number of Internet and Cell Phone Connections per 100,000 Population in the City of Toronto (WCCD, 2015).

\section{Home Access}

Data from the 2012 Canadian Internet Use Survey (CIUS) Household Component can be used to break down these connections within Toronto, as seen in Figure 5.2-2. Note that this data is derived from respondents living in the Toronto CMA, and should only be considered as an approximation for the City of Toronto.

Based on this dataset, Toronto had an overall home internet access rate of $87.9 \%$. There are lower rates of access in families with low income (64.3\% for the lowest income quintile) and families with low education $(63.7 \%$ for households with high school or less as the highest education level completed). These findings align with results in Canada and other jurisdictions as found in Section 2. Single person households also have low rates of access at $71.0 \%$. Households with students have higher home internet access rates than households without students. 


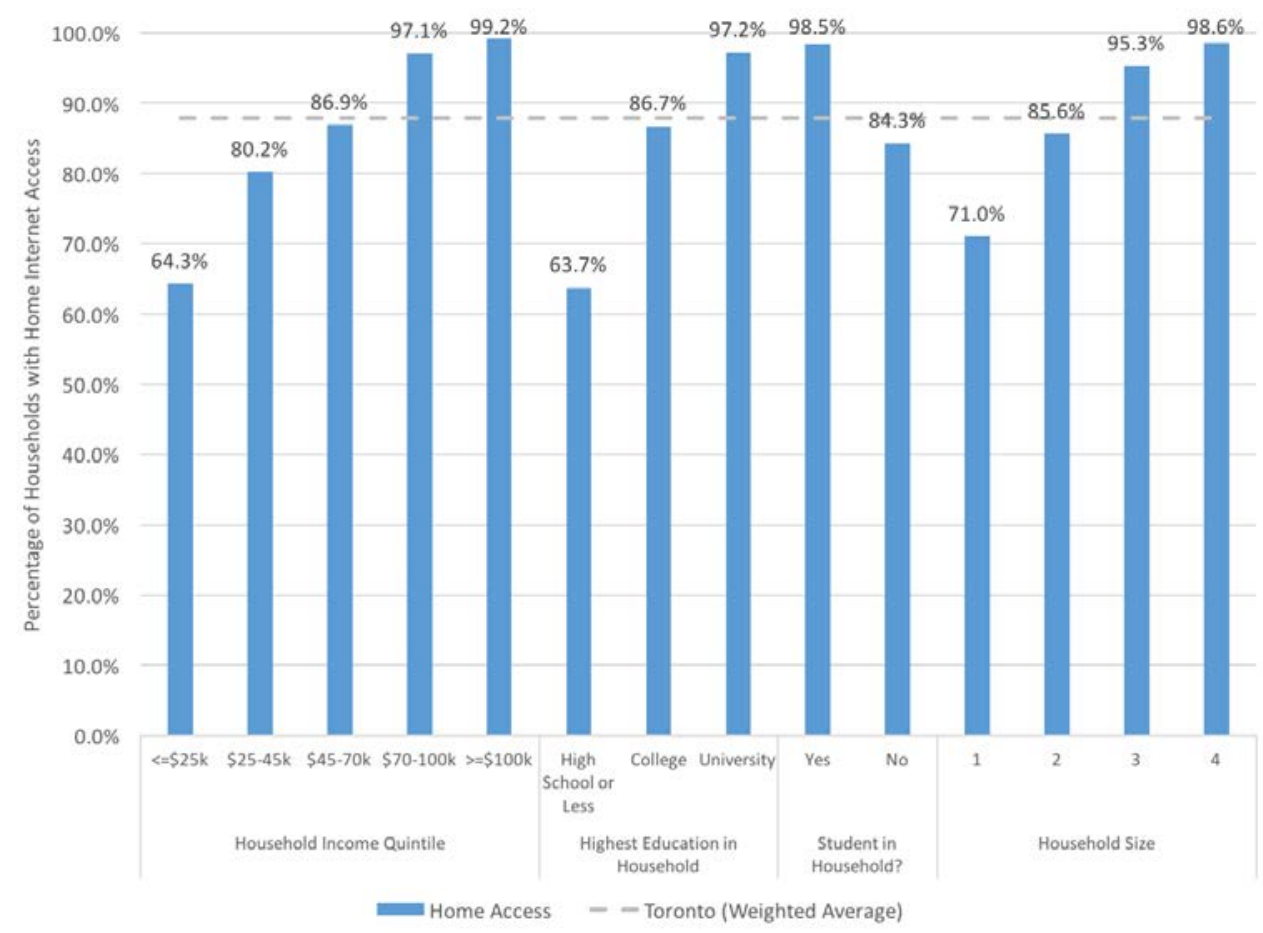

Figure 5.2-2. Home internet access in Toronto CMA households in 2012 by demographic characteristics.

\section{Personal Internet Use}

Internet access can also be examined through data for personal internet use from the 2012 CIUS Individual Component. Personal use data looks at issues of access on an individual level and includes access to the internet outside of one's home, such as at work, school and other locations.

Figure 5.2-3 below shows personal internet use in Toronto by demographic group. Similar to results regarding home access and from previous research, low rates of internet use are found in individuals with low education ( $64.7 \%$ of individuals with high school education or less use the internet) and individuals with low income (73.2\% of individuals in the lowest quintile use the internet). Internet use decreases with age, with only $51.1 \%$ of individuals aged 65 and over reporting personal internet use.

Based on a comparison of Figures 5.2-3 and 5.2-2, it appears that income may have less effect on internet use than home access. $64.3 \%$ of households in the lowest income quintile have home internet access compared to $99.2 \%$ of households in the highest quintile, while $73.2 \%$ of 
individuals in the lowest income quintile use the internet compared to $95.7 \%$ of the highest quintile. This would point to the presence of cost-related barriers preventing low-income households from obtaining home access, which some individuals compensate for by accessing internet through other means.

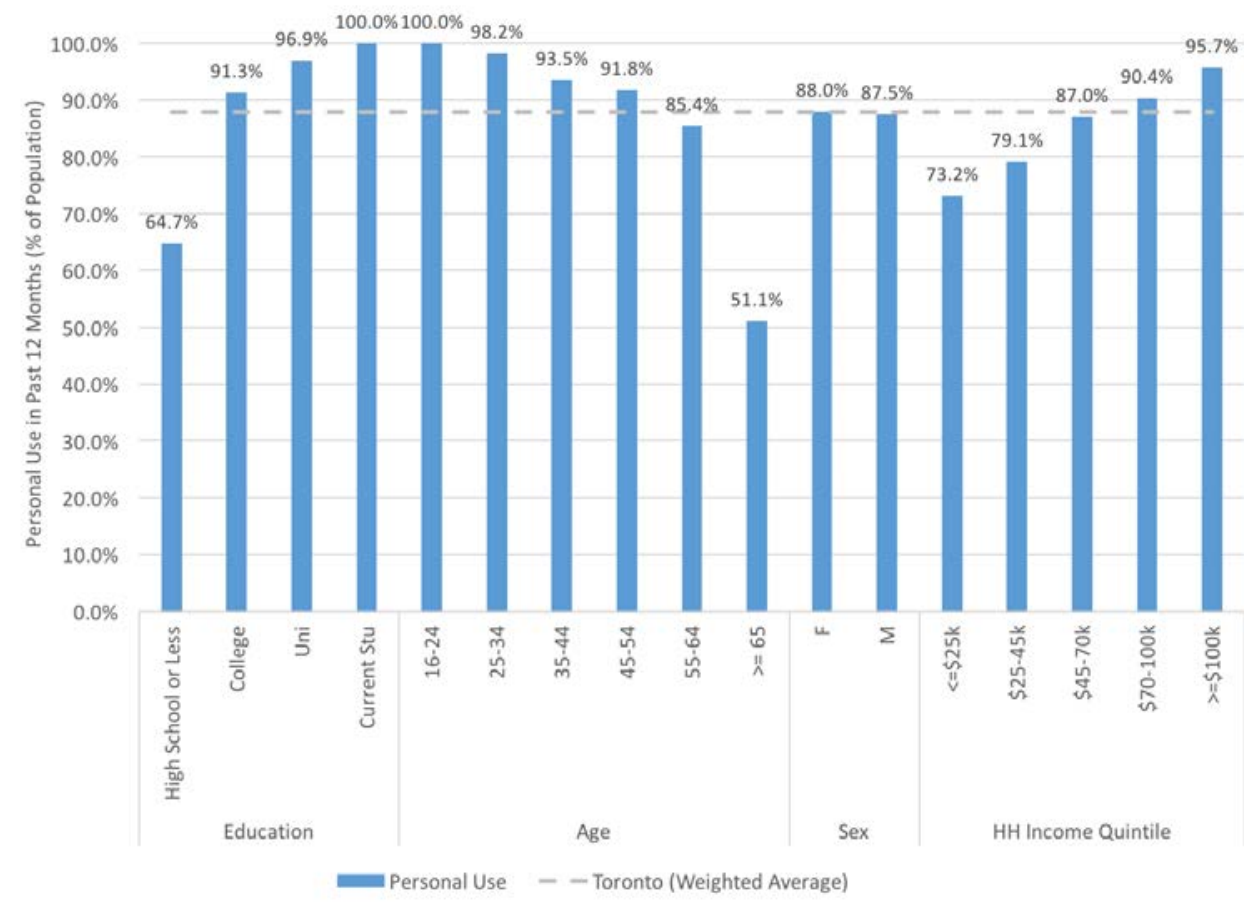

Figure 5.2-3. Personal use of the internet by individuals in Toronto CMA in 2012 by demographic characteristics.

\subsubsection{Quality of Access}

\section{Type of Connection}

One way to understand quality of access is to examine the technical infrastructure available for types of connections throughout the city. As Canada's largest urban area, Toronto generally has comprehensive coverage by fixed and mobile broadband networks with a few gaps.

Figure 5.2.1-1 below shows the coverage areas of both fixed and mobile internet in Toronto, based on data collected by the Government of Canada from internet service providers and updated on September 2016. Network coverage data is shown over a base layer of major arterials and population density by dissemination area. It should be noted that while this map 
shows the general coverage areas, it has not been verified on-the-ground and services may not be available in all households in the area.

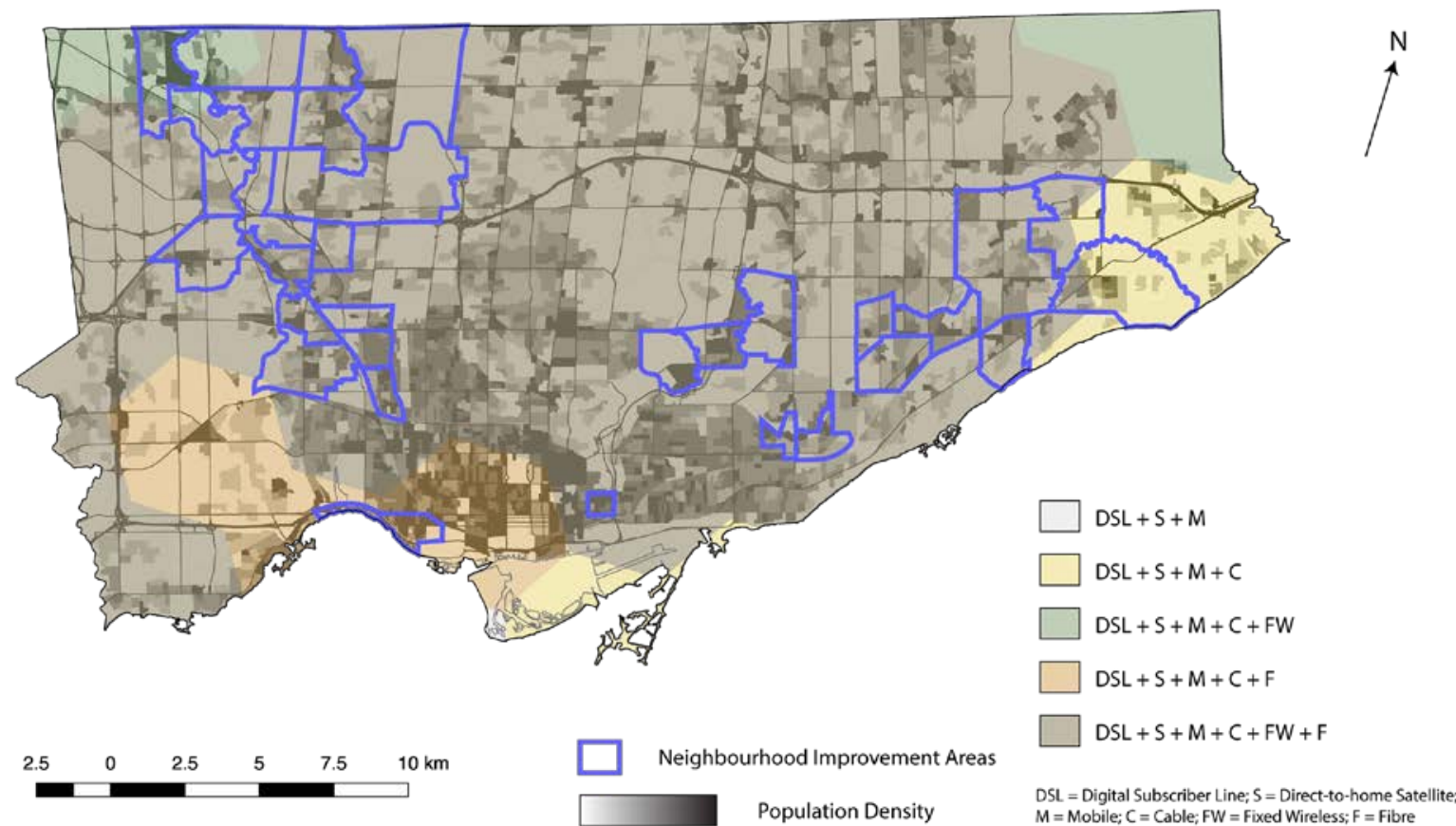

Figure 5.2.1-1. Internet service coverage areas in Toronto.

As displayed in Figure 5.2.1-1, all areas of the city have access to DSL, mobile, and satellite networks. Some areas, however, have less choice in access to other types of fixed broadband service. Of particular interest is areas that do not have access to fibre optic networks ${ }^{2}$, which delivers affordable broadband with faster speeds than DSL and cable technology. While some of these areas have little to no residents such as parts of Rouge Valley and Tommy Thompson Park, there are a few zones of higher population density in north Etobicoke and east Scarborough including parts of Neighbourhood Improvement Areas (NIAs).

While Figure 5.2.1-1 shows the technological availability of each network, their actual uptake by residents is unknown. The 2012 CIUS questionnaire results were found to be outdated and excluded new technologies such as fibre optic networks. The information of interest was collected in the SHS and the CRTC may have access to such data from subscriber information

\footnotetext{
${ }^{2}$ Figure 4.22-4 also shows that fixed wireless networks are not available in all areas of the city. This is of less concern as these networks are primarily higher-cost alternatives used only in areas with limited access to other networks.
} 
obtained from service providers. The availability of this information would help municipalities to understand where high quality access may be lacking, indicating areas where public internet access may be in high demand. Additionally, this information would allow planners and other municipal staff to understand if digital engagement and service delivery would be appropriate and what adaptations may have to be made. For instance, targeting a community that is heavily reliant on cellphone access would require mobile-friendly websites and applications that can be easily loaded with low bandwidth requirements on limited data allowances.

In the absence of readily available data regarding the quality of internet access in each household such as information about speed and bandwidth, there are some approximations that may be used. The Environics Analytics Household Expenditure Potential (HEP), which is based on SHS data and other demographic and income statistics, provides estimates for average household spending on internet access services by dissemination area (DA). Generally, higher average household spending in a dissemination area would suggest that residents in that DA subscribe to a higher level of service, and lower spending would indicate lower service levels or lower rates of connectivity. In this way, neighbourhood-level estimates for rate and quality of access were found for internet access spending in Figure 5.2.1-2. 


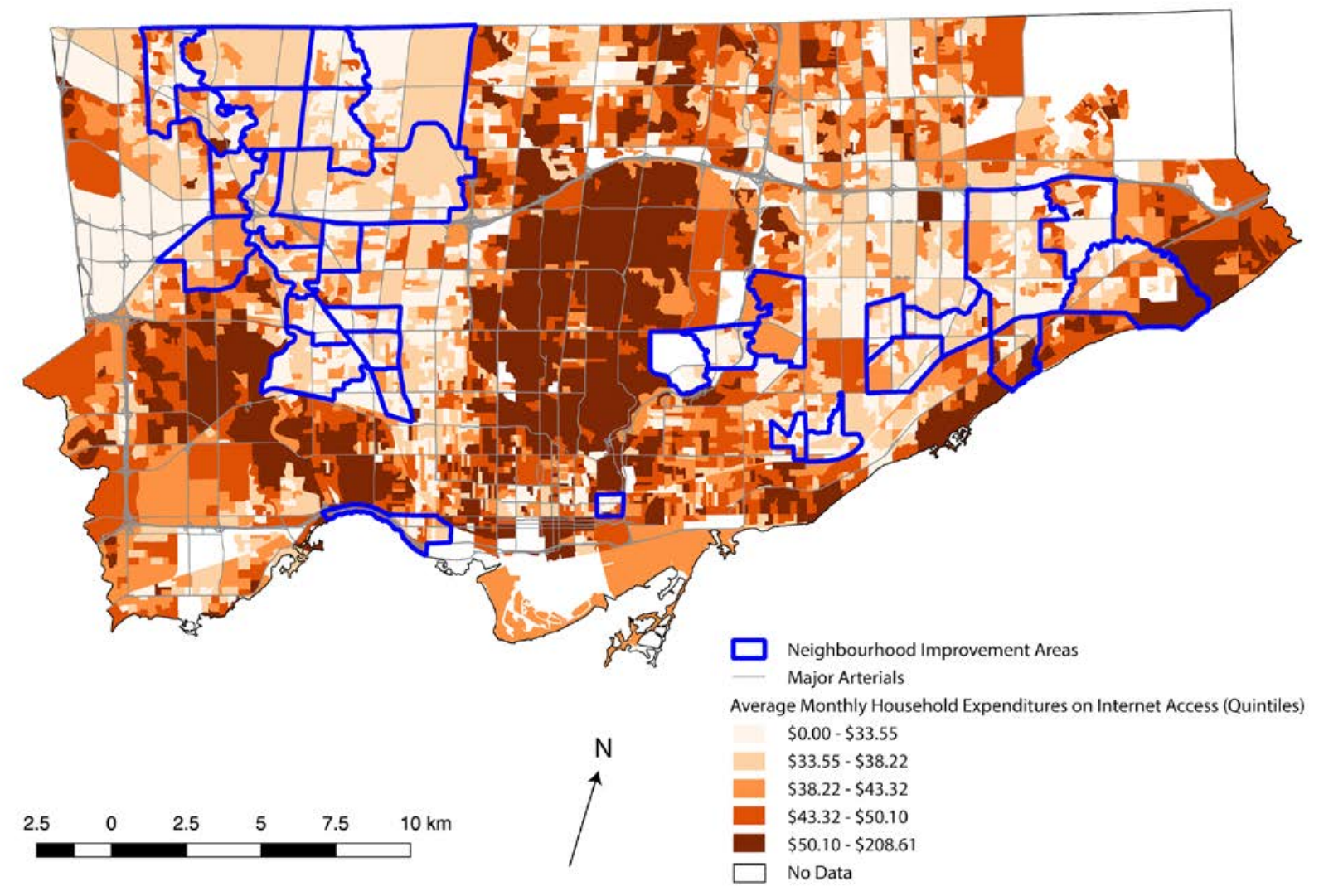

Figure 5.2.1-2. Average monthly household spending on internet access services by dissemination area, 2016.

Figure 5.2.1-2 shows that there is a heavy concentration of high internet access spending from Bloor Street to Highway 401 between the Don Valley Parkway and Allen Road, as well as in southern Etobicoke, the Beach and the Scarborough Bluffs. Pockets of high spending also exist in the western side of the downtown core and Rosedale, East York, northern North York and northern Scarborough. The general low level of spending is stark in the NIAs and some adjacent areas in central Scarborough and north Etobicoke. Unsurprisingly, this geographic distribution corresponds closely with income, as seen in a comparison with Figure 5.1.1-2.

\section{Mobile Access}

Figure 5.2.1-1 above showed that mobile broadband networks are available across the city via the four main providers: Bell, Rogers, Telus and Wind Mobile (now Freedom Mobile). This only represents broad coverage areas reported by telecommunications providers, however, and may 
not reflect actual performance. Some data regarding actual performance is available from a third-party source, OpenSignal. The mobile application uses crowdsourced data to map mobile network signal strength, using data collected from mobile devices that have downloaded the application. Figure 5.2.1-3 below shows OpenSignal's signal strength map for Toronto in the 9 months prior to February 2017 for 2G, 3G and 4G networks by the four major mobile internet providers. It finds strong signals for the downtown core and large areas of the suburbs. As the Google Maps base layer shows, poor signal strength is generally found within or in close proximity to natural areas including the ravines, Scarborough Bluffs, parts of the Toronto Islands, and Tommy Thompson Park.

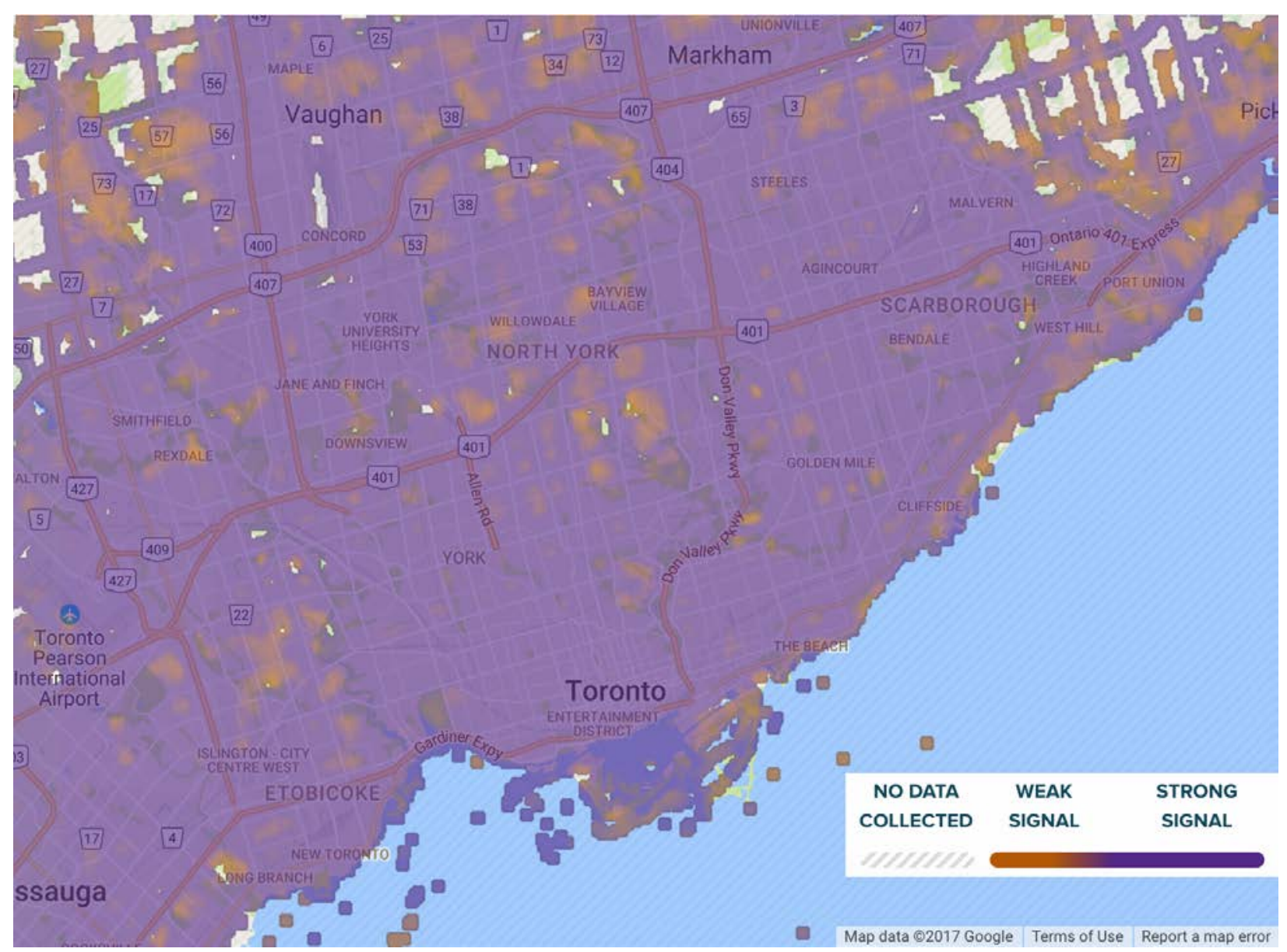

Figure 5.2.1-3. OpenSignal crowdsourced data for mobile network coverage in Toronto.

Like the mapping of internet access spending in Figure 4.23-2 to estimate quality of connection, Figure 5.2.1-4 below uses a similar methodology for cellphone service expenditures. The areas 
of high and low spending revealed are generally similar to the findings for internet access above.

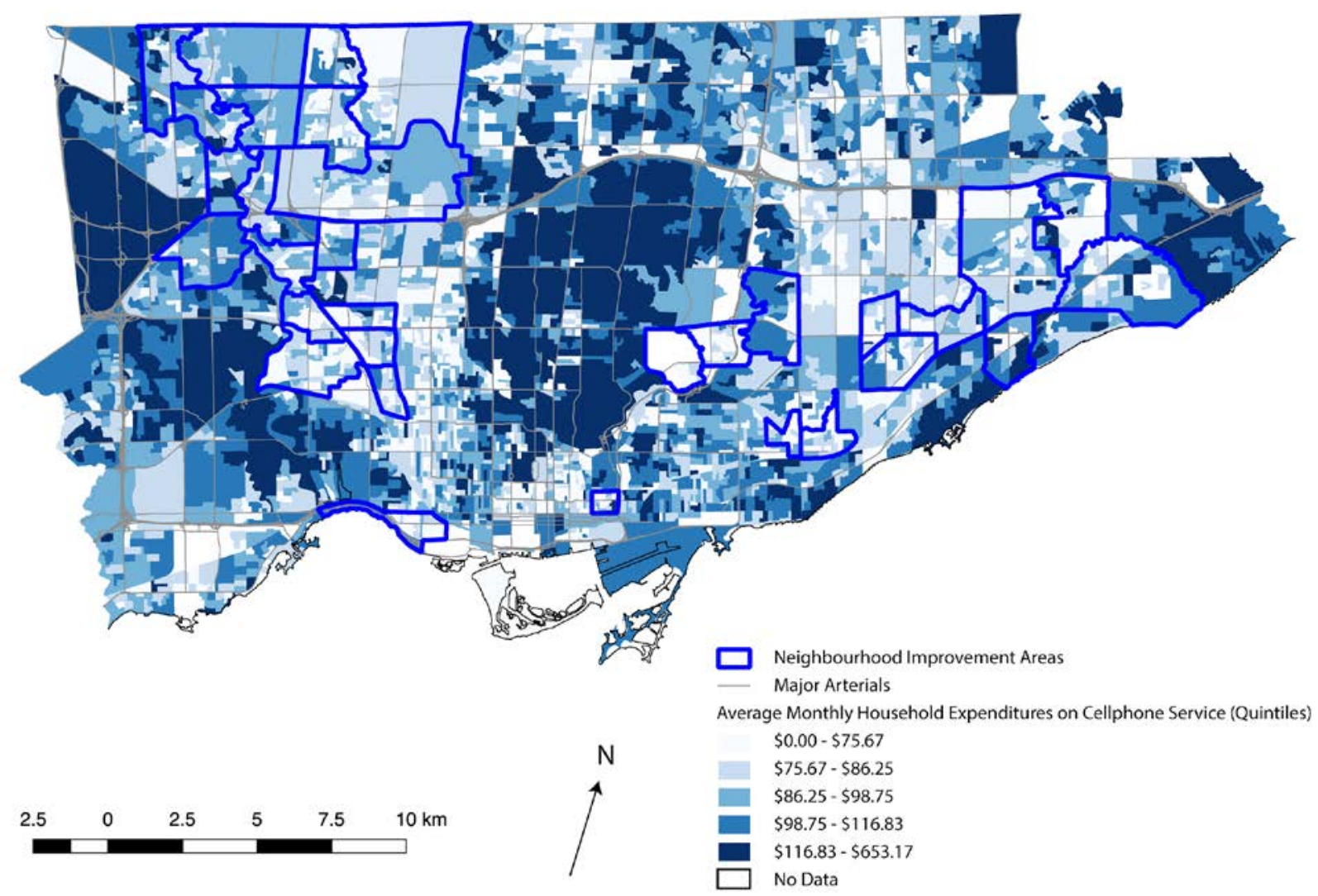

Figure 5.2.1-4. Average monthly household spending on cellphone services by dissemination area, 2016.

\section{Equipment for Internet Access}

With regards to the equipment required for internet access, Figure 5.2.1-5 shows the results from the 2012 CIUS for devices used to access the internet at home. It should be noted that these results reflect device use by any member of the household, and only encompass internet use at home. In Toronto households that have access to the internet, $60.2 \%$ used desktop computers, $80.3 \%$ used laptop computers, $25.6 \%$ used video game consoles and $65.9 \%$ used a mobile device. 


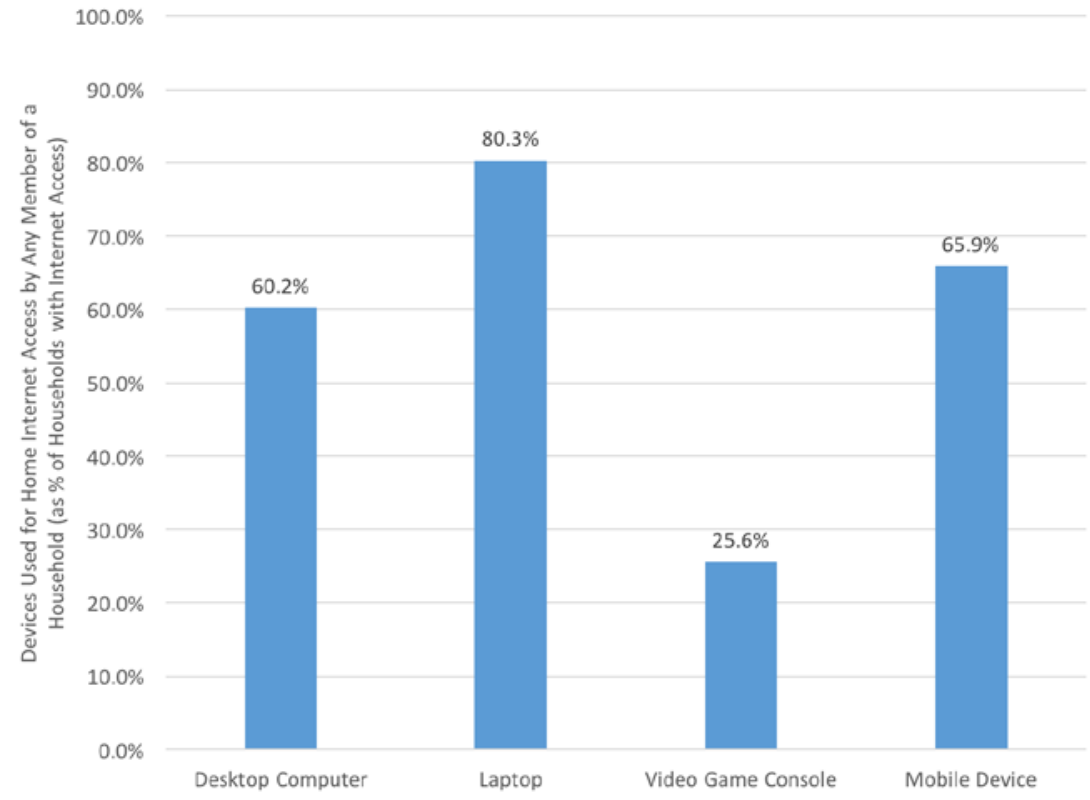

Figure 5.2.1-5. Devices used by Toronto households to access home internet in 2012.

Breaking down device availability in households by demographic groups reveals generally similar inequalities as findings from home internet access, and a summary of these proportions may be found in Appendix 8.2. In general, availability of each device increased with income, education and household size, and households with students are more likely to have used each device than households without students. As all of these households must have at least one device to access the internet, the implication of these results is that some households have more devices to access the internet than others. Data from SHS would be able to supplement this finding, but is not currently publicly available.

\subsubsection{Location of Access}

Figure 5.2.2-1 graphs the locations from which internet users in Toronto have accessed the internet, showing that home, mobile, and work were the most popular locations of access. 


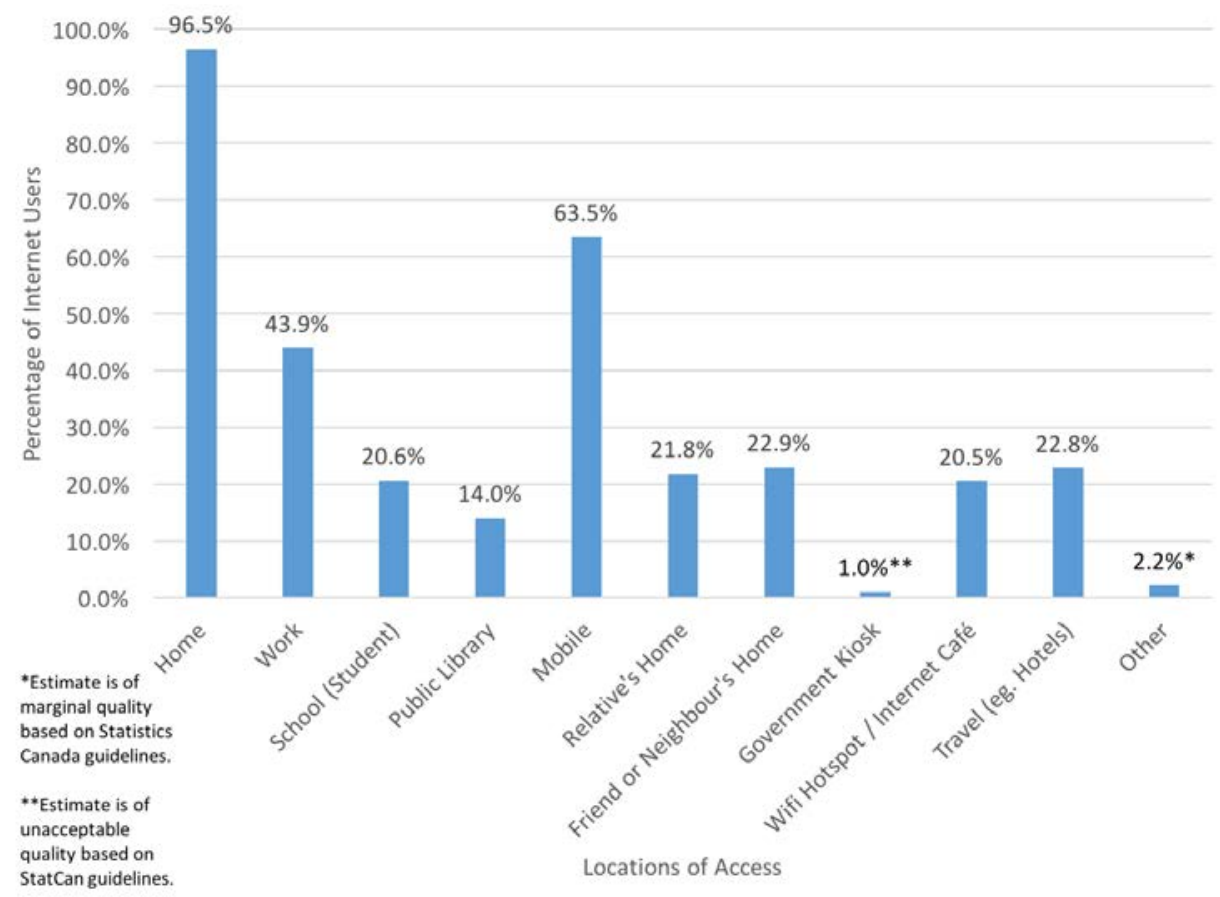

Figure 5.2.2-1. Locations of internet access for internet users in Toronto CMA in 2012.

Because of the access services provided by the Toronto Public Library, the rates of internet access at the public library were examined in greater detail in Figure 5.2.2-2. While some estimates are of poor quality because of small sample sizes, general trends can still be seen. Based on education and age, internet use in public libraries appear to follow the same trends as for home access and personal use.

With regards to income, however, it appears that lower income quintiles used public library access more than higher income quintiles. Together with the previous finding that income seems to be less of a factor in determining personal use than home access, this would suggest that low-income individuals are making use of the public library to make up for cost-related barriers preventing them from having home access. Comparatively, the lower rates of internet access at public libraries for other groups with low access rates, namely individuals with lower education as well as seniors, seem to indicate that factors other than cost play a bigger role in their lack of access, such as attitudes or time. 


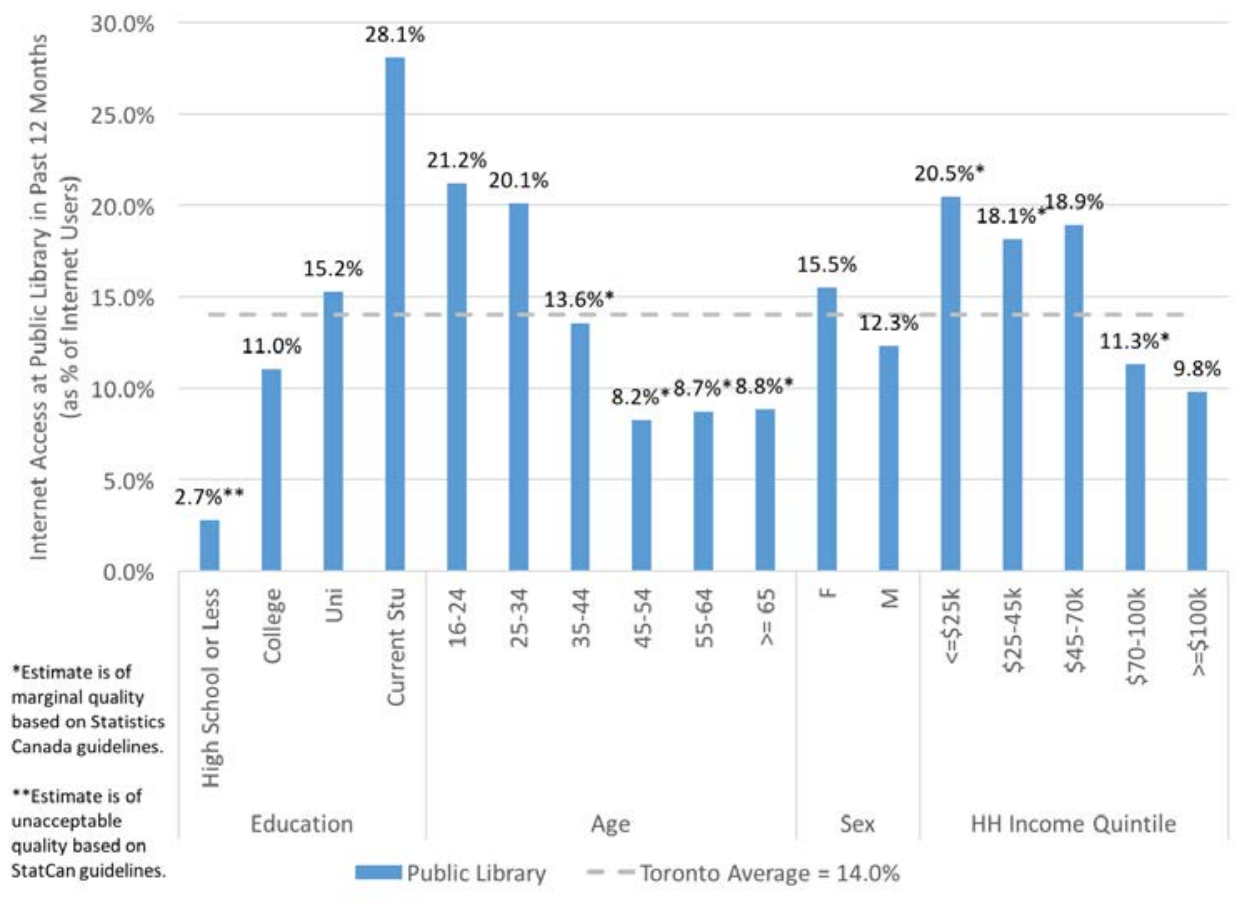

Figure 5.2.2-2. Internet access at public libraries across demographic groups in Toronto CMA, 2012.

\subsubsection{Affordability}

\section{Cost of Internet}

With generally good network coverage in Toronto (refer to Figure 5.2.1-1), affordability of internet service becomes an important factor in determining digital access. In a CRTCcommissioned report, Nordicity (2016) outlines the average prices for fixed and mobile broadband plans, grouped into service "buckets"3. Prices for service bucket level 1 (entry-level or low-volume usage) and level 2 (average or medium usage) in Toronto and other Canadian and international cities are shown in Figures 5.2.3-1 for fixed broadband and Figure 5.2.3-2 for mobile broadband.

\footnotetext{
${ }^{3}$ Service level "buckets" are defined as follows:

Fixed broadband level 1: Speeds of 3-9 Mbps, $10 \mathrm{~GB}$ data usage per month Fixed broadband level 2: Speeds of 10-15 Mbps, $50 \mathrm{~GB}$ data usage per month Mobile broadband level 1: 2-5 GB data usage per month Mobile broadband level 2: 5-10 GB data usage per month
} 
For each data point, the lowest prices in the service bucket were collected from all service providers and averaged. In 2016, the average lowest cost for fixed broadband service in Toronto was $\$ 33.63$ per month for basic plans and \$61.92 for average plans. The average price for mobile broadband in Toronto was $\$ 46.53$ for level 1 services and $\$ 63.19$ for level 2 services.

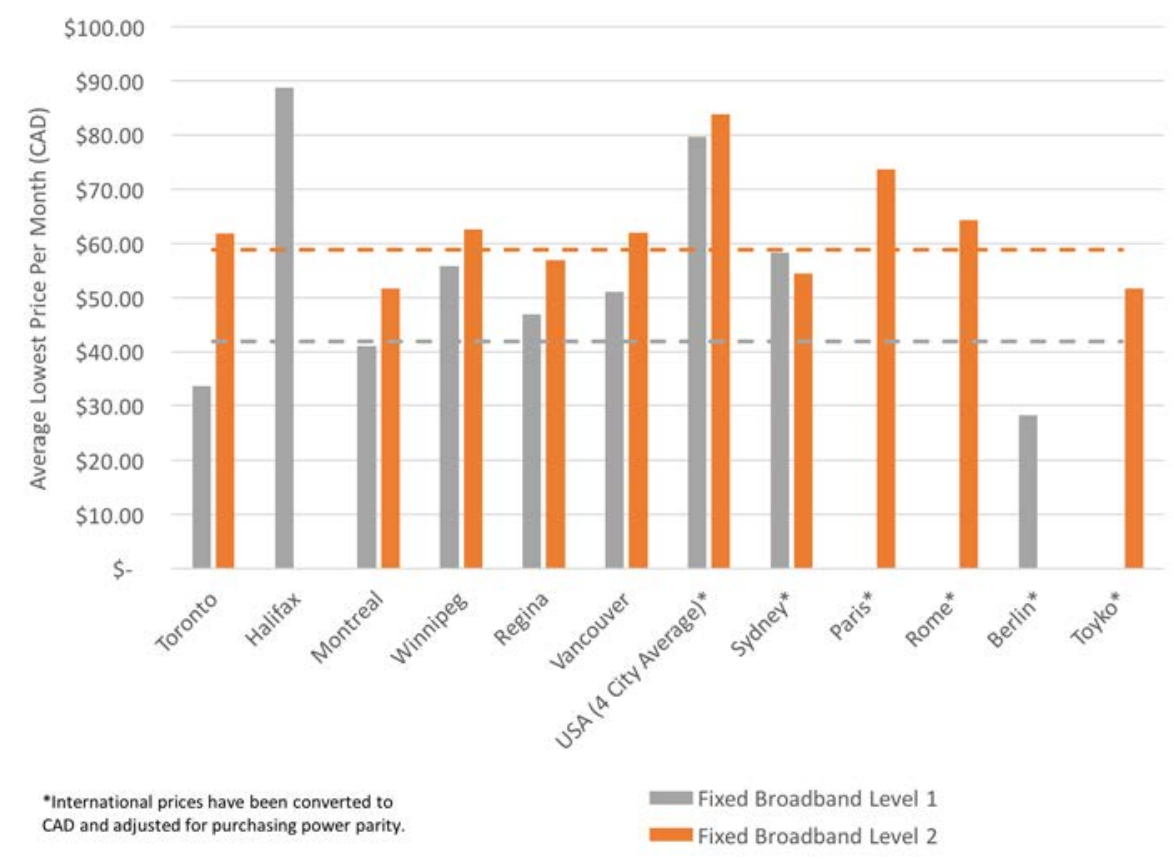

Figure 5.2.3-1. Toronto's fixed broadband prices in comparison to Canadian and international cities in 2016.

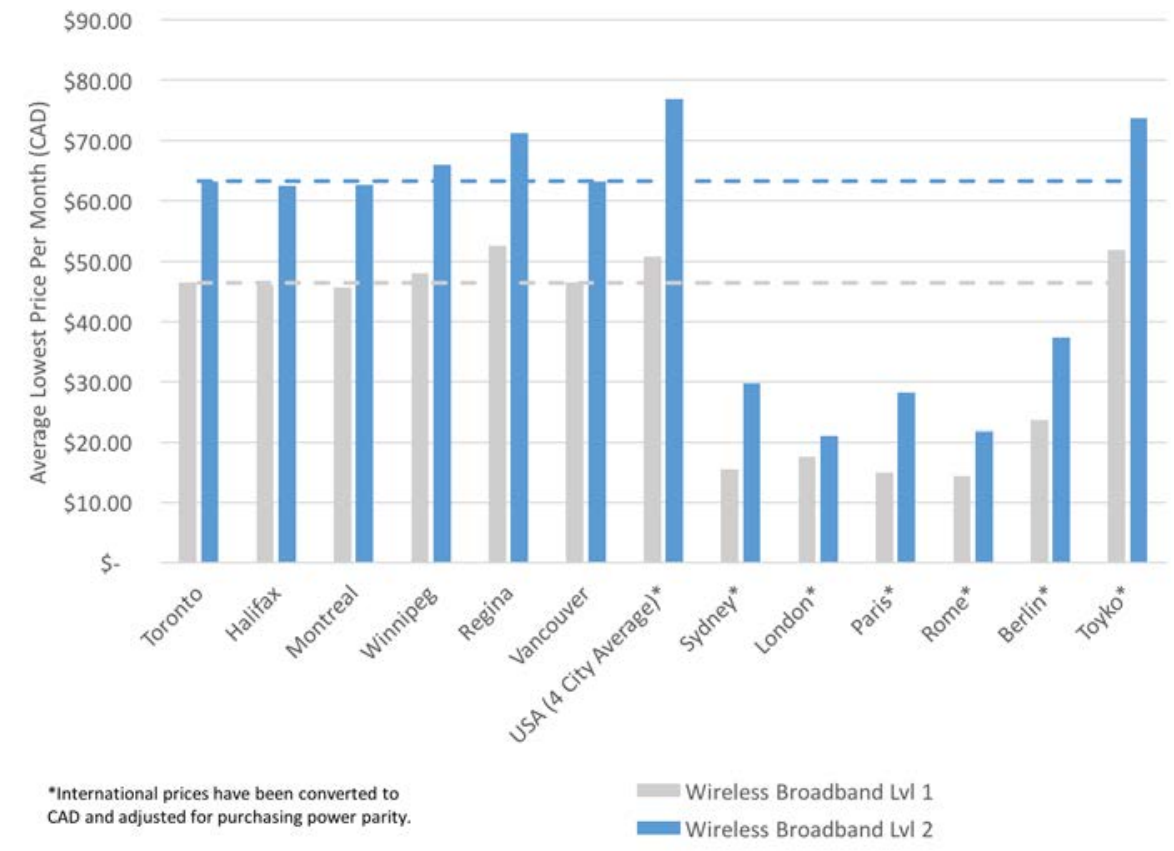

Figure 5.2.3-2. Toronto's mobile broadband prices in comparison to Canadian and international cities in 2016. 
In comparison to other Canadian cities, Toronto is on the lower end of the spectrum for prices for level 1 fixed broadband services and levels 1 and 2 mobile broadband. Prices are above the Canadian average for level 2 fixed broadband services. When compared to international cities, fixed broadband prices were found to be comparable but residents of Toronto paid significantly higher prices for mobile broadband than residents of several other major cities. With data from both Canada (CRTC, 2016) and the United States (Pew Research, 2015) showing that lower income individuals are increasingly relying on mobile phones for internet access, sometimes as their sole internet connection, this high cost is a cause for concern, particularly as a single household may require multiple cellular connections unlike the case for fixed broadband service.

Household Telecommunications Spending

In addition to data for the current year, Nordicity's (2016) report also summarized the price of broadband over the past few years. A caveat of this analysis, however, is that the service levels at which the buckets were defined were fixed over time even though technology has changed during this time period, driving the requirement for greater speed and bandwidth to access online applications and services. This means that a broadband plan that was considered as high volume five years ago may only be considered basic today, even though the absolute value of speed and bandwidth is the same.

In CRTC's 2016 Communications Report, data from Statistics Canada's Consumer Price Index (CPI) and SHS were used to better reflect the true cost of telecommunications services. For a Toronto-specific analysis in the absence of access to current SHS microdata files, the Environics HEP was used. Figure 5.2.3-3 demonstrates the growing burden of telecommunications spending on households, with large increases in estimated household spending on internet access and cellphone services from 2010 to 2016 . On average, monthly spending on cellphone services rose $15 \%$ a year in Toronto and in Canada. Average monthly spending on internet access increased by $10 \%$ a year in Toronto and $7 \%$ a year in Canada. The average household spending on internet and cellphone services is higher in Toronto than in Canada overall, and may be growing at a faster rate. 


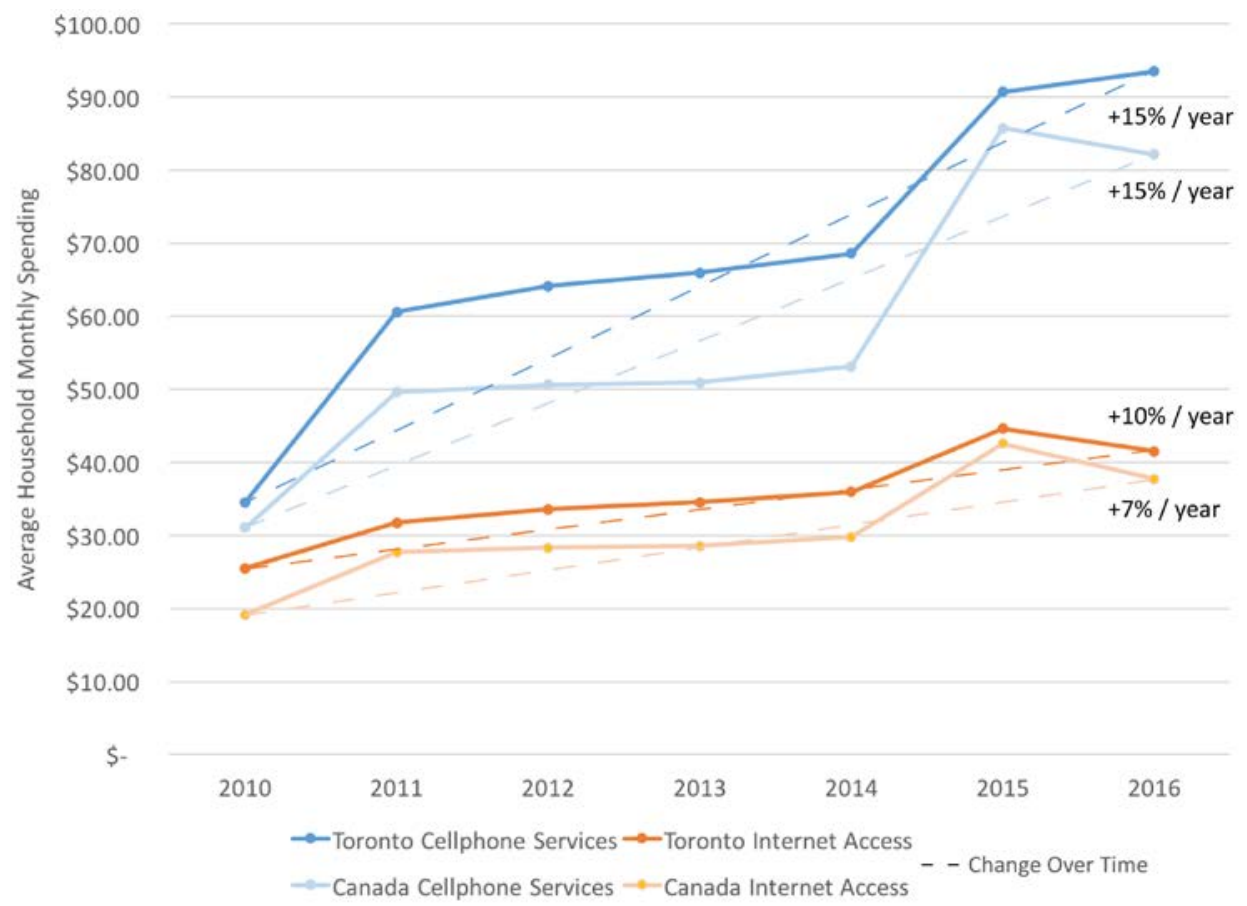

Figure 5.2.3-3. Average household spending on cellphone and internet access services over time in Toronto and Canada.

In particular, households with lower incomes spend a disproportionate amount of their income on internet access and cellphone service. The ratio of average annual internet and cellphone service expenditures to the average household income was calculated for DAs in Toronto. While the methodologies used for estimating expenditures and income were different so that these ratios do not represent actual budgets, they can be used to compare the relative financial burdens across income levels. Figure 5.2.3-4 shows that low-income DAs had higher expenditures than high-income DAs relative to their incomes, similar to CRTC's (2016) findings for all Canadians in 2014 based on the SHS. Note that Figure 5.2.3-4 excludes DAs with average household incomes that are more than three standard deviations above the average (\$390,000 or higher) to give clearer visualization of the majority of DAs. 


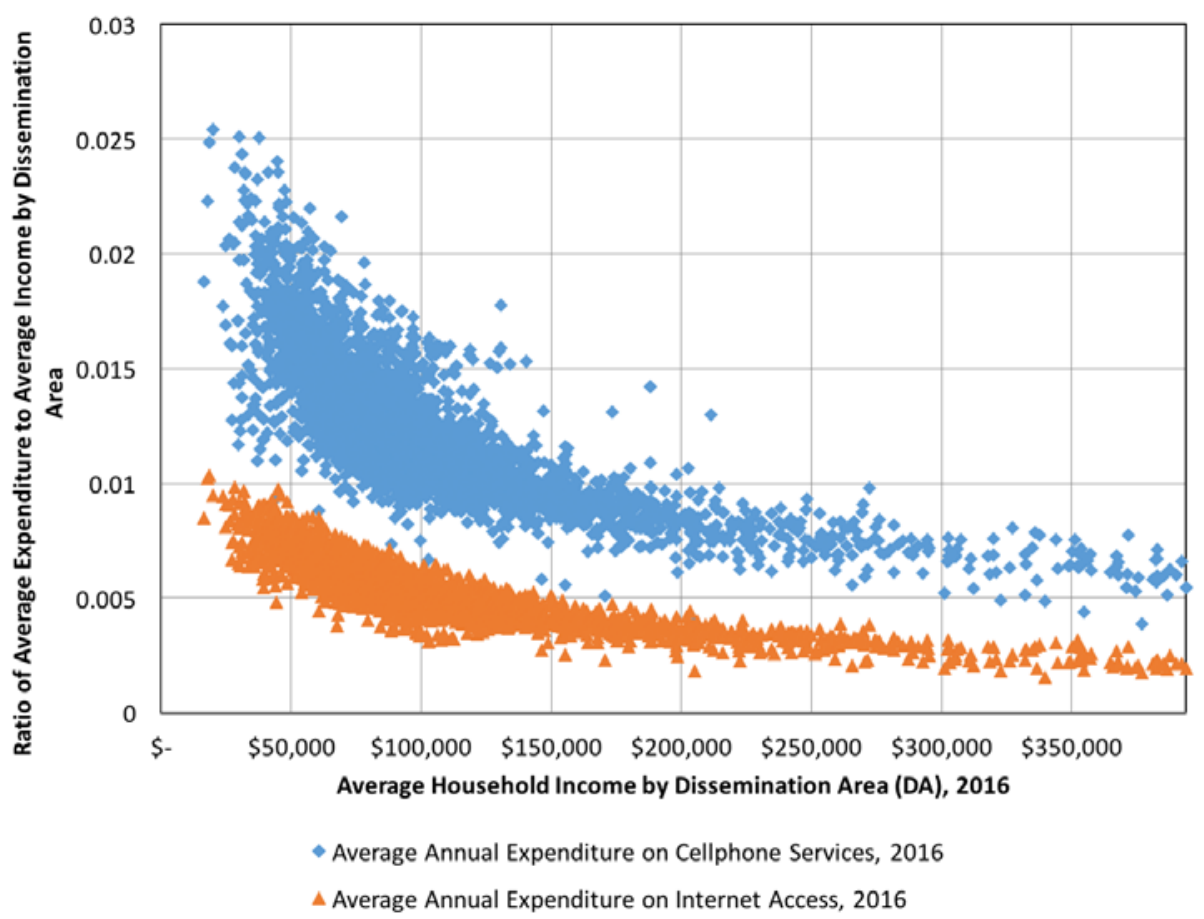

Figure 5.2.3-4. Spending on cellphone and internet services relative to income in Toronto, 2016.

Finally, equipment for digital access also require significant spending by users and may impact the ease and experience of connectivity. SHS 2013 data on average annual expenditures on some of these equipment is available for Toronto as whole (City of Toronto, 2015c), and is displayed in Figure 5.2.3-5. In 2013, residents of Toronto spent an average of \$222 on computer hardware, $\$ 87$ on tablet computers and $\$ 80$ on mobile communications equipment.

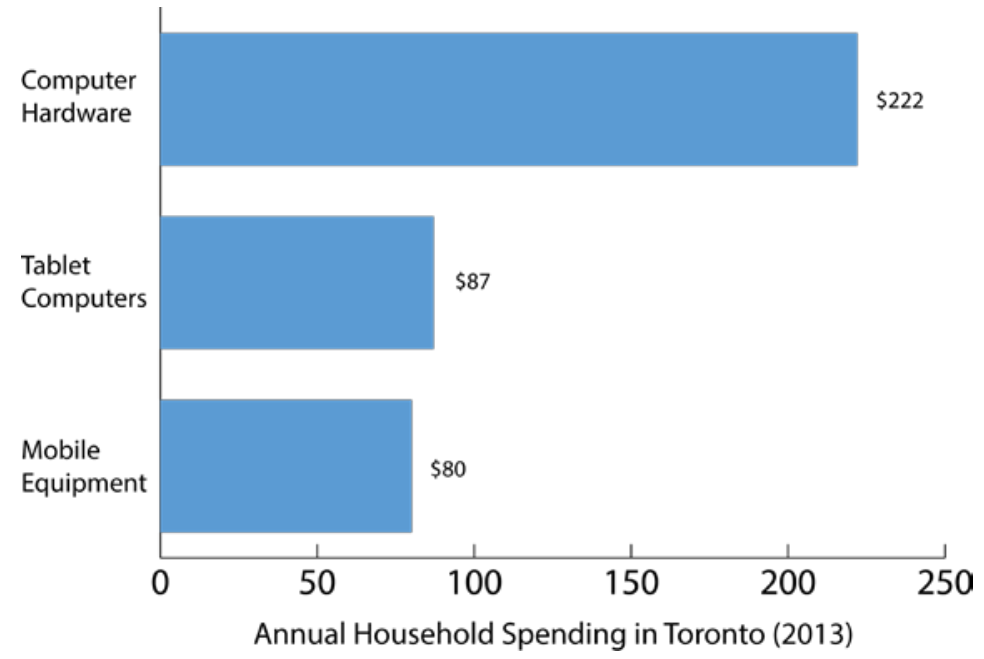

Figure 5.2.3-5. 2013 Survey of Household Spending results for annual spending on computer and mobile phone equipment in the city of Toronto. 


\subsection{Usage Activities}

The 2012 CIUS surveyed participants on the use of 22 online activities. For a general sense of the level of online activity of different demographic groups in Toronto, responses for these activities were aggregated into a count of the number of reported activities based on Haight et al.'s (2014) methodology. Figure 5.3-1 shows the presence of a usage activities divide in Toronto along familiar lines of education, age and income, with a weighted average of 11.9 activities for all of Toronto. Men were also found to have used the internet for more activities than women, revealing an additional divide that was not seen when examining connectivity or personal internet use.

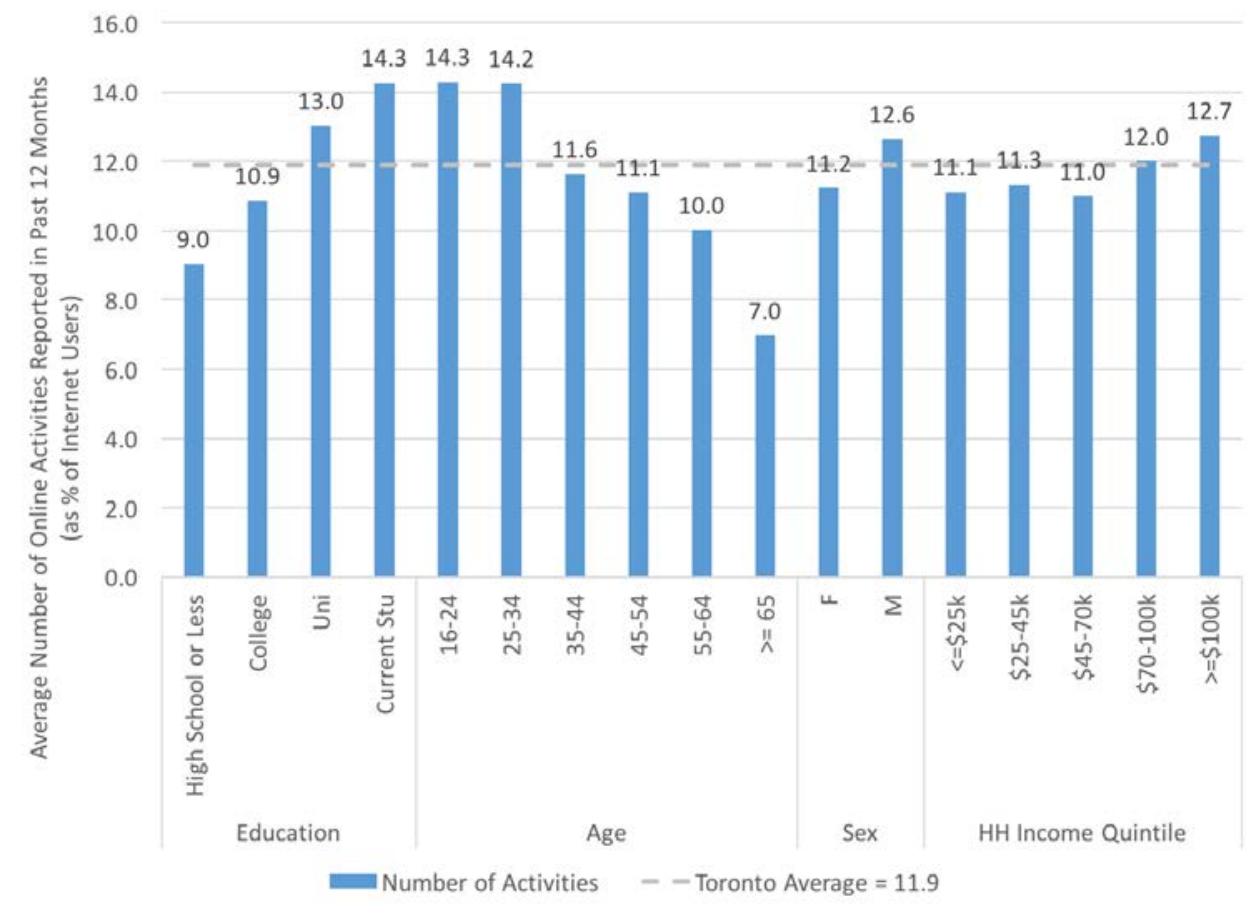

Figure 5.3-1. Level of online activity by demographic groups in Toronto CMA, 2012.

For a detailed examination of the specific activities reported by Torontonians, 4 activities were chosen based on the interests of planners in digital inclusion. The use of the internet to search for employment was chosen as it represents a direct impact on socioeconomic outcomes. The use of government websites may be used as a measure of the reach of current digital government initiatives, and social media is chosen as it represents another platform for 
emerging communication between governments and citizens. Finally, the use of internet to search for community events is used as an indicator of civic engagement.

Figure 5.3-2 shows online job search rates across all segments of the population, finding very high rates in current students and youth. Lower income quintiles are also more likely to search for employment online than higher income quintiles, a finding that aligns with some previous research and lends itself to the hypothesis that lower income individuals use the internet to overcome the lack of traditional connections to economic opportunities (Mossberger et al., 2003).

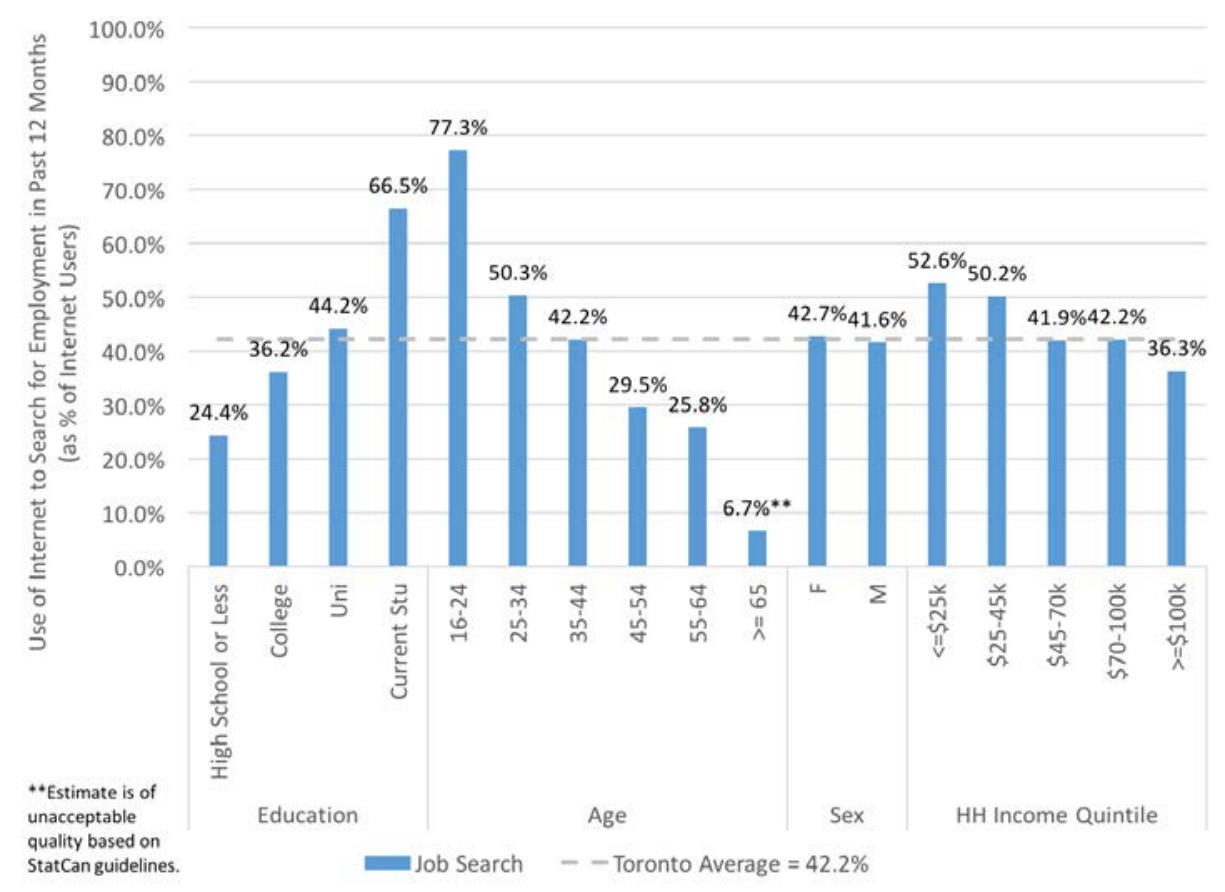

Figure 5.3-2. Use of the internet to search for employment across demographic groups in Toronto CMA, 2012.

Figure 5.3-3 shows that a relatively large percent of Torontonians have visited government websites in the past 12 months, at 66.8\%. Educational divides are again apparent for this activity. Use of government websites decreases with age, although individuals aged 25-34 appear to have slightly higher rates of use than those aged 16-24. Government website use also seems to generally increase with income levels although individuals in the second lowest income quintile access government websites more than expected following this trend. Inequality along gender lines is also seen for this activity, with men being more likely to visit government websites than women. 
This type of demographic data regarding usage of online government platforms is especially important for planners and government staff to have when making decisions regarding using the internet as a form of outreach. As website visits are generally anonymous, surveys like the CIUS provide insight on who the audience is, allowing for efforts to both target engagement towards specific populations as well as to seek groups who are not represented on these platforms.

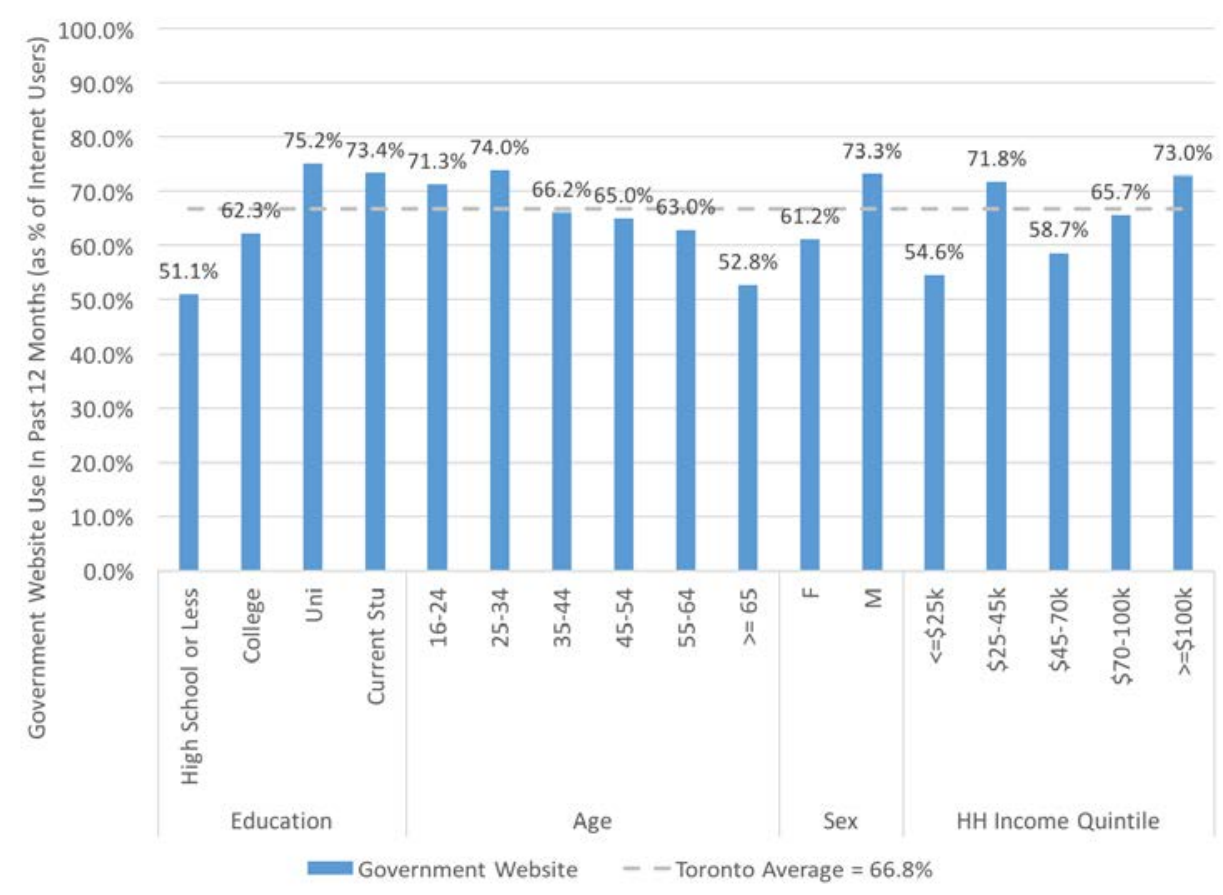

Figure 5.3-3. Use of government websites across demographic groups in Toronto CMA, 2012.

The use of social networking sites in Toronto in 2012 follows closely with access rate trends regarding education and age. In particular, the distribution of use across age groups is greatly skewed towards the younger end of the spectrum, which provides support for attempts to engage younger demographics through these sites. Meanwhile, there is little difference in social media use based on gender or income. The finding regarding income aligns with previous research by Haight et al. (2014), and provides opportunities for creating more equitable forums for public engagement by leveraging social media. 


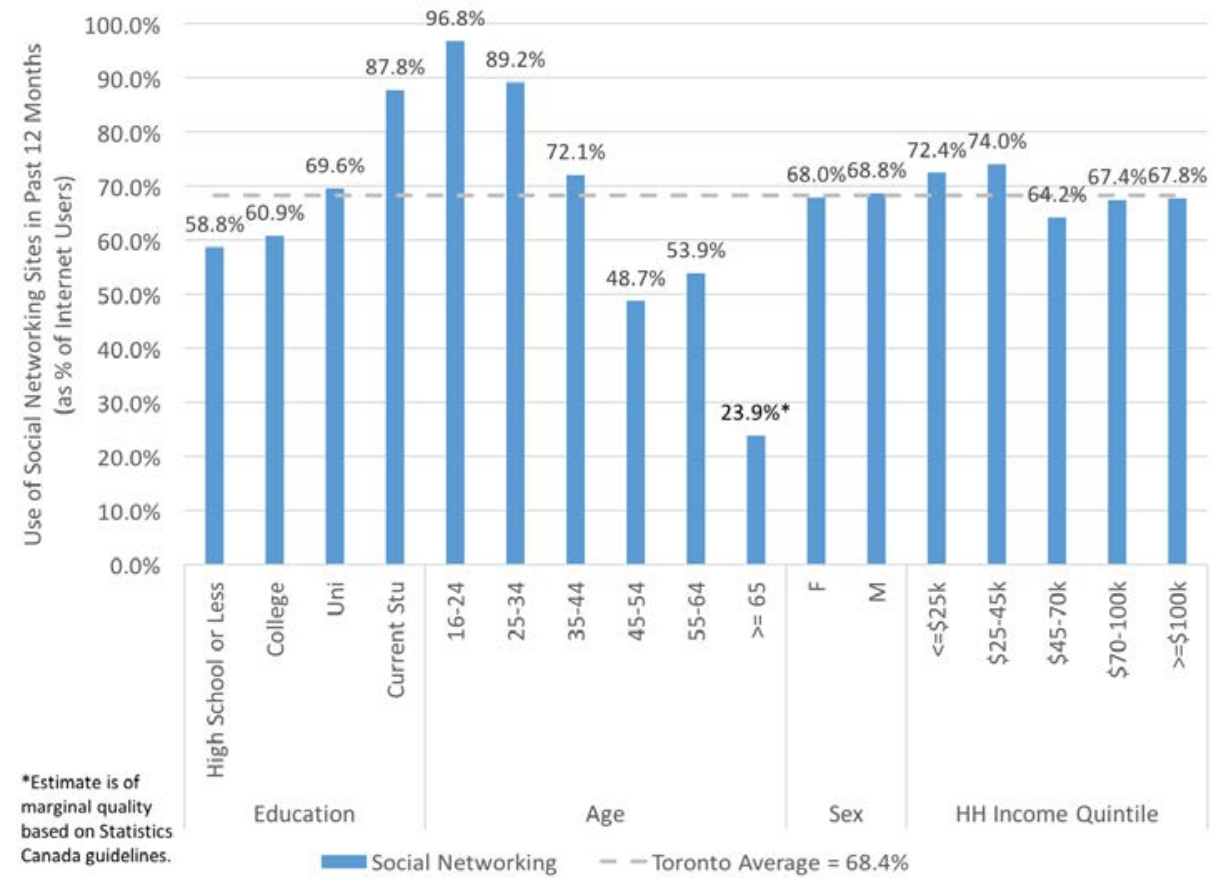

Figure 5.3-4. Use of social networking sites across demographic groups in Toronto CMA, 2012.

Finally, Figure 5.3-5 shows the use of the internet to research community events, which can be analyzed as one indicator of civic engagement. Again, inequality based on education level is apparent, and general trends may be seen regarding age and income level. Interestingly, the age group of 25-34 years is more likely to research community events on the internet than other age cohorts including the youngest cohort of 16-24 years. Along with the similar result regarding use of government websites in Figure 5.3-3, this finding suggests that this age group is the most likely to use the internet to engage with their communities online, followed by individuals aged 16-24 as the second most likely age group. These findings provide support for efforts by planners and governments to use online platforms to reach younger audiences who are typically less engaged in offline engagement processes. 


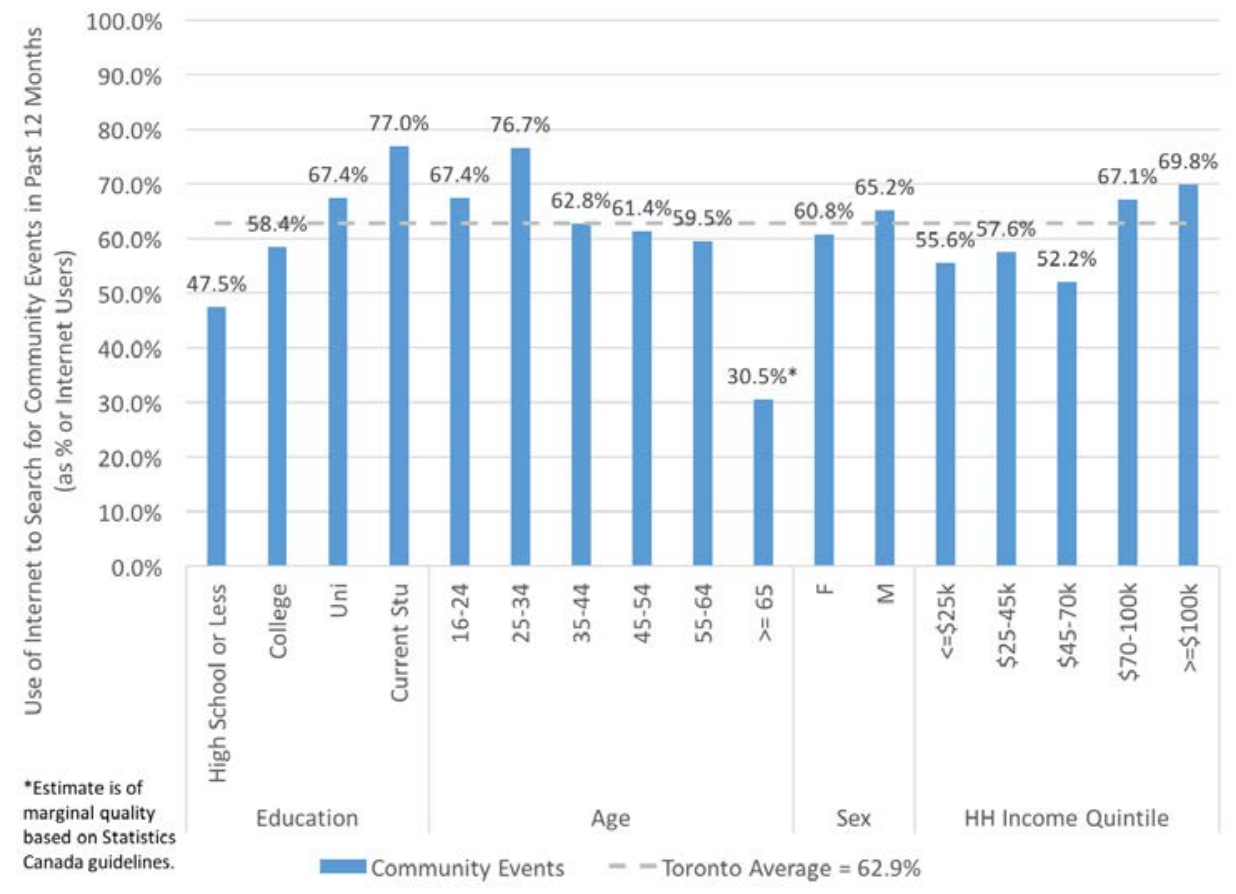

Figure 5.3-5. Use of the internet to research community events across demographic groups in Toronto CMA, 2012.

In summary, examination of trends across these four online activities find individuals with low education levels and elderly individuals as the most consistently digitally excluded. When developing digital engagement and governance processes, planners and policymakers need to be aware of their lack of effectiveness in reaching these populations and find alternative methods of engaging these groups. The digital inequalities along educational levels is of particular concern as it may be both one presentation of broader social and economic inequities, as well as a factor in further exacerbating these offline inequities. They represent a group who should be targeted in efforts to more equally distribute resources and opportunities, including in the digital realm.

On the other hand, the relatively greater online activity levels in individuals of low income and youth are a positive finding for digital engagement and governance initiatives. It suggests that online techniques create more equitable opportunities for these groups who are generally less likely to participate in offline engagement processes.

Examining the intersections between income and education may provide useful insights as to the reasons for the discrepancy between these two variables on online activity levels. This 
analysis is not conducted using CIUS results, however, because small sample sizes limit the meaningfulness of any findings. This is an area where further research is recommended by more targeted surveys, interviews or workshops. The CIUS PUMF dataset also has major gaps relating to neighbourhoods, ethnicity and immigration status. The intersection of these variables with education and income is another area where more study is needed.

\subsection{Attitudes}

For respondents who indicated that they do not have home internet access or use the internet for personal uses, the 2012 CIUS questioned them as to the reasons for the lack of access or use. Figure 5.4-1 shows the reasons given by respondents for not having home access, and Figure 5.4-2 shows the reasons for not using the internet.

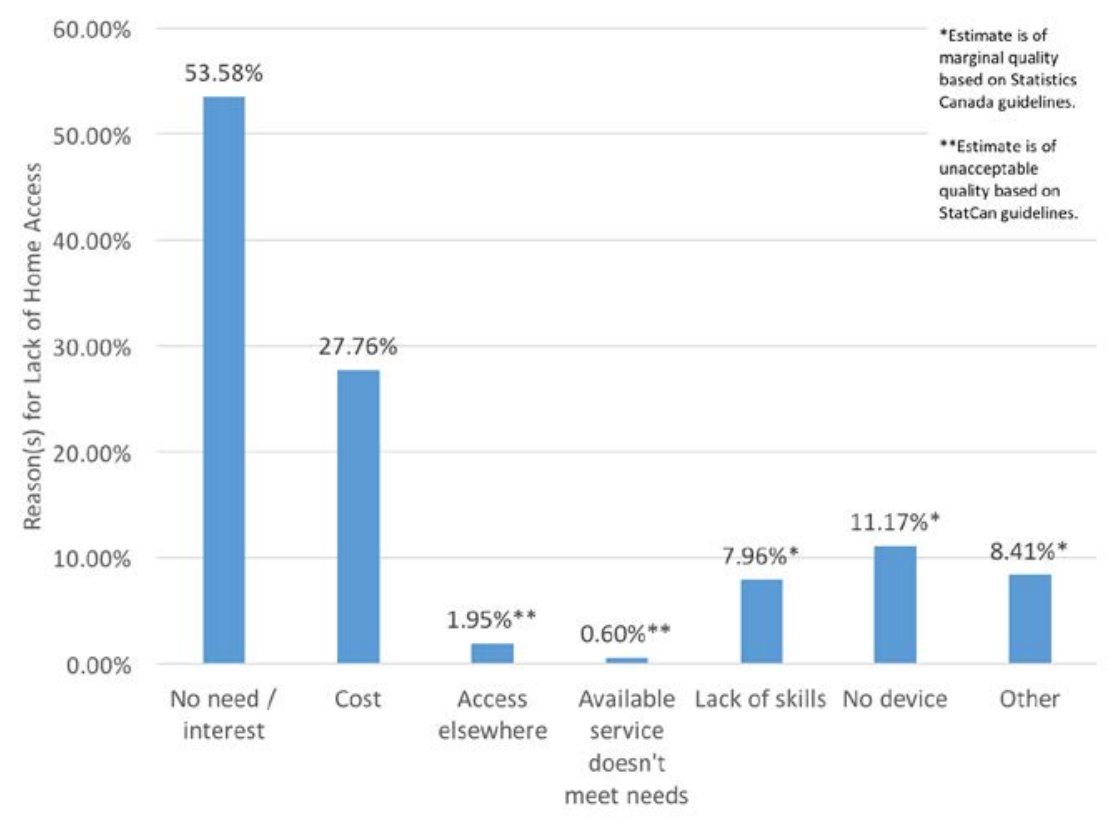

Figure 5.4-1. Reasons for not having home internet access in Toronto CMA, 2012. 


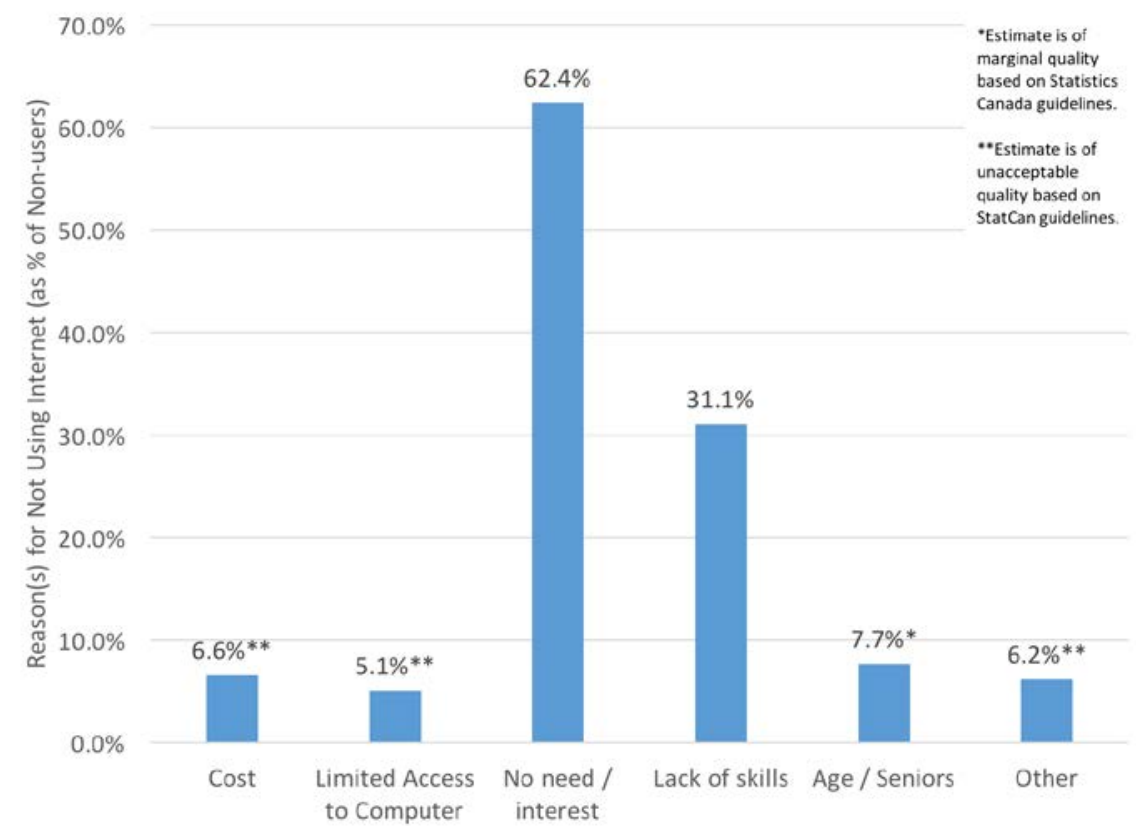

Figure 5.4-2. Reasons for not accessing the internet for personal use in Toronto CMA, 2012.

Figures 5.4-1 and 2 show that lack of need or interest is a major barrier to not having home internet access or not using the internet. Cost also represents a major barrier for households without home access, but play a less significant role for individuals who do not use the internet. This further suggests that individuals lacking home access due to affordability concerns are able to obtain access elsewhere, though the quality of this access is uncertain. Meanwhile, lack of skills is a major concern for individuals who do not use the internet, suggesting that there is significant demand for digital literacy programs. Comparing these barriers by demographic groups may reveal additional insights, but this analysis was not conducted on the CIUS data because of uncertainty regarding the meaningfulness of results due to small sample size.

Additionally, the data only reflects the barriers of people who do not have home access or do not use the internet. It does not look at the attitudes of people who do have access or use the internet, and how those attitudes may influence the quality of their connections or their usage patterns. Future research in this area could provide insight on the needs and challenges for people who do access the internet but may vary in the quality of access, skill levels, amount of use, and other variables. 


\subsection{Programs: Toronto Public Library}

The Toronto Public Library (TPL) currently has 100 branches throughout the city as mapped in Figure 5.5-1, all of which have access to computer workstations and wireless internet connections. In addition, there are also other digital internet services available at some branches. There are 17 Computer Learning Centres that offer digital literacy courses, including one-on-one sessions. Digital Innovation Hubs with 3D printing, design, recording studios and other equipment are available at 3 branches. A pilot wifi hotspot lending program is in place at 6 branches, where wifi hotspots can be borrowed for 6 months as an initiative to counter costrelated barriers to internet access.

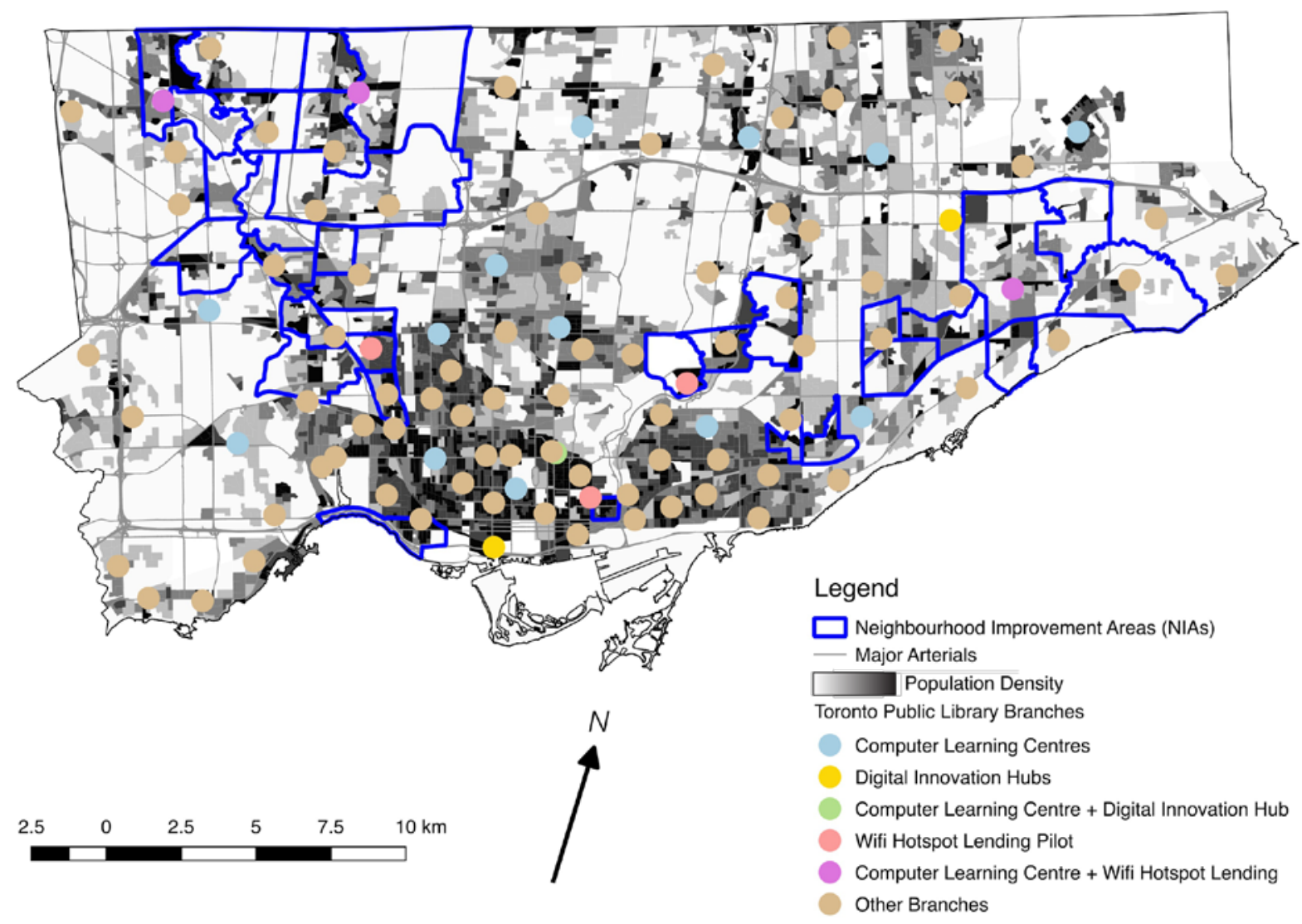

Figure 5.5-1. Toronto Public Library branches by digital services available.

Figure 5.5-2 shows TPL data regarding the numbers of wireless sessions (wifi connections) and computer workstation users from 2012-2015 with projections for 2016. It shows that the use of public internet connections at TPL have increased over the past few years, particularly for 
wireless sessions. In 2015, there were 3,227,441 wireless sessions and there were 6,692,409 workstation users. In comparison, 2016 census counts put the City of Toronto's population at 2,731,571 (Statistics Canada, 2017). On average, Toronto residents used TPL internet connections 1.18 times through wifi, and 2.45 times through computer workstations in 2015.
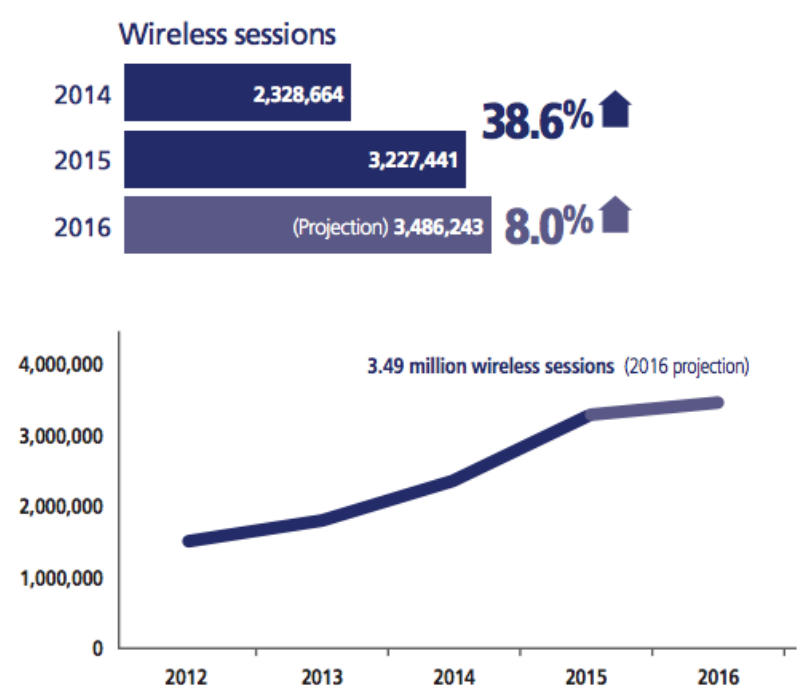
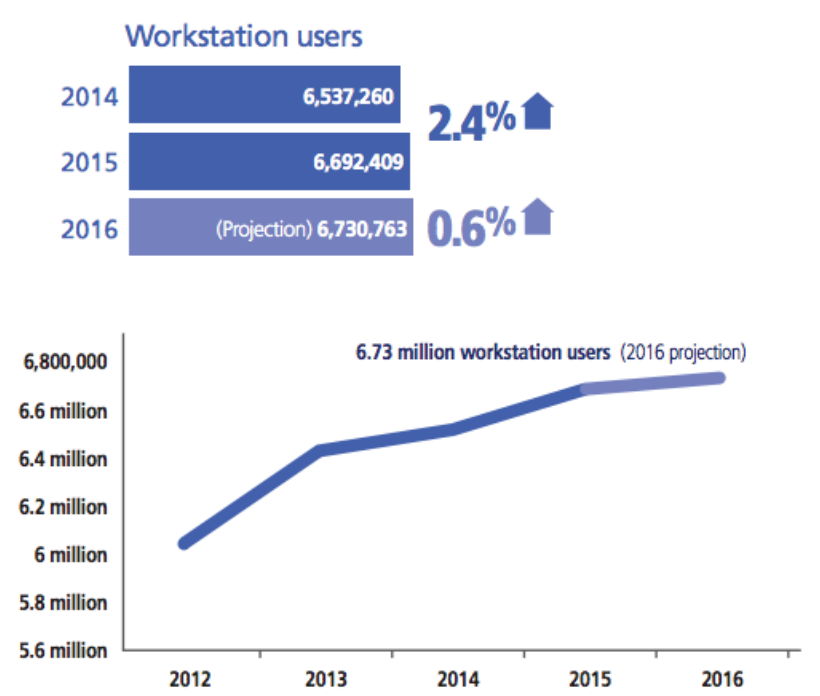

Figure 5.5-2. Wireless sessions and workstation users (by session) in Toronto Public Library branches over time.

The wireless sessions numbers are not released by branch, but workstation user trends can be broken down by branch and is shown in Figure 5.5-3. This analysis shows five-year change in number of workstation users from 2010-2015. Branches where workstation user numbers have increased by more than $10 \%$ are displayed in green, branches where numbers have decreased by more than $10 \%$ are displayed in red, and the remaining branches are displayed in yellow. The Fort York and Scarborough Civic Centre branches are excluded from this analysis as they have been in operation for less than 5 years.

Based on this categorization, 21 branches have decreasing workstation usage, 32 branches have increasing workstation usage, and 45 branches have seen stable workstation usage. An interesting pattern is that all branches in the downtown core have seen stable or increasing workstation usage, while all branches with decreasing workstation usage are in the suburbs. This trend could be a reflection of the growth in downtown population in general over the past few years (TD Economics, 2013). Another possible contributing factor may be the addition of 
computer workstations in particular branches, but this could not be determined as the number of workstations in previous years has not been released.

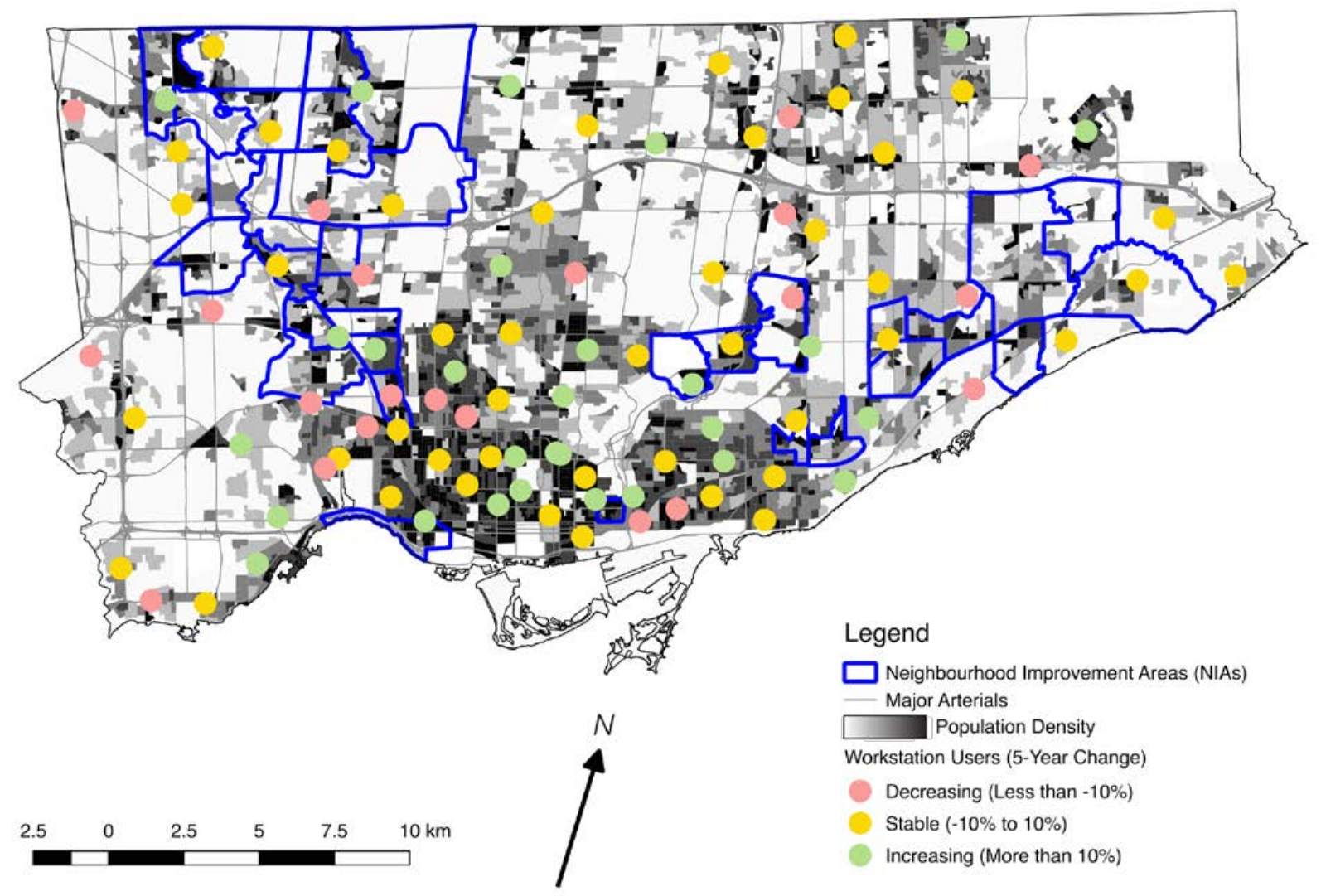

Figure 5.5-3. Change in workstation users in Toronto Public Library by branch, 2010-2015.

The number of workstation users can also be compared to the number of computer workstations available. The dark red branches in Figure 5.5-4 have proportionately higher demand on their computer workstations, and Table 5.5-5 shows the branches with the five highest number of users per workstation. These branches may represent areas requiring greater investment. A summary of these calculations are included in Appendix 8.4. 


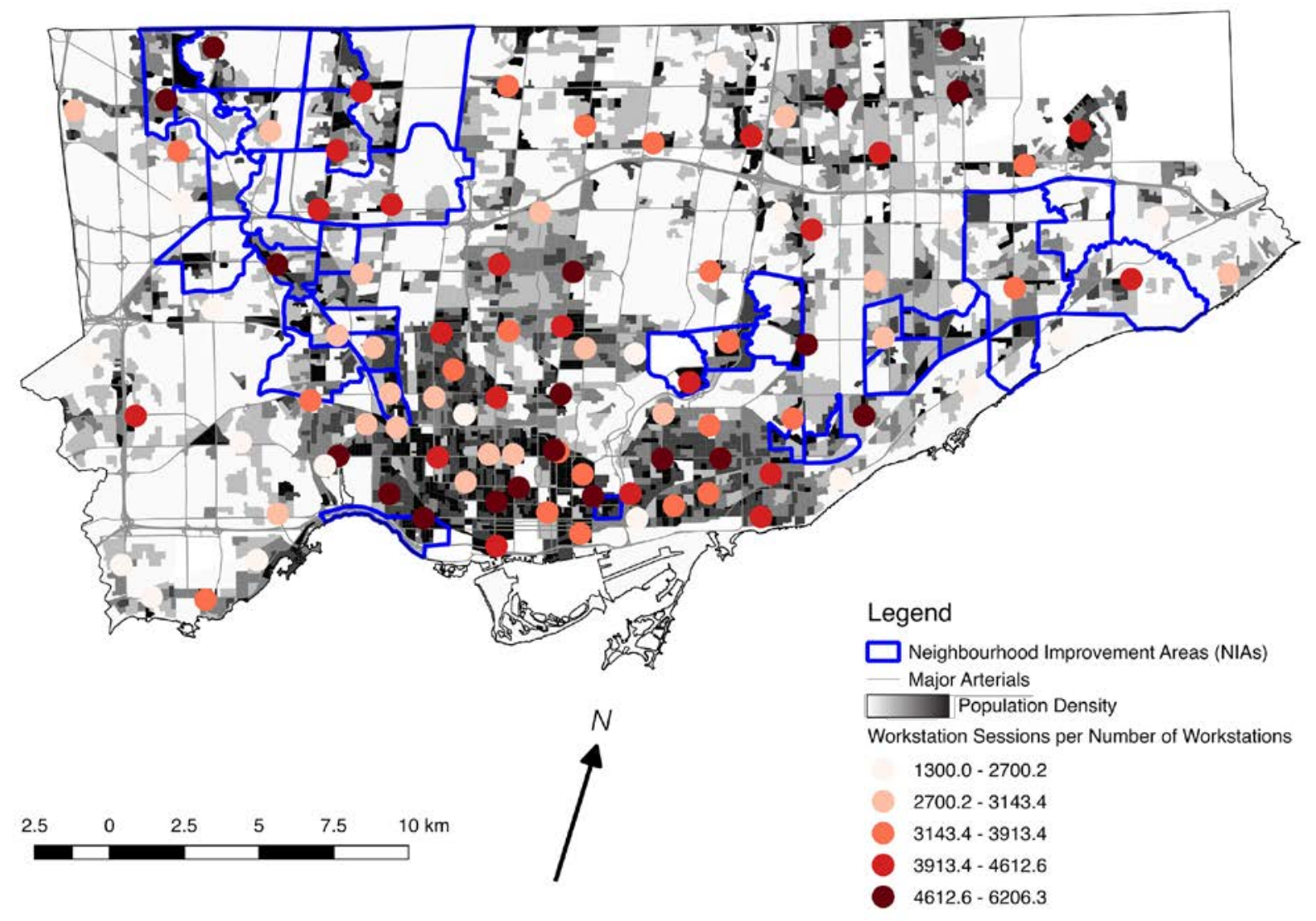

Figure 5.5-4. Toronto Public Library branches by workstation users per workstation, 2015.

Table 5.5-5. Toronto Public Library branches with five highest number of workstation users per workstation, 2015.

\begin{tabular}{|l|l|l|l|l|l|}
\hline Branch & NIA? & $\begin{array}{l}\text { Number of } \\
\text { Workstations }\end{array}$ & $\begin{array}{l}\text { Workstation } \\
\text { Users } \\
\mathbf{( 2 0 1 5 )}\end{array}$ & $\begin{array}{l}\text { 5-Year Change in } \\
\text { Workstation Users } \\
\mathbf{( 2 0 1 0 - 2 0 1 5 )}\end{array}$ & $\begin{array}{l}\text { Catchment } \\
\text { Population } \\
\mathbf{( 2 0 1 1 )}\end{array}$ \\
\hline $\begin{array}{l}\text { Parliament } \\
\text { Street }\end{array}$ & $\mathrm{N}$ & 11 & 68,269 & $14.4 \%$ & 35,152 \\
\hline Bridlewood & $\mathrm{N}$ & 7 & 41,463 & $1.0 \%$ & 39,671 \\
\hline Parkdale & $\mathrm{Y}$ & 23 & 127,130 & $38.7 \%$ & 26,555 \\
\hline Pape Danforth & $\mathrm{N}$ & 14 & 75,404 & $2.9 \%$ & 26,128 \\
\hline $\begin{array}{l}\text { Danforth } \\
\text { Coxwell }\end{array}$ & $\mathrm{N}$ & 7 & 37,125 & $14.3 \%$ & 14,641 \\
\hline
\end{tabular}


In addition to public internet and computer access, the TPL also runs programs addressing digital literacy, but statistics for the number of these programs and their participants are not publicly-available.

There are also many other programs in Toronto by public, private, and non-profit sector organizations that address digital inequality. Examples include the Connected for Success program where Toronto Community Housing residents can receive low-cost internet from Rogers, and the Parkdale Activity-Recreation Centre's (PARC) free wifi hotspots throughout the Parkdale neighbourhood (TCHC, 2017; reBOOT, 2016). These programs are not examined in this study because of time limitations, but future research regarding digital inequality in Toronto may wish to explore the impacts of these programs.

\subsection{Limitations and Gaps}

As mentioned throughout the case study, there are a number of gaps and limitations in the research. Partly, this lack of information stems from the inability to access existing data without long application processes such as through Statistics Canada's Research Data Centre proposal process. A source of data that could provide more current and detailed information regarding connectivity is the Survey of Household Spending (SHS). The SHS collects data related to whether a household has fixed and mobile broadband access, the type of connection and expenditures, as well as devices including computers, mobile phones, and tablets. This data, along with associated demographic variables and detailed geographic location based on address provided (Statistics Canada, 2017a), would be able to provide a more accurate and nuanced look at the connectivity dimension of digital inequality, including quality of access and affordability concerns.

Two major categories of demographic variables that could not be explored in this case study are ethnicity and immigration, which were not included in the CIUS PUMF dataset. Because of the diversity of Toronto, these variables represent very relevant issues of concern. The CIUS is administered in association with the Labour Force Survey (LFS) which does not include variables of ethnicity but does collect information regarding whether the respondent is an immigrant, the period of immigration, and the country of birth (Minister of Industry, 2012). This data could help enhance understanding of the needs and challenges faced by immigrants, and suggest whether digital inclusion programs that target immigrants may be needed. 
Another limitation of the analysis of CIUS data in this paper is the lack of certainty regarding the meaningfulness of results relating to smaller segments of the population. For instance, detailed breakdowns of households without internet access and people who do not use the internet were not created due to concerns regarding the quality of the estimates. More specific analysis of particular risk groups including individuals with low education, low income, or elderly individuals also could not be conducted. While it is possible that access to the full CIUS dataset can improve the estimate quality, it is likely that the sample of Toronto residents in the CIUS is too small for these further breakdowns. The 2012 CIUS had a sample size of 1065 for the Household component and 872 for the Individual component for the Toronto CMA, which had a population of 5,583,064 in 2011 (Statistics Canada, 2016a). In comparison, the Barcelona study had a sample of 5000 participants representing a population of 1,609,550 (Mobile World Capital, 2016), and the Chicago study had a sample of 2400 respondents for a 2010 population of 2,695,598(Mossberger et al., 2014; US Census Bureau, 2017). Filling in these gaps in the data would require a more focused survey of Toronto with a bigger sample size, or targeted surveys or interviews with the populations of interest identified in this study.

There are also gaps in publicly-available information regarding the Toronto Public Library. Wireless workstation numbers for each branch was not released, which would show the use of libraries for internet connections with the patrons' own devices. There is also a lack of data regarding participation in specifically digital literacy-related programs.

Finally, while this case study has endeavoured to take social and economic contexts into account through an understanding of major issues in the city, it has been limited in addressing issues related to the lived experience of being digital excluded. Future research involving interviews with residents and service providers or other qualitative methods may be able to corroborate some of the results from this study and provide additional insights on impacts and attitudes regarding digital inequality. 


\subsection{Discussion and Conclusion}

This study endeavoured to understand the components of digital inequality as they relate to the work of planners, and to apply the findings in a case study of Toronto. A review of academic and grey literature was used to build a conceptualization of digital inequality for the study, as shown in Figure 2.1-1 repeated below. This literature review revealed the dimensions that should be considered, methods of measuring specific indicators, and how they relate to various sociodemographic characteristics. While inequalities may be found in connectivity, usage activities, digital literacy, and attitudes, these disparities lead to two main categories of broader outcomes in society that affect the work and interests of planners: civic participation and socioeconomic status.

\begin{tabular}{|c|}
\hline $\begin{array}{l}\text { Connectivity } \\
\text { - Technology and } \\
\text { equipment } \\
\text { - Type and quality of } \\
\text { connection } \\
\text { - Location of access } \\
\text { - Affordability } \\
\text { Usage Activities } \\
\text { Digital Literacy } \\
\text { Attitudes }\end{array}$ \\
\hline
\end{tabular}

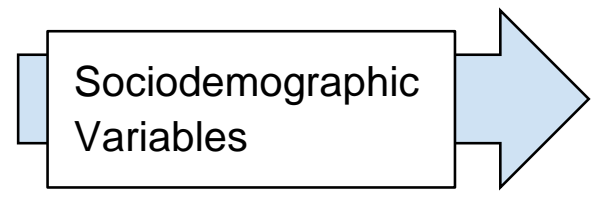

Civic Participation Outcomes Socioeconomic Outcomes

Figure 2.1-1. The dimensions of digital inequality emerging from the literature review.

An environmental scan of existing approaches provided guides as to how these components may be addressed in planning and policy practice. This study gathered and critiqued methodologies used by international organizations, national and municipal governments, and some researchers and non-governmental organizations. This toolbox of methodologies and their advantages and disadvantages are summarized in Table 6.0-1. 
Table 6.0-1. Best practices of methodologies for collecting and analyzing digital inequality data.

\begin{tabular}{|c|c|c|c|}
\hline Practice & Description & Advantages & Disadvantages \\
\hline $\begin{array}{l}\text { Aggregated } \\
\text { Index } \\
\text { (e.g. ITU, 2017; } \\
\text { Baller et al., } \\
\text { 2016; } \\
\text { European } \\
\text { Commission, } \\
\text { 2017) }\end{array}$ & $\begin{array}{l}\text { Many existing } \\
\text { frameworks } \\
\text { aggregate several } \\
\text { indicators into a } \\
\text { single score. }\end{array}$ & $\begin{array}{l}\text { - Considers multiple } \\
\text { dimensions of digital } \\
\text { inequality. } \\
\text { - Provides quick } \\
\text { summary for } \\
\text { policymakers and } \\
\text { public education. } \\
\text { - Allow for comparison } \\
\text { across jurisdictions } \\
\text { and over time. }\end{array}$ & $\begin{array}{l}\text { - Existing frameworks } \\
\text { typically do not measure } \\
\text { community-level } \\
\text { differences. } \\
\text { - May oversimplify the } \\
\text { issue. } \\
\text { - Underlying social, } \\
\text { economic and political } \\
\text { factors may be ignored. }\end{array}$ \\
\hline $\begin{array}{l}\text { Survey of } \\
\text { Population } \\
\text { (e.g. Mobile } \\
\text { World Capital, } \\
\text { 2016; } \\
\text { Mossberger et } \\
\text { al., 2014) }\end{array}$ & $\begin{array}{l}\text { Surveys are } \\
\text { conducted regarding } \\
\text { various dimensions } \\
\text { of digital inequality. } \\
\text { Results are linked } \\
\text { with demographic } \\
\text { characteristics of } \\
\text { concern and } \\
\text { geographic data to } \\
\text { understand } \\
\text { neighbourhood-level } \\
\text { differences. }\end{array}$ & $\begin{array}{l}\text { - Provides detailed } \\
\text { breakdowns by } \\
\text { different groups in the } \\
\text { population. } \\
\text { - Purpose-built surveys } \\
\text { allow for analysis of } \\
\text { specific issues of } \\
\text { interest. }\end{array}$ & $\begin{array}{l}\text { - Data collection may be } \\
\text { a resource-intensive } \\
\text { process. } \\
\text { - If data is leveraged from } \\
\text { an existing survey for } \\
\text { another purpose, not all } \\
\text { issues of interest may } \\
\text { be covered and sample } \\
\text { sizes could affect level } \\
\text { of analysis. } \\
\text { - Self-reports may not be } \\
\text { reliable for some } \\
\text { measures, such as } \\
\text { digital skill levels. }\end{array}$ \\
\hline $\begin{array}{l}\text { Risk Groups } \\
\text { (e.g. Huesing } \\
\text { and Selhofer, } \\
\text { 2002; Park and } \\
\text { Kim, 2014; } \\
\text { United } \\
\text { Kingdom, 2014) }\end{array}$ & $\begin{array}{l}\text { Groups that are at } \\
\text { risk of being digitally } \\
\text { excluded are } \\
\text { followed and } \\
\text { compared to the } \\
\text { performance of the } \\
\text { general population. }\end{array}$ & $\begin{array}{l}\text { - Provides groups of } \\
\text { focus for policy and } \\
\text { programs. } \\
\text { - Allows for simple } \\
\text { comparisons over } \\
\text { time. }\end{array}$ & $\begin{array}{l}\text { - Group membership is } \\
\text { not exclusive, which } \\
\text { may result in duplication } \\
\text { and ignore relationships } \\
\text { between factors. } \\
\text { - Identifying some risk } \\
\text { groups over others may } \\
\text { result in some } \\
\text { populations being left } \\
\text { out. }\end{array}$ \\
\hline $\begin{array}{l}\text { User Profiles } \\
\text { (e.g. Mobile } \\
\text { World Capital, } \\
\text { 2016; United } \\
\text { Kingdom, 2014) }\end{array}$ & $\begin{array}{l}\text { Data from a } \\
\text { population-level } \\
\text { survey is used to } \\
\text { categorize } \\
\text { respondents into } \\
\text { profiles. }\end{array}$ & $\begin{array}{l}\text { - Provides quick } \\
\text { summary for decision- } \\
\text { makers and public } \\
\text { education purposes. }\end{array}$ & $\begin{array}{l}\text { - Definition of profiles is } \\
\text { sometimes arbitrary. }\end{array}$ \\
\hline
\end{tabular}




\begin{tabular}{|c|c|c|c|}
\hline $\begin{array}{l}\text { Program-based } \\
\text { Indicators } \\
\text { (e.g. City of } \\
\text { New York, } \\
\text { 2013; City of } \\
\text { Vancouver, } \\
\text { 2017) }\end{array}$ & $\begin{array}{l}\text { The progress of } \\
\text { programs are } \\
\text { tracked through } \\
\text { quantitative } \\
\text { indicators, such as } \\
\text { the number of public } \\
\text { wifi hotspots } \\
\text { installed or number } \\
\text { of people reached. }\end{array}$ & $\begin{array}{l}\text { - Allows for tracking of } \\
\text { program } \\
\text { achievements. }\end{array}$ & $\begin{array}{l}\text { - May lack context and } \\
\text { ignore underlying } \\
\text { factors and } \\
\text { relationships. }\end{array}$ \\
\hline $\begin{array}{l}\text { Program } \\
\text { Participant and } \\
\text { Partner } \\
\text { Feedback } \\
\text { (e.g. } \\
\text { Mossberger et } \\
\text { al., 2014) }\end{array}$ & $\begin{array}{l}\text { Interviews and } \\
\text { surveys are } \\
\text { conducted with } \\
\text { participants of } \\
\text { programs and } \\
\text { partner } \\
\text { organizations, and } \\
\text { may be } \\
\text { administered } \\
\text { throughout or after } \\
\text { the program. }\end{array}$ & $\begin{array}{l}\text { - Provides better } \\
\text { understanding of the } \\
\text { impacts of programs in } \\
\text { the context of other } \\
\text { social and } \\
\text { psychological factors. } \\
\text { - Feedback may be } \\
\text { useful in improving } \\
\text { future versions of the } \\
\text { program. }\end{array}$ & $\begin{array}{l}\text { Data collection and } \\
\text { analysis may be } \\
\text { resource-intensive. }\end{array}$ \\
\hline $\begin{array}{l}\text { Skill Capability } \\
\text { Mapping for } \\
\text { Service } \\
\text { Delivery } \\
\text { (United } \\
\text { Kingdom, 2014) }\end{array}$ & $\begin{array}{l}\text { The skill levels } \\
\text { required to use a } \\
\text { service is mapped } \\
\text { on a scale. This is } \\
\text { supplemented with } \\
\text { user feedback and } \\
\text { testing to create a } \\
\text { stronger match } \\
\text { between the skillsets } \\
\text { of target audiences } \\
\text { and government } \\
\text { services. }\end{array}$ & $\begin{array}{l}\text { - Allows governments to } \\
\text { understand the target } \\
\text { audiences of their } \\
\text { programs and develop } \\
\text { them to match the } \\
\text { capabilities of } \\
\text { recipients. }\end{array}$ & $\begin{array}{l}\text { - Process may be } \\
\text { resource-intensive. }\end{array}$ \\
\hline
\end{tabular}

Based on the findings from the literature review and the environmental scan, a case study of Toronto was conducted with the aim of both applying the methodologies developed in the study and to uncover existent digital inequalities in Toronto. While significant gaps existed in the data sources available, some findings were derived regarding connectivity and usage activities. The inequalities found generally correspond to those discovered in previous research based on education, age, income, and in some cases, gender, although some variations existed between specific indicators. Unfortunately, digital inequalities based on ethnicity and immigration status could not be investigated based on a lack of available data, even though these variables are of particular interest in a diverse city like Toronto. Neighbourhood-level data was also limited, which could have potentially revealed community-level influences and areas for investment. 
The results from this study have led to the development of recommendations for planners in two areas. Firstly, Section 6.1 will outline suggestions and implications for planners in approaching digital inequality in their jurisdictions. Section 6.2 will focus on the findings from the case study of Toronto, and what they mean for planners, policymakers and community program providers in the city.

\subsection{An Urban Planning Approach to Digital Inequality}

\subsubsection{The Importance of Context}

Digital inequality is not a monolithic measure of internet connection. It consists of multiple dimensions whose relative importance will differ based on the social, economic, cultural and political contexts of the area being considered. Rather than applying a rigid framework, it is suggested that planners develop an understanding of all dimensions of digital inequality that may be relevant to their area of study. The dimensions of digital inequality identified as major themes in this study, as shown in Figure 2.1-1, could serve as a starting point for thinking about the factors that may need to be considered, which may then be adapted to place emphasis on specific components and elaborated to suit the local context.

In the example of the Toronto case study, availability of technical infrastructure is fairly widespread, so greater emphasis is placed on other barriers to connectivity such as affordability and attitudes as well as the quality of connections. A study in a rural or northern community may require a different approach. This study also places a heavy focus on the impacts of digital inequality on digital engagement and governance practices based on the current context of moves in this direction by governments. The development of an area-specific approach to digital inequality should therefore begin with an understanding of the jurisdiction of interest including existing offline disparities and issues, as well as emerging trends in society and policy.

Based on this background information, methods of approaching and organizing the data may be chosen from a set of best practices as found in Section 3.0 of this report and summarized in Table 6.0-1 above. The advantages and disadvantages presented in this report may help to determine the appropriate approach based on the needs and limitations of the study. The role of the study within broader policy contexts and initiatives may necessitate the type of data required 
such as at population, subpopulation or program-based levels, and whether the purpose of the undertaking is to track detailed changes over time, present figures for decision-makers and public education, or others. Other factors that may influence selection includes existing data sources, timeline and budget concerns.

\subsubsection{Data Collection Across the Dimensions of Digital Inequality}

Canadian data sources exist for systematic population-wide data across several components of digital connectivity, including the rate of connectivity amongst the population, the type of connections and digital devices, and affordability issues. The collection of up-to-date data outside of the connectivity dimension is less complete. The CIUS does provide information regarding online activities and some data on attitudes, but these statistics are dated and the survey has been discontinued. With the rapid pace of technological innovation and uptake, findings derived from this data are at best an approximation and may misrepresent current conditions.

While connectivity issues are important in the discussion of digital inequality, they represent only one inequality amongst many inequalities that have impact on civic participation and socioeconomic outcomes. The availability of physical access to digital technologies does not mean that an individual will necessarily use them, or use them in ways that would advance their position in society. It is therefore essential that information is collected regarding the additional dimensions of digital inequality, in order to gain a complete understanding of who the beneficiaries and disadvantaged individuals are in the digital world. For planner and public sector staff, this data is required for the responsible rollout of digital engagement and governance practices to identify and address gaps to ensure inclusive representation and access.

This data would also be valuable for program and service development by governments and community organizations, such as for digital literacy courses. While the study has found that digital literacy skills are difficult to assess accurately, particularly at a large scale, approximations may be derived through surveys of online activities performed and whether respondents feel fearful or intimidated by the level of skills required to use digital technology. 


\subsubsection{Data Access for Better Planning}

This study has found that the federal government is a source of comprehensive, detailed data relating to digital inequality, especially relating to the connectivity dimension. In particular, the SHS collects several data series relating to availability, type, and spending on broadband connections, as well as ownership and spending on equipment for digital access. In combination with subscriptions data from the CRTC, this provides a relatively clear picture of digital connectivity as demonstrated in the Communications Monitoring Report (CRTC, 2016).

Unfortunately, most of this data is not readily available to most professionals or members of the public at the scale of communities. This report's case study of Toronto has encountered many obstacles in acquiring data, resulting in gaps in important areas of concerns as described in Section 5.6. While some data sharing between governments is evident, such as through the City of Toronto's publication of 2013 SHS results in the city (City of Toronto, 2015c), it is uncertain whether this access is consistent over time and available to all Divisions in the City as well as its agencies, boards and commissions. It is also unknown whether all jurisdictions have access to this data, particularly smaller municipalities with less staff and resources than Toronto. Additionally, the lack of public data access impacts the work of planners outside of the public sector who may wish to conduct digital engagement, as well as community organizations that provide programs for residents.

This lack of openness undermines effective planning by other levels of government and community organizations. It represents an underutilization of the full potential of these data products, and potentially leads to wasteful duplication of work. The findings from this report provide support for initiatives for greater sharing of data. This could take the form of data sharing agreements between governments and with community organizations, such as through the Community Data Program that provides some Statistics Canada products to these organizations (Canadian Council on Social Development, 2014). There may be opportunities to release some data products publicly after accounting for confidentiality and quality concerns, following the Open by Default initiatives of the Canadian and Ontario governments (Government of Canada, 2016a; Government of Ontario, 2015). 


\subsection{Findings from Toronto}

\subsubsection{Digital Tools for Greater Inclusivity}

Generally, this case study finds that most Toronto residents have some degree of online interaction with governments, with at least half of internet users in each demographic group examined reporting use of government websites in the past 12 months. One group of interest with high levels of use is younger age groups. Contrary to their generally lower rates of participation in offline processes, individuals under 35 show significant interest in governmental processes in the online realm, presenting opportunities to widen audiences through outreach on digital platforms.

Social networking sites in particular showed potential for reaching youth as well as low-income individuals, who are also usually underrepresented in traditional public engagement. The age group of 16 - to 24 -year-olds have very high rates of use of these websites at $96.8 \%$. Use of social media is similar along income levels, and some lower income quintiles even appear to have higher rates of use. These results show that leveraging digital tools for public engagement has the potential to create more equitable engagement practices.

\subsubsection{Understanding Digitally Excluded Groups}

Based on data from Toronto, the two demographic groups that are most consistently digitally disadvantaged are elderly persons and individuals with low education. This provides impetus for digital inclusion programs that target these two groups, and for digital engagement and service delivery practices to be paired with comparable offline alternatives. For planners, digital inequalities based on education are of particular concern, especially for public engagement purposes. This is because these individuals are often excluded in offline engagement processes as well as digital processes, whereas seniors are typically better represented through traditional engagement.

More research is needed to examine the barriers and challenges faced by these two groups to aid in the creation and implementation of successful programs to address these disparities. As there are differences in digital inequalities based on education and income, cost may not be the primary concern. This indicates the need for initiatives beyond the provision of internet and 
computer access, such as public education of the benefits of internet use and digital skills training.

\subsection{Moving Forward}

Over the past few decades, the daily lives of Canadians have become increasingly digitized. Recently, there has been growing momentum for digital government as all three levels of government across the country examine ways to use digital tools to improve engagement and service delivery. This movement represents opportunities to improve inclusivity by reaching some segments of the population, but may also result in leaving other populations behind. In particular, since some digital inequalities fall along the same lines as social and economic inequalities, there is a danger of exacerbating these existing disparities.

In order to fully understand the impacts of these inequalities and to develop effective strategies to mitigate them, better data is needed to show a comprehensive, detailed and current picture of where these inequalities lie and to shine light on possible causes and variables. This paper argues that planners should take a greater interest in digital inequality issues because of their implications on civic participation processes and the socioeconomic outcomes of citizens. The dimensions and methodologies for measurement presented in this report may act as a starting point for planners to curate existing data and procure additional information to assess digital inequality in their communities. Just as data regarding demographics, employment, housing and other issues exist to inform social and economic development policies, an understanding of the distribution of digital resources and opportunities is needed to achieve equity in the emerging digital world. 
Appendices 
7.1 Summary of Jurisdictional Scan 
7.2 2012 Canadian Internet Use Survey Household Component - Summary of Selected Questions in Toronto CMA 
7.3 2012 Canadian Internet Use Survey Individual Component - Summary of Selected Questions in Toronto CMA 
7.4 Toronto Public Library Branch, Workstation, and Workstation Users Summary 


\section{References}

Adcock, J., \& Singh, S. (2015). Digital Strategy Update. Retrieved from http://council.vancouver.ca/20150429/documents/ptec1-Presentation-DigitalStrategyUpdate.pdf

Ajuntament de Barcelona. (2016). Barcelona Digital City. Retrieved from http://ajuntament.barcelona.cat/estrategiadigital/en

Baller, S., Dutta, S., \& Lanvin, B. (Eds.) (2016). The Global Information Technology Report 2016: Innovating in the Digital Economy. Retrieved from http://www3.weforum.org/docs/GITR2016/GITR_2016_full\%20report_final.pdf

Barzilai-Nahon, K. (2006). Gaps and bits: Conceptualizing measurements for digital divide/s. The Information Society, 22, 269-278.

Berman, T., Case, M., Daniels, J., Larsen-Fleming, M., \& Lee, S.H. (2007). Digital Inclusion in San Francisco. Retrieved from http://www.sfgov3.org/ftp/uploadedfiles/digital_inclusion/reports_publications/UCBDigitallnclusionReport0602820 07Final.pdf

Bimber, B. (2000). Measuring the gender gap on the internet. Social Science Quarterly, 81(3), 868-876.

Bruno, G., Esposito, E., \& Genovese, A. (2011). A critical analysis of current indexes for digital divide measurement. The Information Society, 16, 16-28.

Buente, W. (2015). Digital citizenship or inequality? Linking internet use and education to electoral engagement in the 2008 U.S. presidential election campaign. Bulletin of Science, Technology \& Society, 35(5-6), 145-157.

Campos-Castillo, C. (2015). Revisiting the first-level digital divide in the United States: Gender and race/ethnicity patterns, 2007-2012. Social Science Computer Review, 33(4), 423-439.

Canadian Council on Social Development. (2014). Community Data Program. Retrieved from http://communitydata.ca/

Cheung, K.-C., Mak, S.-K., \& Sit, P.-S. (2013). Online reading activities and ICT use as mediating variables in explaining the gender difference in digital reading literacy: Comparing Hong Kong and Korea. The Asia-Pacific Education Researcher, 22(4), 709-720.

City of Calgary. (2014). The City's Digital Strategy. Retrieved from http://www.calgary.ca/cfod/it/Pages/Digitalstrategy.aspx

City of Chicago. (2015). Chicago Tech Plan. Retrieved from http://techplan.cityofchicago.org/

City and County of San Francisco. (2007). Digital Inclusion Documents. Retrieved from https://sfgov.org/dt/ftp/uploadedfiles/dtis/tech_connect/DigitallnclusionStrategyOverview.pdf

City and County of San Francisco. (n.d.). San Francisco City Survey, 2007-2015. Retrieved from http://openbook.sfgov.org/webreports/search.aspx?searchString=city\%20survey\&year=1986\&year2=2017\&type= All\&index $=0$ \&index2=0\&index3=0

City of New York. (2011). Road Map for the Digital City: Achieving New York's Digital Future. Retrieved from http://www.nyc.gov/html/media/media/PDF/90dayreport.pdf

City of New York. (2013). New York City's Digital Leadership 2013 Roadmap. Retrieved from http://www.slideshare.net/smartcity/nyc-digital-roadmap-2013

City of New York. (2016). \#OneNYC: The Plan for a Strong and Just City. Retrieved from http://www1.nyc.gov/html/onenyc/index.html

City of Toronto. (2014). Toronto Strong Neighbourhoods Strategy 2020 - Recommended Neighbourhood Improvement Areas. Retrieved from http://www.toronto.ca/legdocs/mmis/2014/cd/bgrd/backgroundfile-67382.pdf 
City of Toronto. (2015a). Making Toronto a Tech-Friendly City and Bridging the Digital Divide. Retrieved from http://www.toronto.ca/legdocs/mmis/2015/ed/bgrd/backgroundfile-82328.pdf

City of Toronto. (2015b). Establishing a Connectivity Advisory Group (CAG). Retrieved from http://www.toronto.ca/legdocs/mmis/2015/ed/bgrd/backgroundfile-83238.pdf

City of Toronto. (2015c). Survey of Household Spending. Retrieved from http://www1.toronto.ca/City\%200f\%20Toronto/Economic\%20Development\%20\&\%20Culture/Business\%20Page s/News,\%20Reports\%20\&\%20Resources/Data\%20Centre/Data\%20Centre\%20Files/Survey\%20of\%20Househol d\%20Spending.xls

City of Toronto. (2016a). Open Government: A Connected, Informed Public Empowered by an Accountable, Transparent and Collaborative City Government. Retrieved from http://www1.toronto.ca/City\%200f\%20Toronto/City\%20Clerks/Corporate\%20Information\%20Management\%20S ervices/Links/A1600757_OpenGovt_ProgressReport_Aug30_WEB.pdf

City of Toronto. (2016b). Review of internet Connectivity and Advancing Toronto as a Smart City. Retrieved from http://www.toronto.ca/legdocs/mmis/2016/ed/bgrd/backgroundfile-97202.pdf

City of Toronto. (2017a). Accessing City Hall. Retrieved from http://www1.toronto.ca/wps/portal/contentonly?vgnextoid=f81aa9a59754c310VgnVCM1000006cd60f89RCRD

City of Toronto. (2017b). Neighbourhood Profiles. Retrieved from http://www1.toronto.ca/wps/portal/contentonly?vgnextoid=ae17962c8c3f0410VgnVCM10000071d60f89RCRD

City of Vancouver. (2013). Digital Strategy. Retrieved from http://vancouver.ca/files/cov/City_of_Vancouver_Digital_Strategy.pdf

City of Vancouver. (2016). Timeline of Digital Strategy Achievements. Retrieved from http://vancouver.ca/yourgovernment/digital-strategy-achievements.aspx

CRTC. (2016). Telecom Regulatory Policy CRTC 2016-496: Modern telecommunications services - The path forward for Canada's digital economy. Retrieved from http://www.crtc.gc.ca/eng/archive/2016/2016-496.htm

van Deursen, A., \& van Dijk, J. (2010). internet skills and the digital divide. New Media \& Society, 13(6), 893-911.

van Deursen, A., \& van Dijk, J. (2014). The digital divide shifts to differences in usage. New Media \& Society, 16(3), 507-526.

van Dijk, J. (2003). A framework for digital divide research. Electronic Journal of Communication, 12(1). Retrieved from https://www.utwente.nl/bms/vandijk/research/digital_divide/Digital_Divide_overigen/a_framework_for_digital_divi del

van Dijk, J. (2006). Digital divide research, achievements and shortcomings. Poetics, 34, 221-235.

DiMaggio, P., \& Hargittai, E. (2001). From the "digital divide" to "digital inequality": Studying internet use as penetration increases. Working paper \#15, Center for Arts and Cultural Policy Studies, Princeton University.

DiMaggio, P., \& Bonikowski, B. (2008). Make money surfing the web? The impact of internet use on the earnings of U.S. workers. American Sociological Review, 73, 227-250.

Dixon, L.J., Correa, T., Straubhaar, J., Covarrubias, J., Graber, D., Spence, J., \& Rojas, V. (2014). Gendered space: The digital divide between male and female users in internet public access sites. Journal of Computer-Mediated Communication, 19, 991-1009.

DolTT. (2015). Department of Information Technology and Telecommunications Strategic Plan 2015-2017. Retrieved from https://www1.nyc.gov/assets/doitt/downloads/pdf/strategic_plan_2015-2017.pdf

Dunbar, J. (2011). Wealthy suburbs get best broadband deals; D.C., rural areas lag behind. Retrieved from http://investigativereportingworkshop.org/connected/story/washington-dc-broadband-speed/ 
Ellison, N.B., Steinfield, C., \& Lampe, C. (2007). The benefits of Facebook "friends:" Social capital and college students' use of online social network sites. Journal of Computer-Mediated Communication, 12, 1143-1168.

Eshet-Alkalai, Y. (2004). Digital literacy: A conceptual framework for survival skills in the digital era. Journal of Educational Multimedia and Hypermedia, 13(1), 93-106.

European Commission. (2016). Digital Skills Indicator - Methodological Note, 2016. Retrieved from https://ec.europa.eu/digital-single-market/en/human-capital

European Commision. (2017). The Digital Economy and Society Index (DESI). Retrieved from https://ec.europa.eu/digital-single-market/en/desi

Eurostat. (2016). Digital economy and society statistics - households and individuals. Retrieved from http://ec.europa.eu/eurostat/statistics-explained/index.php/Digital_economy_and_society_statistics__households_and_individuals

Flanagin, A.J., \& Metzger, M.J. (2001). internet use in the contemporary media environment. Human Communication Research, 27(1), 153-181.

Gant, J.P., Turner-Lee, N.E., Li, Y., \& Miller, J.S. National minority broadband adoption: Comparative trends in adoption, acceptance and use. Retrieved from http://jointcenter.org/sites/default/files/MTI_BROADBAND_REPORT_WEB.pdf

Government of Canada. (2016a). Draft New Plan on Open Government 2016-2018. Retrieved from http://open.canada.ca/en/consultations/canadas-new-plan-open-government-2016-2018

Government of Canada. (2016b). Government of Canada Information Technology Strategic Plan 2016-2020. Retrieved from https://www.canada.ca/en/treasury-board-secretariat/services/information-technology/informationtechnology-strategy/strategic-plan-2016-2020.html

Government of Ontario. (2015). Ontario's Open Data Directive. Retrieved from https://www.ontario.ca/page/ontarios-open-data-directive

Government of Ontario. (2016). September 2016 Mandate letter: Digital Government. Retrieved from https://www.ontario.ca/page/september-2016-mandate-letter-digital-government

Government of Ontario. (2017a). Digital Government. Retrieved from https://www.ontario.ca/page/digitalgovernment

Government of Ontario. (2017b). Open Government. Retrieved from https://www.ontario.ca/page/opengovernment

Greater London Authority. (2015). A Digital Inclusion Strategy for London. Retrieved from https://www.london.gov.uk/sites/default/files/a_digital_inclusion_strategy_for_london.pdf

Greene, J.A., Yu, S.B., \& Copeland, D.Z. Measuring critical components of digital literacy and their relationships with learning. Computers \& Education 76, 55-69.

Haight, M., Quan-Haase, A., \& Corbett, B.A. (2014). Revisiting the digital divide in Canada: the impact of demographic factors on access to the internet, level of online activity, and social networking site usage. Information, Communication \& Society, 17(4), 503-519.

Hampton, K., \& Wellman, B. (2003). Neighboring in Netville: How the Internet supports community and social capital in a wired suburb. City \& Community, 2(4), 277-311.

Hargittai, E. (2002). The second-level digital divide: differences in people's online skills. First Monday: Peer-Reviewed Journal on the internet, 7(4). Retrieved from http://firstmonday.org/ojs/index.php/fm/issue/view/144

Hargittai, E. (2005). Survey measures of web-oriented digital literacy. Social Science Computer Review, $23(3), 371-$ 379 
Hargittai, E. (2010). Digital na(t)ives? Variation in internet skills and and uses among members of the "net generation". Sociological Inquiry, 80(1), 92-113.

Hargittai, E., \& Hinnant, A. (2008). Digital inequality: Differences in young adults' use of the internet. Communication Research, 35(5), 602-621.

Hargittai, E., \& Walejko, G. (2008). The participation divide: Content creation and sharing in the digital age. Information, Communication \& Society, 11(2), 239-256.

Helsper, E.J., \& Galacz, A. (2009). Understanding the links between social and digital inclusion in Europe. In Cardoso, G., Cheong, A., \& Cole, J. (Eds.), The Worldwide internet: Changing Societies, Economies and Cultures (pp. 146-178). Taipa, China: University of Macau Press.

Hilbert, M. (2016). The bad news is that the digital access divide is here to stay: Domestically installed bandwidths among 172 countries for 1986-2014. Telecommunications Policy, 40, 567-581.

Horrigan, J.B. (2010). Broadband adoption and use in America. OBI Working Paper Series No.1. Retrieved from https://apps.fcc.gov/edocs_public/attachmatch/DOC-296442A1.pdf

Howard, P.N., Busch, L., \& Sheets, P. (2010). Comparing digital divides: Internet access and social inequality in Canada and the United States. Canadian Journal of Communication,35(1), 109-128.

Huesing, T., \& Selhofer, H. (2002). The Digital Divide Index: A measure of social inequalities in the adoption of ICT. ECIS 2002 Proceedings. Paper 35. Retrieved from http://aisel.aisnet.org/ecis2002/35

Industry Canada. (1994). The Canadian Information Highway: Building Canada's Information and Communications Infrastructure. Retrieved from http://prism.ucalgary.ca/handle/1880/43195

Industry Canada. (1996). Building the Information Society: Moving Canada into the 21st Century. Ottawa: Industry Canada.

Innovation, Science and Economic Development Canada. (2016a). Connecting Canadians. Retrieved from https://www.ic.gc.ca/eic/site/028.nsf/eng/h_00587.html

Innovation, Science and Economic Development Canada. (2016b). Innovation for a Better Canada: What We Heard. Retrieved from http://www.ic.gc.ca/eic/site/062.nsf/eng/h_00051.html

Institute of Museum and Library Services. (2012). Building Digital Communities: A Framework for Action. Retrieved from https://www.imls.gov/sites/default/files/publications/documents/buildingdigitalcommunitiesframework.pdf

International Telecommunication Union. (2010). Definitions of World Telecommunication / ICT Indicators. Retrieved from https://www.itu.int/ITU-D/ict/material/TelecomICT_Indicators_Definition_March2010_for_web.pdf

International Telecommunication Union. (2016). ICT Development Index 2016: Canada. Retrieved from https://www.itu.int/net4/ITU-D/idi/2016/\#idi2016countrycard-tab\&CAN

International Telecommunication Union. (2017). The ICT Development Index (IDI): Conceptual framework and methodology. Retrieved from https://www.itu.int/en/ITU-

D/Statistics/Pages/publications/mis2016/methodology.aspx

Kaminski, J. (2016). eHealth and Canadian nurses: Just getting acquainted. Canadian Journal of Nursing Informatics, 11(3). Retrieved from http://search.proquest.com/docview/1827636481/fulltext/4151BE2B5F874E75PQ/1?accountid=13631

Katz, J., \& Aspden, P. (1997). Motivations for and barriers to internet usage: results of a national public opinion survey. internet Research: Electronic Networking Applications and Policy, 7(3), 170-188.

Katz, V.S., \& Gonzalez, C. (2016). Toward meaningful connectivity: Using multilevel communication research to reframe digital inequality. Journal of Communication, 66, 236-249.

Kavanaugh, A., Carroll, J.M., Rosson, M.B., Zin, T.T., \& Reese, D.D. (2005). Community networks: Where offline communities meet online. Journal of Computer-Mediated Communication, 10(4), article 3. 
Kenski, K., \& Stroud, N.J. (2006). Connections between internet use and political efficacy, knowledge, and participation. Journal of Broadcasting \& Electronic Media, 50(2), 173-192.

Kim, Y.-C., Jung, J.-Y., \& Ball-Rokeach, S.J. (2007). Ethnicity, place, and communication technology: Effects of ethnicity on multi-dimensional internet connectedness. Information Technology \& People, 20(3), 282-303.

Kleinman, M. (2016). Cities, data, and digital innovation. IMFG Papers on Municipal Finance and Governance. Retrieved from http://munkschool.utoronto.ca/imfg/uploads/338/imfgpaper_no24_citiesdatadigitalinnovation_markkleinman_feb_ 9_2016.pdf

Liu, Y.Q., Martin, C., Roehl, E., Yi, Z., \& Ward, S. (2006). Digital information access in urban/suburban communities: A survey report of public digital library use by the residents in Connecticut. OCLC Systems \& Services: International digital library perspectives, 22(2), 132-144.

Mappin, D. (1995). Canada's SchoolNet initiative. Educational Technology Research and Development, 43(2), 94-95.

Mayor of London. (2013). Smart London Plan. Retrieved from http://www.london.gov.uk/sites/default/files/smart_london_plan.pdf

Mesch, G.S., \& Talmud, I. (2011). Ethnic differences in internet access. Information, Communication \& Society, 14(4), 445-471.

Middleton, C., Veenhof, B., \& Leith, J. (2010). Intensity of internet use in Canada: Understanding different types of users. Business Special Surveys and Technology Statistics Division Working Papers, Catalogue no. 88F0006X, no. 2.

Minister of Industry. (2012). Guide to the Labour Force Survey. Retrieved from http://www.statcan.gc.ca/pub/71-543g/71-543-g2012001-eng.pdf

Mobile World Capital. (2016). The Digital Divide in the City of Barcelona. Retrieved from http://www.mobileworldcapital.com/escletxa-digital/

Mossberger, K., Tolbert, C.J., Bowen, D., \& Jimenez, B. (2012). Unraveling different barriers to internet use: Urban residents and neighborhood effects. Urban Affairs Review, 48(6), 771-810.

Mossberger, K., Tolbert, C.J., \& Feeney, M.K. (2014). Overview and Highlights: Smart Communities Evaluation. Retrieved from https://live-

policyinformatics.ws.asu.edu/sites/default/files/\%5Bterm\%3Aname\%5D/\%5Bnode\%3Acreate\%3Acustom\%3AY m\%5D/smartcommunities_overviewhighlights.pdf

Mossberger, K., Tolbert, C.J., \& Stansbury, M. (2003). Virtual Inequality: Beyond the Digital Divide. Washington, D.C.: Georgetown University Press.

Murray, E. (2014). eHealth: Where next? The British Journal of General Practice, 64(624), 325-326.

Naccarato, L. (2017, February 21). Expect Toronto's newest library bus to be packed with technology as well as books. CBC News. Retrieved from http://www.cbc.ca/news/canada/toronto/toronto-mobile-library-books1.3991581

National Telecommunications \& Information Administration. (1995). Falling Through the Net: A Survey of the "Have Nots" in Rural and Urban America. Retrieved from https://www.ntia.doc.gov/ntiahome/fallingthru.html

National Telecommunications \& Information Administration. (1998). Falling Through the Net: Defining the Digital Divide. Retrieved from https://www.ntia.doc.gov/legacy/ntiahome/fttn99/contents.html

OECD. (2014). Skills and jobs in the internet economy. OECD Digital Economy Papers, No. 242, OECD Publishing. Retrieved from http://dx.doi.org/10.1787/5jxvbrjm9bns-en

Ono, H., \& Zavodny, M. (2003). Gender and the internet. Social Science Quarterly, 84(1), 111-121. 
Ono, H., \& Zavodny, M. (2008). Immigrants, English ability and the digital divide. Social Forces, 86(4), 1455-1479.

Park, S., and Kim, G.J. (2014). Lessons from South Korea's digital divide index (DDI). info, 16(3), 72-84.

Pew Research Centre. (2015). Home Broadband 2015. Retrieved at http://www.pewinternet.org/2015/12/21/homebroadband-2015/

Prieger, J.E. (2015). The broadband digital divide and the benefits of mobile broadband for minorities. Journal of Economic Inequality, 13, 373-400.

Rashid, A.T. (2016). Digital inclusion and social inequality: Gender differences in ICT access and use in five developing countries. Gender, Technology and Development, 20(3), 306-332.

Robinson, L. (2011). Information-channel preferences and information-opportunity structures. Information, Communication \& Society, 14(4), 472-494.

Robinson, L. (2012). Information-seeking 2.0: The effects of informational advantage. Reset, 1. Retrieved from http://reset.revues.org/135

Robinson, L. et al. (2015). Digital inequalities and why they matter. Information, Communication \& Society, 18(5), 569-582.

Schlozman, K.L., Verba, S., \& Brady, H.E. (2010). Weapon of the strong? Participatory inequality and the internet. Perspectives on Politics, 8(2), 487-509.

Selwyn, N. (2003). Apart from technology: Understanding people's non-use of information and communication technologies in everyday life. Technology in Society, 25(1), 99-116.

Selwyn, N. (2010). Degrees of digital division: Reconsidering digital inequalities and contemporary higher education. Revista de Universidad y Sociedad del Conocimiento, 7(1). Retrieved from http://www.analisi.cat/index.php/rusc/article/view/v7n1_selwyn

Selwyn, N., Gorard, S., \& Furlong, J. (2005). Whose internet is it anyway? Exploring adults' (non)use of the internet in everyday life. European Journal of Communication, 20(1), 5-26.

Sieber, R.E., Robinson, P.J., Johnson, P.A., \& Corbett, J.M. (2016). Doing public participation on the geospatial web. Annals of the American Association of Geographers, 106(5), 1030-1046.

Statistics Canada. (2013). Table 358-0171 - Canadian internet use survey, households with access to the internet at home, Canada, provinces and census metropolitan areas (CMA), occasional (percent), CANSIM (database). (accessed: February 7, 2017)

Statistics Canada. (2016a). Focus on Geography Series, 2011 Census: Census metropolitan area of Toronto, Ontario. Retrieved from http://www12.statcan.gc.ca/census-recensement/2011/as-sa/fogs-spg/Facts-cmaeng.cfm?LANG=Eng\&GK=CMA\&GC=535

Statistics Canada. (2016b). Immigration and Ethnocultural Diversity in Canada. Retrieved from http://www12.statcan.gc.ca/nhs-enm/2011/as-sa/99-010-x/99-010-x2011001-eng.cfm

Statistics Canada. (2017). User Guide for the Survey of Household Spending, 2015. Retrieved from http://www.statcan.gc.ca/pub/62f0026m/62f0026m2017001-eng.htm

Stern, M.J., Adams, A.E., and Elsasser, S. (2009). Digital inequality and place: The effects of technological diffusion on internet proficiency and usage across rural, suburban, and urban counties. Sociological Inquiry, 79(4), 391417.

Talukdar, D., \& Gauri, D.K. (2011). Home internet access and usage in the USA: Trends in the Socio-economic digital divide. Communications of the Association for Information Systems, 28, 85-98.

TD Economics. (2013). Toronto - A Return to the Core. Retrieved from http://www.td.com/document/PDF/economics/special/ff0113_toronto.pdf 
Telecommunications Act (S.C. 1993, c. 38). Retrieved from http://laws.justice.gc.ca/eng/acts/T-3.4/

Tolbert, C.J., \& McNeal, R.S. (2003). Unraveling the effects of the internet on political participation? Political Research Quarterly, 56(2), 175-185.

Toronto Public Library. (2015). Toronto Public Library Strategic Plan 2016-2019. Retrieved from http://www.torontopubliclibrary.ca/content/about-the-library/strategic-plan/pdfs/strat-plan-2016-2019.pdf

Toronto Public Library. (2017). Computers, Internet Access \& Digital Services. Retrieved from http://www.torontopubliclibrary.ca/using-the-library/computer-services/

United Kingdom. (2014). Government Digital Inclusion Strategy. Retrieved from https://www.gov.uk/government/publications/government-digital-inclusion-strategy/government-digital-inclusionstrategy

Ünlüsoy, A., de Haan, M., Leseman, P.M., \& van Kruistum, C. (2010) Gender differences in adolescents' out-ofschool literacy practices: A multifaceted approach. Computers \& Education, 55(2), 742-751.

U.S. Census Bureau. (2017). QuickFacts: Chicago City, Illinois. Retrieved from https://www.census.gov/quickfacts/table/PST045216/1714000

Ville de Montréal. (2014). Montréal Smart and Digital City: 2014-2017 Montréal Strategy. Retrieved from http://villeintelligente.montreal.ca/sites/villeintelligente.montreal.ca/files/montreal-strategy-smart-and-digital-cityan.pdf

Ville de Montréal. (2017). A Fruitful Collaboration: Midterm Report. Retrieved from http://villeintelligente.montreal.ca/sites/villeintelligente.montreal.ca/files/midterm_report_feb_2017.pdf

Warschauer, M. (2003). Technology and social inclusion: Rethinking the digital divide. Cambridge, Mass.: MIT Press.

Wasserman, I.M., \& Richmond-Abbott, M.R. Gender and the internet: Causes of variation in access, level, and scope of use. Social Science Quarterly, 86(1), 252-270. 


\section{Glossary of Terms}

Broadband Internet: High-speed internet, with access of at least 1.5 Mbps (CRTC, 2016).

Cable: A communications technology that provides data transmission over coaxial cable. (CRTC, 2016)

Dial-Up Internet: Dial-up is a connection to the Internet via a modem and fixed telephone line, which requires that the modem dial a phone number when Internet access is needed (ITU, 2010).

Digital Subscriber Line (DSL): A data communications technology that provides data transmission over a copper local loop. (CRTC, 2016)

Fibre: A technology that uses glass threads or plastic fibres to transmit data using pulses of light. (CRTC, 2016)

Fixed Broadband: Wired broadband subscriptions to a fixed location, such as through cable, DSL, and fibre technologies (ITU, 2010).

Fixed Wireless: A wireless network that uses either licensed or unlicensed spectrum to provide communications services (voice and/or data) where the service is intended to be used in a fixed location. (CRTC, 2016)

Low-Speed Internet: Low-speed or narrowband internet services provide speeds of up to 64 kilobits per second and is usually accessed through dial-up wirelines. (CRTC, 2016)

Mobile Broadband: Broadband connections to the internet on a mobile network with a data plan, such as through HSPA (3G) and LTE (4G) networks (CRTC, 2016).

Satellite Internet Services: Access to the Internet can be facilitated in remote areas by using satellite transport in two ways. One is a direct-to-home service where a subscriber has a small antenna (typically in the Ka-band) at their premises. The other is where a provider of telecommunications services has an agreement with a satellite operator for satellite transport 
services (typically in the C-band, which requires large antennas) that is connected to a terrestrially-based distribution system in a community. Typically, access to Internet services via satellite is only used in communities where there is no suitable terrestrially-based transmission service (CRTC, 2016). 